\title{
Impact of the West Virginia University Mountaineer Success Academy Program from 2012-2015
}

Ashley D. Watts

West Virginia University, ashley.watts@mail.wvu.edu

Follow this and additional works at: https://researchrepository.wvu.edu/etd

Part of the Scholarship of Teaching and Learning Commons

\section{Recommended Citation}

Watts, Ashley D., "Impact of the West Virginia University Mountaineer Success Academy Program from 2012-2015" (2020). Graduate Theses, Dissertations, and Problem Reports. 7627.

https://researchrepository.wvu.edu/etd/7627

This Dissertation is protected by copyright and/or related rights. It has been brought to you by the The Research Repository @ WVU with permission from the rights-holder(s). You are free to use this Dissertation in any way that is permitted by the copyright and related rights legislation that applies to your use. For other uses you must obtain permission from the rights-holder(s) directly, unless additional rights are indicated by a Creative Commons license in the record and/ or on the work itself. This Dissertation has been accepted for inclusion in WVU Graduate Theses, Dissertations, and Problem Reports collection by an authorized administrator of The Research Repository @ WVU.

For more information, please contact researchrepository@mail.wvu.edu. 


\title{
Impact of the West Virginia University Mountaineer Success
}

Academy Program from 2012-2015

\author{
Ashley Dawn Watts \\ Dissertation submitted to the \\ College of Agriculture, Natural Resources and Design \\ at West Virginia University \\ in partial fulfillment of the requirements \\ for the degree of
}

\author{
Doctor of Philosophy \\ in
}

Human and Community Development

Harry N. Boone, Jr., Ph.D., Chair

Deborah A. Boone, Ph.D.

Jason B. McKibben, Ph.D.

Ann M. Richards, Ph.D.

Nathan M. Sorber, Ph.D.

School of Design and Community Development

Morgantown, WV

2020

Keywords: student success, retention, success programs, undecided students, atrisk, graduation rates, academic performance

Copyright 2020

Ashley Dawn Watts 


\section{ABSTRACT \\ Impact of the West Virginia University Mountaineer Success \\ Academy Program from 2012-2015}

Ashley Dawn Watts

As state funding for universities decline and funding becomes based more on outcomes like retention and graduation rates, universities must focus their efforts on assessment and delve deeper into uncovering issues that prevent students from graduating. Once issues are identified, it is in the best interest of the university to develop, implement, and assess support services that may provide students with resources that could lead to their success, thus improving graduation rates. At West Virginia University, the Mountaineer Success Academy (MSA) was created to serve eligible students who were undecided or did not meet the requirements for their desired major. Participation in the program was voluntary and nearly all the students who were invited to participate and who participated encompassed WVU's two lowest levels of academic preparation and achievement which is measured by high school GPA and ACT/SAT scores.

The purpose of this study was to examine the West Virginia University Mountaineer Success Academy participants' graduation rates and academic performance (GPA) upon graduation in comparison to eligible non-participants and non-eligible students entering as first-time, full-time freshen at West Virginia University during the fall semester of 2012 through 2015. This study also examined if attributes identified including ethnicity, gender, high school GPA, state residency, and SAT/ACT scores appeared to have an impact on graduation rates or academic performance (GPA) upon graduation.

The data collected in collaboration with the Office of Institutional Research using the identified boundaries were analyzed by the researcher using the Statistical Package for Social Sciences (SPSS). Descriptive statistics were used to report the profile and demographics of participants. Chi square was used to analyze the difference in graduation rates among the groups. Analysis of covariance was used to partially adjust for preexisting differences between groups in an ex post facto design. ANCOVA adjusts scores on the dependent variable for any initial differences on the extraneous variable. A .05 alpha level of significance was used for all data analysis.

There were significant differences found within 4 year and more than 4-year graduation rates among the groups. The MSA non-eligible participants who graduated in 4 years $(40.2 \%)$ completed their degree at a higher percentage than their MSA $(25.5 \%)$ and MSA eligible non-participant counter parts (25.6\%). Participants in three groups who graduated in "more than 4 years," did so at a similar rate. $(17.1 \%, 18.7 \%$, and $17.0 \%$ for MSA participants, MSA eligible non-participants, and MSA non-eligible participants, respectively)

There was a significant difference found in academic performance (GPA) upon graduation among the groups. An analysis of covariance that used high school GPA as a 
covariant, revealed that MSA non-eligible participants who graduated in 4 years (3.36) had a higher college GPA than their MSA (3.13) and MSA eligible non-participant counter parts (3.15). There were also differences in participants in three groups who graduated in "more than 4 years" $(2.97,2.79,2.91$ for MSA participants, MSA eligible non-participants, and MSA non-eligible participants, respectively).

While statistical differences existed in the college GPAs, the researcher stopped short of deciding if the differences had practical significances. 


\section{ACKNOWLEDGEMENTS}

I would like to sincerely thank my committee members for guiding me through this process, Dr. Harry Boone, my chair, Dr. Debby Boone, Dr. Ann Richards, Dr. Nathan Sorber, and Dr. Jason McKibben. Each member has brought their own expertise and strengths to this endeavor and have provided excellent guidance and support through this process. I would like to especially thank Dr. Harry Boone for his guidance. I am eternally grateful for your support.

I would also like to thank everyone who helped me collect the data for this research: the WVU Institutional Research staff, Donielle Maust and Liz Reynolds; the WVU Office of the Provost; Dr. Kenneth Blemings; Dr. Todd Petty; Dr. Matthew Wilson; and a special thank you to Vickie Sigley.

I would also like to thank everyone who worked beside me during the Mountaineer Success Academy's tenure. A special thank you to Dr. Jacob Sanwidi and Dr. Bernadette Jungblut.

I would especially like to thank the family that is the Honors College. I have been blessed with wonderful colleagues in such a positive and supportive environment. It has truly been an honor to work with all of you. I would especially like to thank Dr. Damien Clement for taking time out of his schedule to write with me and help me keep a timeline for this project.

For all of you, I am grateful. 


\section{DEDICATION}

This work is dedicated to those who have been taught to believe they should not or could not. May you freely pursue the God given purpose for your life.

I also dedicate this work to my beloved Benson Dakota. 


\section{TABLE OF CONTENTS}

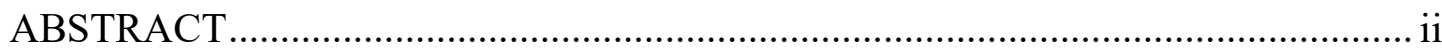

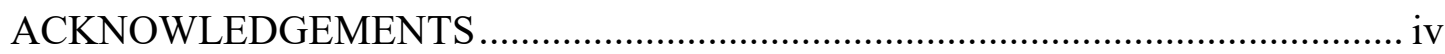

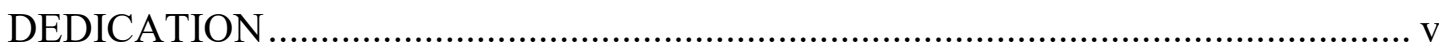

TABLE OF CONTENTS ............................................................................ vi

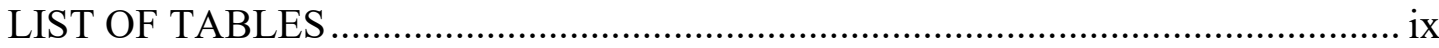

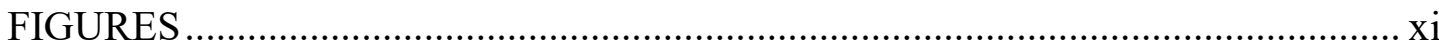

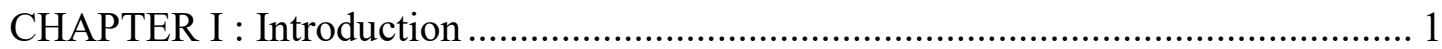

Statement of the Problem............................................................................. 4

Purpose of the Study .............................................................................. 5

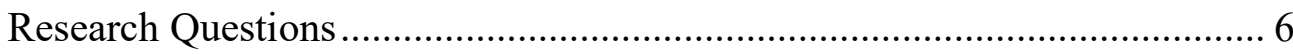

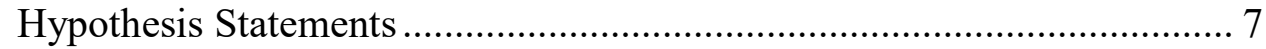

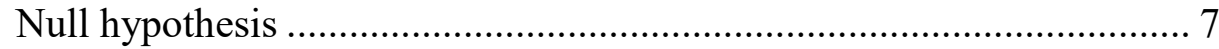

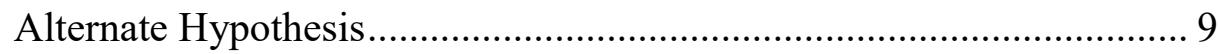

Definitions of Terms ........................................................................... 10

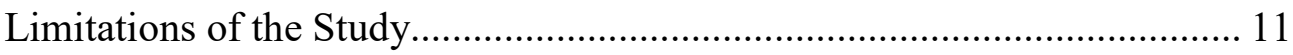

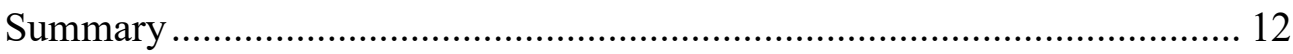

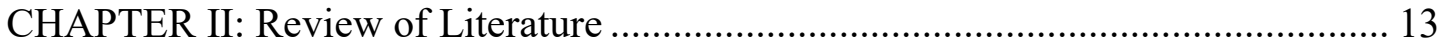

Summer Bridge Programs ........................................................................ 13

Live Learn Communities ........................................................................... 20

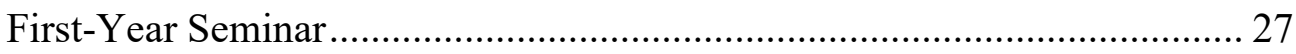

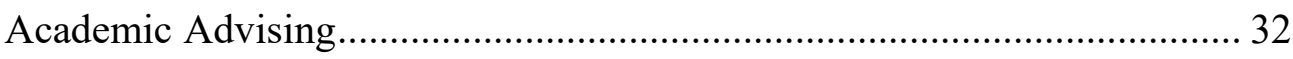

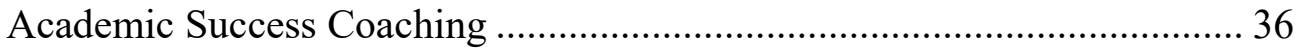

Resources for Career Exploration ............................................................. 39

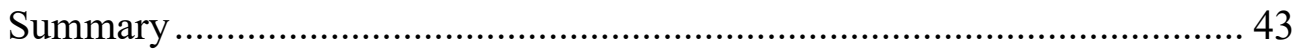

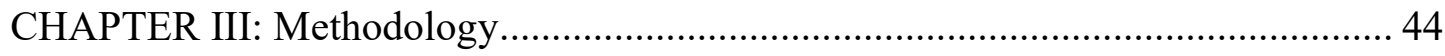

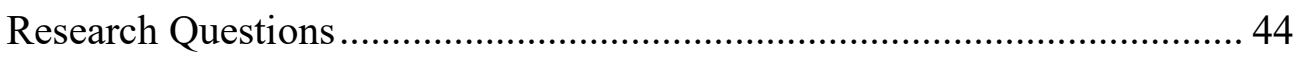

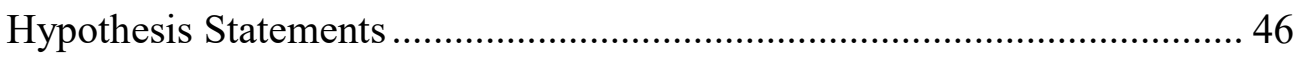

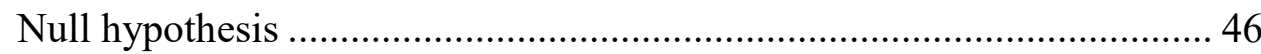

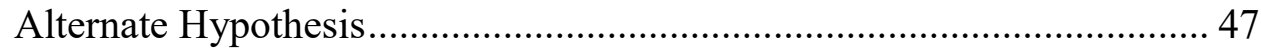

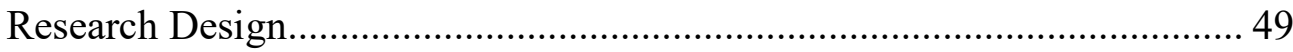

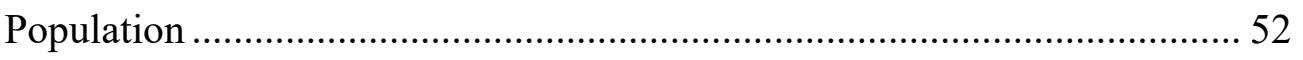




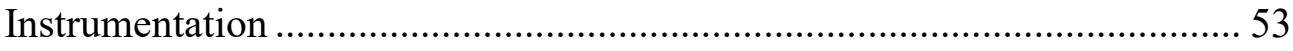

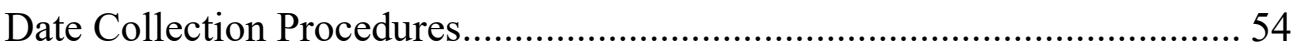

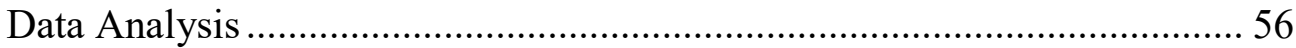

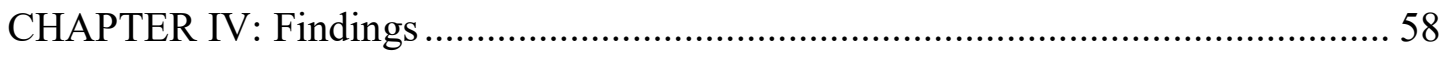

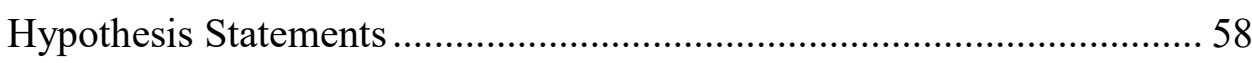

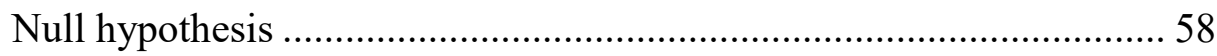

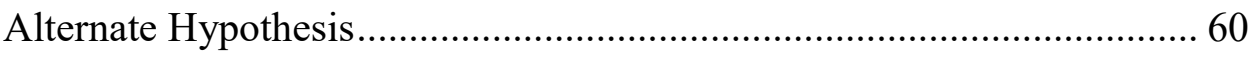

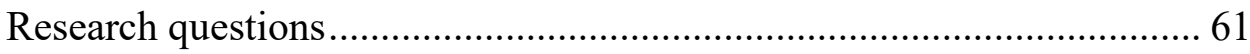

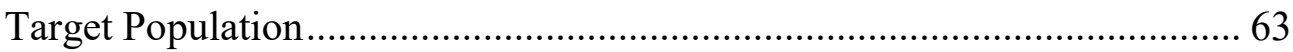

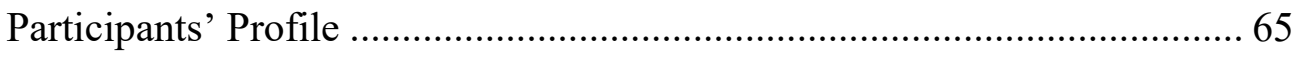

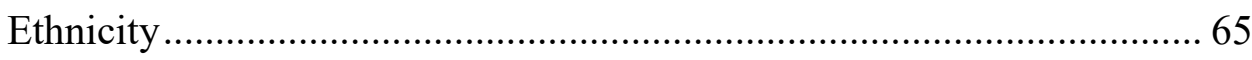

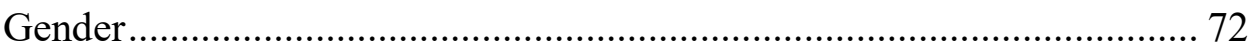

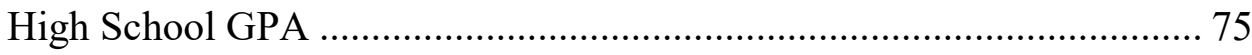

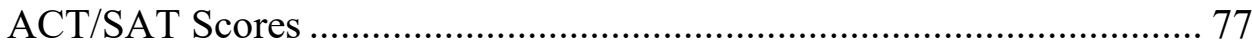

In-State/Out of-State Residency ……………………………………....... 79

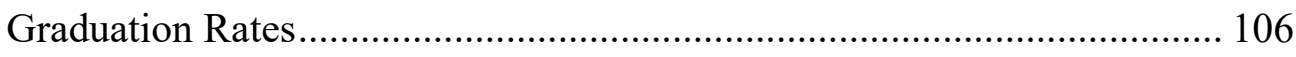

Academic Performance (GPA) Upon Graduation ...................................... 128

Graduation Rates Within The Mountaineer Success Academy

Participant Group............................................................................ 133

Academic Performance (GPA) Upon Graduation Within The Mountaineer Success Academy Participant Group ............................... 138

Attributes Contributing to the Successful Completion of College

Degrees for Mountaineer Success Academy Participants ...................... 141

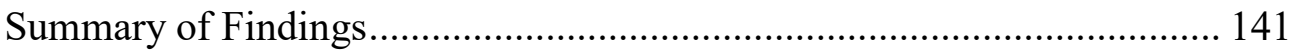

Chapter V: Summary, Conclusions, Implications and Recommendations ................ 142

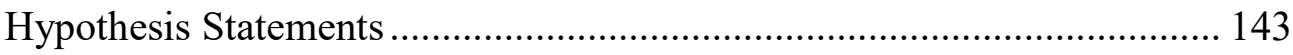

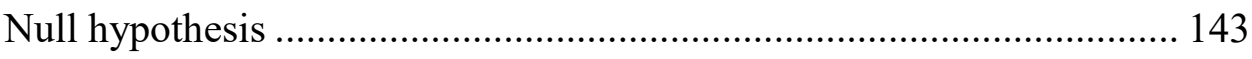

Alternate Hypothesis............................................................................ 144

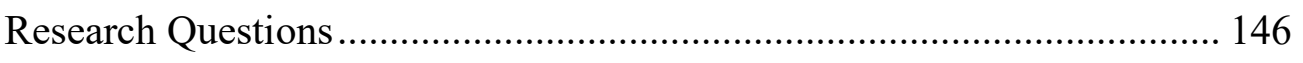

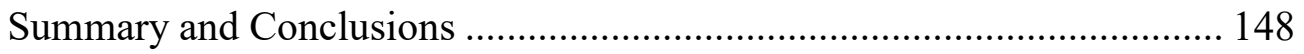

Participants Profile ............................................................................... 148

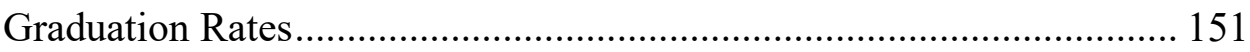

Academic Performance (GPA) Upon Graduation ................................... 153 
Attributes Impacting Graduation Rates ......................................... 154

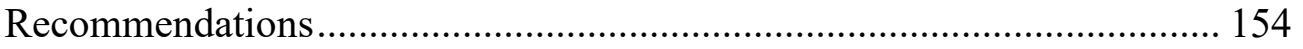

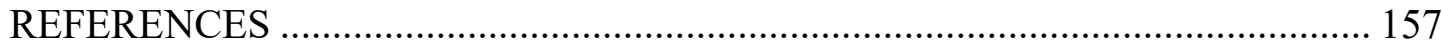

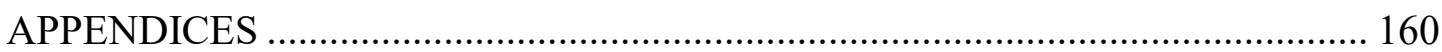

APPENDIX A: Mountaineer Success Academy Frequently Asked Questions........ 161

APPENDIX B: Conversion Tables from SAT Scores to ACT Scores ..................... 166

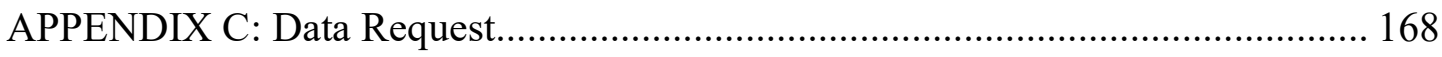

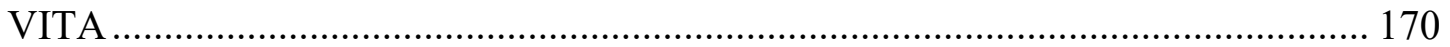




\section{LIST OF TABLES}

1. Enrollment of Mountaineer Success Academy participants, Eligible NonParticipants, and Non-Eligible Student Groups for the 2012, 2013, 2014, and 2015 Cohorts.

2. Number of Participants in the Mountaineer Success Academy, Eligible Non-Participants and Non-Eligible Students for the 2012, 2013, 2014 and 2015 Cohorts.

3. Number of Mountaineer Success Academy Participants who participated in MSA Links for the 2014 and 2015 Cohorts.

4. Ethnicity of Mountaineer Success Academy Participants, Eligible NonParticipants and Non-Eligible Students for the 2012, 2013, 2014 and 2015 Cohorts

5. Ethnicity of Mountaineer Success Academy Participants who participated in MSA Links

6. Gender of Mountaineer Success Academy Participants, Eligible NonParticipants, and Non-Eligible Students for Cohorts 2012, 2013, 2014 and 2015.

7. Gender of Mountaineer Success Academy Participants who participated in MSA Links.

8. Mean High School GPA of Mountaineer Success Academy Participants, Eligible Non-Participants and Non-Eligible Students for the 2012, 2013, 2014 and 2015 Cohorts

9. High School GPA of Mountaineer Success Academy participants who participated in MSA Links

10. ACT scores of Mountaineer Success Academy Participants, Eligible NonParticipants, and Non-Eligible Students for the 2012, 2013, 2014 and 2015 Cohorts

11. ACT/SAT Scores of Mountaineer Success Academy Participants Who Participated in MSA Links.

12. Residency of Mountaineer Success Academy participants, Eligible NonParticipants and Non-Eligible Students for the 2012, 2013, 2014 and 2015 Cohorts

13. Residency of Mountaineer Success Academy Participants who participated in MSA Links

14. Residency by State of Mountaineer Success Academy Participants, Eligible Non-Participants and Non-Eligible Students for the 2012, 2013, 2014 and 2015 Cohorts

15. Residency by State of Mountaineer Success Academy Participants Who Participated in MSA Links 
16. Citizenship of Mountaineer Success Academy Participants, Eligible NonParticipants and Non-Eligible Students for the 2012, 2013, 2014 and 2015 Cohorts

17. Citizenship of Mountaineer Success Academy Participants who Participated in MSA Links

18. Graduation Rates of Mountaineer Success Academy Participants, Eligible Non-Participants, and Non-Eligible Student Groups for the 2012, 2013, 2014, 2015 Cohorts

19. Graduation Rates of Mountaineer Success Academy Participants, Eligible Non-Participants, and Non-Eligible Student Groups for the 2012, 2013, 2014 and 2015 Cohorts by Year

20. Graduation Rates of First-Generation Mountaineer Success Academy Participants, Eligible Non-Participants and Non-Eligible Students for the 2012, 2013, 2014 and 2015 Cohorts

21. Graduation Rates of First-Generation Mountaineer Success Academy Participants who participated in MSA Links

22. Graduation Rates by Ethnicity

23. Chi Square Analysis- Graduation Rates of Mountaineer Success Academy Participants, Eligible Non-Participants, and Non-Eligible Student GroupsCross Tabulations.

24. Chi-Square Analysis- Graduation Rates of Mountaineer Success Academy Participants and Eligible Non-Participants- Cross Tabulations.

25. Academic Performance (GPA) Upon Graduation of Mountaineer Success Academy Participants, Eligible Non-Participants and Non-Eligible Students for the 2012, 2013, 2014, and 2015 Cohorts

26. Descriptive Data for Analysis of Covariance for Academic Performance (GPA) Based on Participation and time of graduation Mountaineer Success Academy Participants, Eligible Non-Participants and NonEligible Students

27. Summary Data: Analysis of Covariance for Academic Performance (GPA) Based on Participation and time of graduation Mountaineer Success Academy Participants, Eligible Non-Participants and Non-Eligible Students

28. Graduation Rates of Mountaineer Success Academy Students who also Participated in MSA Links for the 2014 and 2015 Cohorts.

29. Chi-Square Analysis- Graduation Rates of Mountaineer Success Academy Participants who also Participated in MSA Links and Mountaineer Success Academy Participants who did not Participate in MSA Links.

30. GPA Upon Graduation of Mountaineer Success Academy Participants who also Participated in MSA Links for the 2014 and 2015 Cohorts 


\section{FIGURES}

1. Categories of first-year students who were eligible or not eligible for the Mountaineer Success Academy .......................................................................... 4 


\section{CHAPTER I}

\section{Introduction}

In 2011, the four-year graduation rate at West Virginia University was 33.7\%. Students who were first-time, full-time freshmen entering college in 2007 were included in this graduation rate. The six-year graduation rate in 2013 was 57.1\%. (The Chronicle of Higher Education College Completion, n.d.) Comparatively, the average four-year graduation rates in the United States for four-year public institutions were 33.3\% while the six-year graduation rates were 57.6\% (The Chronicle of Higher Education College Completion, n.d.).

Compared to other institutions in West Virginia, WVU's six-year graduation rates were significantly higher than Marshall University (44.6\%) and West Liberty University (41.4\%). Six-year graduation rates at WVU were also higher than Shepherd University (37.9\%), Concord University (35.8\%), Fairmont State University (34.2\%), Glenville State College (30.3\%), and Bluefield State College (17.7\%) (The Chronicle of Higher Education College Completion, n.d.).

Although WVU's graduation rates are higher than other institutions in West Virginia, WVU is a land grant, flagship institution with R1 (high research activity) status and may therefore be compared with other institutions in the United States of the same stature. WVU's peer institutions have relatively higher graduation rates compared to WVU. University of Florida has a $65.2 \%$ four-year graduation rate and an $86.5 \%$ six-year graduation rate. The Ohio State University has a 58.5\% four-year graduation rate and an 83.2\% six-year graduation rate. The University of Arizona has a 39.9\% four-year 
graduation rate and a $61.4 \%$ six-year graduation rate (The Chronicle of Higher Education College Completion, n.d.).

Naturally, this information may make one wonder why there is a significant difference among graduation rates at various institutions, so it is important to note the admission requirements and acceptance rates at each institution. For WVU, the admission criteria is a high school GPA of 2.0 or higher for WV residents and 2.5 or higher for nonresidents. WV residents should have at least a 990 on the SAT and a 19 on the ACT. Nonresidents should have at least at 1060 on the SAT and 21 on the ACT. The acceptance rate at WVU was $85.8 \%$ for the year 2015 (West Virginia University Undergraduate Admissions, n.d.) At the University of Florida, the average high school GPA is a 4.1 on a 4.0 scale and the average SAT score is $580-680$ for the reading and writing portion and a $600-690$ for the math portion. The acceptance rate is $47.5 \%$ (UF Admissions, n.d.) at The Ohio State University, a high school GPA of 3.78 is required. The required SAT ranges from 1320-1490 and the required ACT score is between a 27 and 31 . The acceptance rate is $48.1 \%$ (The Ohio State University, n.d.) Finally, the University of Arizona admission criteria is a high school GPA of 2.5. The acceptance rate is $83.6 \%$ (Arizona State University Admission, n.d.).

As state funding for universities decline and funding becomes based more on outcomes like retention and graduation rates, universities must focus their efforts on assessment and delve deeper into uncovering issues that prevent students from graduating. Once issues are identified, it is in the best interest of the university to develop, implement, and assess support services that may be created to provide students with resources that could lead to their success, thus improving graduation rates. 
Although an undecided/exploratory student can be perceived as self-aware, strategic even, by allowing themselves time to explore their options before declaring a major, research shows that students who begin college undecided are less likely to persist (Spight, 2008). Spight (2008) argues that although undecided students may leave an institution of higher education because they are unsure of what to study, and therefore may be bored or feel directionless, there are other factors that affect persistence as an undecided student. Factors that Spight (2008) believes affect attrition at a higher rate than major choice are high school GPA and ACT scores. Students with higher rankings for both factors were more likely to persist and progress through college.

At West Virginia University, the Mountaineer Success Academy (MSA) was created to serve eligible students who were undecided or did not meet the requirements for their desired major. Participation in the program was voluntary and nearly all of the students who were invited to participate and who participated encompassed WVU's two lowest levels of academic preparation and achievement which is measured by high school GPA and ACT/SAT scores. The program provided participants with assistance in deciding on a major or helping create a pathway for their desired major through one-onone academic advising and a class called WVUe 293G: Problem Solving.

The program provided a five day early move-in component called MSA Links, where participants moved into their residence hall room before the regular move-in day. Brooke Tower was designated as the residence hall where MSA participants were encouraged, but not required, to reside. A live learn community was established in Brooke Tower for MSA participants. During MSA Links, participants started their FirstYear Seminar, WVUe 191A and English class, ENGL 101, attended information sessions 
with faculty and upperclassmen, met their student success coach, academic advisor, and traveled to various locations in West Virginia for excursions. The program provided academic advising and coaching throughout the participants' first year of college.

Students were required to meet with their academic advisor once per semester, with a career counselor at the WVU Career Services Center and with their student success coach once per month. MSA was a one year program offered to students entering their first year at West Virginia University. A flow chart is provided below to visualize how students were categorized in the program.

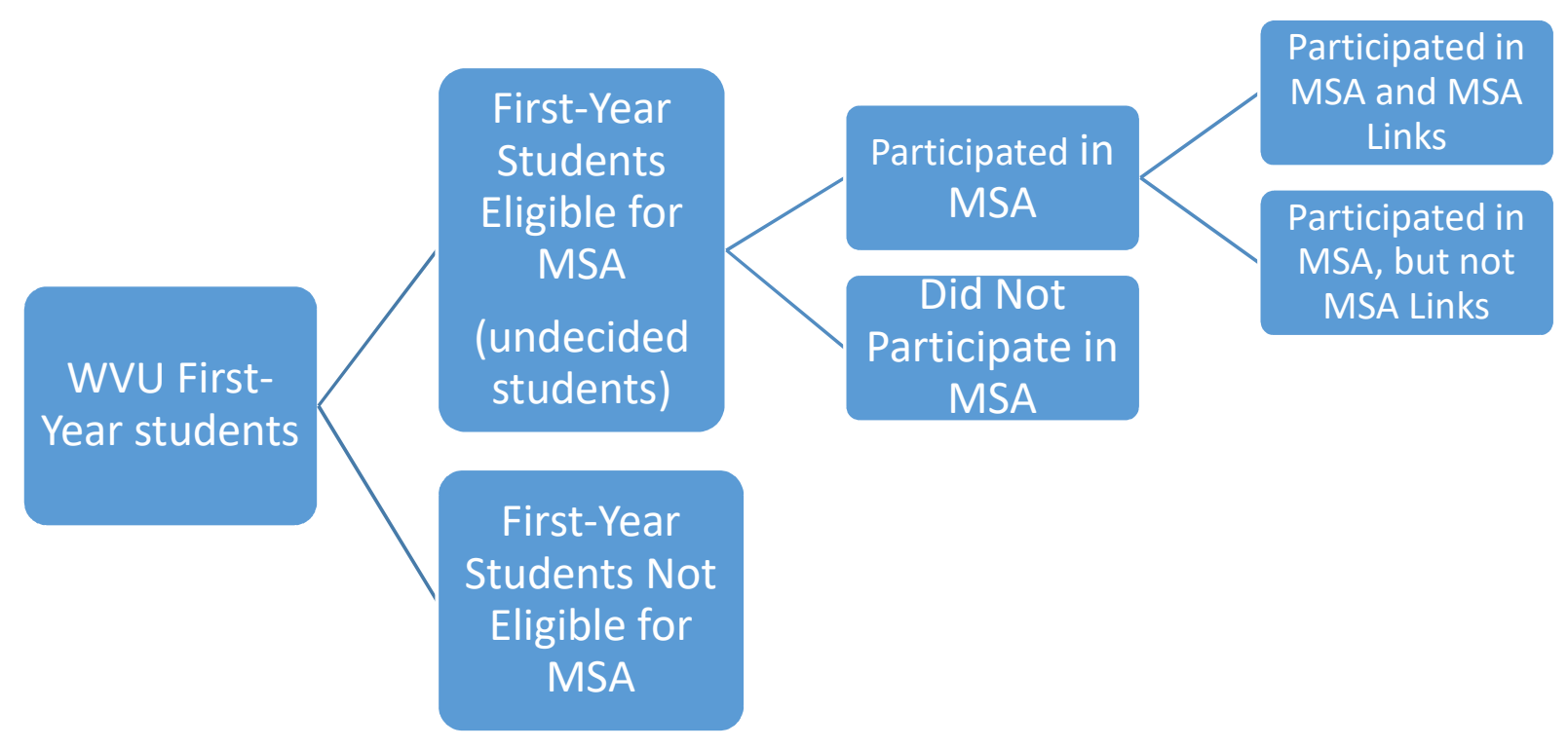

Figure 1: Categories of first-year students who were eligible or not eligible for the Mountaineer Success Academy

\section{Statement of the Problem}

Research has shown that college students who are undecided on a major are at higher risk for stopping out or dropping out of college. One reason is a lack of connection to a home college, school or department. Programs or initiatives designed to focus on the needs of undecided students may improve retention rates and can assist institutions in 
increasing the success rate of this population of students, ultimately leading to higher retention and graduation rates.

The Mountaineer Success Academy was created to serve eligible students who were undecided or did not meet the requirements for their desired major. It is important to determine the extent to which the Mountaineer Success Academy successfully retained students through graduation, not only to increase retention and graduation rates at WVU, but also to positively impact the lives of students, who may be presented with opportunities after obtaining a bachelor's degree that will lead to a life well lived.

\section{Purpose of the Study}

The purpose of this study was to examine the West Virginia University Mountaineer Success Academy participants' graduation rates and academic performance (GPA) upon graduation in comparison to eligible non-participants and non-eligible students at West Virginia University. The information generated from this research could be used in the following ways by West Virginia University:

1. Increase retention for undecided students, therefore increasing retention at West Virginia University

2. Assist undecided students to declare majors that are in their best interest at a faster rate.

3. Create additional programming that will assist students in selecting a major and be successful in the academic career

4. Results can be used by faculty, administrators, parents, career counselors, school counselors and other professionals to better serve at-risk students. 


\section{Research Questions}

The following research questions were formulated to guide this study:

1. What were the demographic characteristics of WVU Mountaineer Success Academy participants, WVU Mountaineer Success Academy participants who participated in MSA Links, WVU Mountaineer Success Academy participants who did not participate in MSA Links, eligible non-participants and noneligible students entering West Virginia University in the fall semesters 2012, 2013, 2014 and 2015?

2. What were the within 8 semester (within 4 year) graduation rates of the West Virginia University Mountaineer Success Academy participants compared to those of eligible non-participants and non-eligible students entering West Virginia University in the fall semesters 2012, 2013, 2014 and 2015?

3. What were the more than 8 semester (more than 4 year) graduation rates of the West Virginia Mountaineer Success Academy participants compared to those of eligible non-participants and non-eligible students entering West Virginia University in the fall semesters 2012, 2013 and 2014?

4. What was the academic performance (GPA) upon graduation of the West Virginia University Mountaineer Success Academy participants compared to that of eligible non-participants and non-eligible students entering West Virginia University in the fall semesters of 2012, 2013, 2014, and $2015 ?$

5. What were the graduation rates of students who participated in the West Virginia University Mountaineer Success Academy compared to students who 
participated in the Mountaineer Success Academy, but not MSA Links for fall semesters 2014 and 2015?

6. What was the academic performance (GPA) of students who participated in the Mountaineer Success Academy compared to students who participated in the Mountaineer Success Academy, but not MSA Links for fall semesters 2014 and 2015?

7. What attributes contributed to the successful completion of college degrees for participants of the West Virginia University Mountaineer Success Academy?

\section{Hypothesis Statements}

\section{Null hypothesis}

Seven null hypotheses were identified for this study:

1. There was no significant difference among the within 8 semester (within 4 year) graduation rates for students who participated in the Mountaineer Success Academy and the within 8 semester (within 4 year) graduation rates for eligible non-participants or non-eligible students.

2. There was no significant difference among the more than 8 semester (more than 4 year) graduation rates for students who participated in the Mountaineer Success Academy and the more than 8 semester (more than 4 year) graduation rates for eligible non-participants or non-eligible students for the 2012, 2013 and 2014 cohorts.

3. There was no significant difference among academic performance (GPA) upon graduation for students who participated in the Mountaineer Success Academy and eligible non-participants and non-eligible students. 
4. Among students who participated in the Mountaineer Success Academy, there was no significant difference in graduation rates for those students who participated in MSA Links and graduation rates for students who participated in the Mountaineer Success Academy, but not MSA Links for fall semesters 2014 and 2015 .

5. Among students who participated in the Mountaineer Success Academy, there was no significant difference in academic performance (GPA) for those students who participated in MSA Links and academic performance (GPA) for students who participated in the Mountaineer Success Academy, but not MSA Links for fall semesters 2014 and 2015.

6. The identified variables: ethnicity, gender, high school GPA, state residency, and SAT/ACT scores were not able to discriminate between participants of the Mountaineer Success Academy who graduated within 8 semesters (within 4 years) and participants of the Mountaineer Success Academy who did not graduate within 8 semesters (within 4 years).

7. The identified variables: ethnicity, gender, high school GPA, state residency, and SAT/ACT scores were not able to discriminate between participants of the Mountaineer Success Academy who graduated in more than 8 semesters (more than 4 years) and participants of the Mountaineer Success Academy who did not graduate in more than 8 semesters (more than 4 years) for the 2012, 2013 and 2014 cohorts. 


\section{Alternate Hypothesis}

Based on the seven identified null hypotheses the following alternative hypotheses statements were identified to reflect the initial predictions of this research study:

1. There was a significant difference among the within 8 semester (within 4 year) graduation rates for students who participated in the Mountaineer Success Academy and eligible non-participants and non-eligible students.

2. There was a significant difference among the more than 8 semester (more than 4 year) graduation rates for students who participated in the Mountaineer Success Academy and eligible non-participants and non-eligible students for the 2012, 2013 and 2014 cohorts.

3. There was a significant difference among academic performance (GPA) upon graduation for students who participated in the Mountaineer Success Academy and eligible non-participants and non-eligible students.

4. Among students who participated in the Mountaineer Success Academy, there was a significant difference in graduation rates for those students who participated in MSA Links and graduation rates for students who participated in the Mountaineer Success Academy, but not MSA Links for fall semesters 2014 and 2015.

5. Among students who participated in the Mountaineer Success Academy, there was a significant difference in academic performance (GPA) for those students who participated in MSA Links and academic performance (GPA) 
for students who participated in the Mountaineer Success Academy, but not MSA Links for fall 2014 and 2015.

6. The identified variables: ethnicity, gender, high school GPA, state residency, and SAT/ACT scores were able to discriminate between participants of the Mountaineer Success Academy who graduated in within 8 semesters (within 4 years) and participants of the Mountaineer Success Academy who did not graduate in within 8 semesters (within 4 years).

7. The identified variables: ethnicity, gender, high school GPA, state residency, and SAT/ACT scores were able to discriminate between participants of the Mountaineer Success Academy who graduated in more than 8 semester (more than 4 years) and participants of the Mountaineer Success Academy who did not graduate in more than 8 semesters (more than 4 years) for the 2012, 2013 and 2014 cohorts.

\section{Definitions of Terms}

Mountaineer Success Academy (MSA)- a first-year student success initiative designed for West Virginia University (WVU) students who are undecided about their major or did not meet the requirements for their desired major.

MSA Links- a five day early move-in program for Mountaineer Success Academy participants.

Undecided student- a student who has not selected a major or was placed as undecided because they were not admitted into their desired major.

Eligible non-participant- A student who meets the requirements to join the Mountaineer Success Academy program but opted out of the program. 
Non-eligible student- a student who does not meet the requirements to join the

Mountaineer Success Academy program.

Mountaineer Success Academy (MSA) participant- a student who joined the Mountaineer Success Academy.

MSA Links participant- a student who participated in MSA Links.

At-risk college student- a student who may struggle in college due to risk factors that have been determined by historical data on student demographics, retention rates and graduation rates.

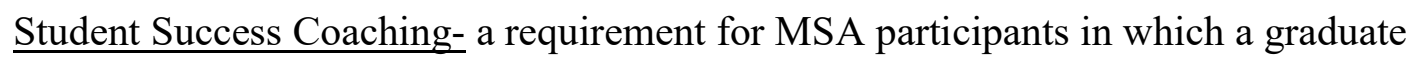
assistant is paired with MSA participants to coach them through the transition between high school and college via monthly meetings.

\section{Limitations of the Study}

This study was limited to first-time, full-time students enrolled at West Virginia University during the fall semesters of 2012, 2013, 2014, and 2015. The Mountaineer Success Academy enrolled between 60 and 236 students per year. Eligible nonparticipants and non-eligible students were selected from the first-time, full-time enrollment of undecided students of the cohort years.

One of the most significant limitations of the study is that of self-selection. Students were identified by the WVU Office of Admissions and an invitation was extended to students who met the requirements of the program. All students who received an invitation to join MSA were automatically enrolled in the program. Students had the option to participate in the program and were directed to contact WVU to opt out of the program. 
Another limitation of this study is the inability of the researcher to gather information about the extent to which eligible non-participants and non-eligible students were utilizing other campus resources similar to resources that were offered to students through the MSA program.

This study is also limited by examining just a few attributes that may have an impact of graduation rates or academic performance.

\section{Summary}

This study was designed to examine the relationship of ethnicity, gender, high school GPA, state residency, and SAT/ACT scores, academic performance and graduation rates between participants of the Mountaineer Success Academy who graduated in 8 semesters (4 years) or those who graduated in more than 4 years; participants of the Mountaineer Success Academy who did not graduate in 8 semester (4 years) or more than 4 years, eligible non-participants and non-eligible students at West Virginia University. The data collected can be used by the Center for Learning, Advising and Student Success, the Vice Provost Office, as well as others including academic advisors, university faculty and administrators, university career coaches, university counselors, legislators, parents and other professionals. 


\section{CHAPTER II}

\section{Review of Literature}

Little research is available regarding success programs targeted specifically for students who are undecided. However, research is available for the various components that constituted the Mountaineer Success Academy. Therefore, the literature review is divided into the following categories: summer bridge programs, live learn communities, First-Year Seminar, academic advising, academic success coaching, and resources for career exploration.

\section{Summer Bridge Programs}

Research has shown that summer bridge programs have the potential to connect students with campus resources, provide a space for social integration, promote a sense of belonging, improve academic engagement and skills, promote self-efficacy and encourage successful course completion, which in turn may boost retention and graduation rates. Kitchen, Sadler, and Sonnert (2018) revealed that institutions of higher education introduced summer bridge programs as colleges began opening their doors to new student populations over time (e.g., minority populations) and these outreach and support programs were introduced to facilitate successful college transitions. Support programs can be traced back to the expansion of access to postsecondary education in the 1800s. Summer bridge programs are designed to be diverse in nature, each having their own historical context and reason for existing and the introduction of remediation. The premise of summer bridge programs in higher education is to compensate for perceived uneven k-12 educational opportunities and are intended to address a plethora of issues 
that may hinder students from completing college, including but not limited to: access, student success, preparation, retention, interests, and educational attainment.

McCurrie (2009) defines a summer bridge program as a "short, intense introduction to college designed to assist underprepared first-year students" (p. 28). The “bridge” from McCurrie's viewpoint is an attempt to connect students' educational experiences with institutional expectations. This concept includes academic and social components, which often times reflects the overall mission of that particular institution.

If summer bridge programs are geared towards students classified as underprepared, what is the working definition of a student who is underprepared? Melzer and Grant (2016) classify students as underprepared if they perform below college standards in math, reading comprehension and/or writing skills. This may present a further challenge for students who perform below college standards because remedial coursework is typically required before students can move on to college level courses. Remedial courses usually do not count for credit towards a degree, and often times are an extra financial burden to students along with adding extra time to complete a degree. This may be especially true for students who begin in remedial math since math classes are often the gateway to other STEM classes such as chemistry. Melzer and Grant (2016) argue that underprepared students are more likely to drop out of college and have lower GPAs compared to students who are more academically prepared for college. Considering other characteristics, who are underprepared students? According to Melzer and Grant (2016), “first-generation college students, students from lower socioeconomic status, and minority students are more likely to be characterized as underprepared compared to other groups" (p.99). Along with poor academic performance, what other 
known characteristics do underprepared students display? Melzer and Grant (2016) argue that underprepared students exhibit low self-efficacy, poor decision-making skills, struggle more with career decisions, and do not take advantage of campus resources like tutoring or counseling centers. Interestingly, underprepared students feel they have little control over events in their lives and may be unrealistic about their own academic abilities. The premise of Melzer and Grant's research focuses on differences in personality traits among prepared and underprepared first-year college students. This is an interesting concept and although research on personality traits remains limited, focusing on these characteristics may open a pathway for student life professionals and professors to engage with underprepared students in a holistic way. Melzer and Grant (2016) note that underprepared students exhibit a great deal of resiliency and perseverance while still underperforming academically and socially compared to prepared students. By studying the differences in personality traits among prepared and underprepared first-year college students, Melzer and Grant (2016) hoped to discover how to improve teaching strategies for instructors and provide insight to administrators who work directly with underprepared students. Through their research, students at Sacred Heart University who were considered underprepared based off of test scores were placed into an Academic Incentive Program. The Incentive Program focuses on reading, writing and study skills with smaller class sizes and students are among peers with similar academic difficulties. The American College Testing Program's (2010) College Student Needs Assessment Survey and the Interpersonal Style Inventory (ISI) were administered to participants. The ISI consists of questions and measures five characteristics of personality including Interpersonal Involvement, Self-Control, 
Autonomy, Socialization, and Emotional Stability. After analyzing the survey results, Melzer and Grant (2016) found that participants in the AIP program responded that becoming an expert in a field of study was less important than non-participants, were less likely to believe they needed help in obtaining work experience in positions related to their field, were less focused on getting career counseling, and also believed they needed more help to increase their math abilities. Participants had lower results in conscientiousness, deliberateness, and persistence than non-participants. Interestingly, participants expressed less guilt than prepared students regarding these characteristics. Melzer and Grant (2016) state that this result may be attributable to lack of expectation of success no matter how much effort is applied. These findings indicate that there are social support needs that impact academic outcomes when working with underprepared students. Melzer and Grant (2016) indicate that it is important to involve professors so they may incorporate strategies like requiring students to complete a learning styles inventory and providing mentoring opportunities.

Summer bridge programs currently serve a small number of students at any given college or university, however, because the infrastructure for programming is in place at many colleges or universities, it may be enticing for institutions of higher education currently offering summer bridge programs to a specific population of students to expand their resources to other populations of students. One study conducted by Kitchen, et al., 2018 focused on a summer bridge program offered to students who were interested in Science, Technology, Engineering and Mathematics (STEM) fields. It was concluded that little research has been conducted to assess summer bridge programs designed for 
specific groups of students. They concluded that most studies were descriptive, rather than relying on rigorous statistical techniques and had a small number of participants.

A study conducted by Suzuki, Amrein-Beardsley and Perry (2012) at Arizona State University looked at a five-week pre-enrollment initiative called the Pathways Summer Bridge (PSB) Program. This program was designed using six components of Tinto's (1993) longitudinal model of institutional departure and geared towards students who were predominately first-generation and underrepresented populations. Tinto (1993) states that in addition to being academically challenged, first-year students who are atrisk have difficulty transitioning into university life because they do not fit within an institutional setting. As Tinto describes:

"positive integration serves to raise one's goals and strengthen one's commitments both to those goals and to the institutions within which they may be attained. Conversely, the model posits that, other things being equal, the lower the degree of one's social communities of the college, the greater the likelihood of departure. To the degree that the individual also participates in communities external to the college (e.g., family, work, and community), the model argues, events in those communities may also shape persistence in college." (as cited in Suzuki et al., 2012, p. 88).

Tinto's model attests that pre-entry attributes like academic preparation, financial disposition, family background, cultural background, and first-generation status can strongly influence a student's initial fit with an institution and can impact their likelihood of degree completion. Tinto (1993) argues that academicians should therefore pay particular attention to the attributes mentioned above as well as learning about students' 
goals regarding major choice and career choice and most importantly, the level of commitment to reaching those goals. In the same vein, it is also important to learn about students' external commitments like family and financial obligations that may interfere with a student's ability to remain committed to obtaining one's goal. Another component of Tinto's model suggests that students need a balance of positive interactions both in the classroom and in social settings in order to be successful. Positive interactions with faculty members in the classroom or laboratory increase students' confidence outside the classroom. Informal interactions with faculty help students see university faculty as support persons. Becoming involved on campus and feeling like part of the university are essential for students to successfully transition from high school to college.

A crucial component of Tinto's model is integration or in other words, fit. If students do not have positive experiences between and within the academic and social systems, they will often choose to leave the institution. This component is important because as students engage at the beginning of their college careers, they often reexamine and change goals. If the student experience conflicts with this process, their commitment to complete their goal may decline. The final component of Tinto's model consists of students finalizing their commitment about meeting their goal. During this final stage, students weigh their goal against the level of support they have received from their academic and social communities.

Often, at-risk students have not had positive interactions to promote their own integration and retention and their expectations are not met. For this study at the University of Arizona, at-risk students were defined as first-generation or underprepared with low high school GPAs and college entrance exam scores. Students with low scores 
on entrance exams were placed into remedial math and science courses for a summer program. The study examined the efforts of the five-week summer bridge program to improve re-enrollment at the university developed using Tinto's model to improve reenrollment and retention rates for first-year students. Specific goals of the program were to help students familiarize themselves with campus resources, participate in student programs on and off campus, meet other students to create and foster friendships and student communities, experience college-level classes while earning four college credits during the summer, develop relationships with faculty inside and outside the classroom, increase their understanding of college expectations and campus life and build other academic skills for succeeding at the university (Suzuki, 2012). Through a pre-post research design, the results revealed that participants felt more familiar with campus resources and more confident in knowing what to expect in college. The program also seemed to help instill a sense of community. Finding new friends was one of the program's most important benefits as program participants were more likely to remain in college because they developed a sense of community. Overall, the findings from this study suggest that the five-week program positively affected participants and impacted their decision to stay at the university and re-enroll the following spring semester (Suzuki, 2012).

Douglas and Attewell (2014) have studied the impact of summer bridge programs and degree completion. The premise of their research is based on what colleges can do to combat the low graduation rates in the U.S. Because graduation rates in the United States are low, stakeholders are looking for solutions to combat these low rates but may be ignoring existing support programs that may offer a solution. According to Douglas and 
Attewell (2014), bridge programs are comprised of fewer than $8 \%$ of entering undergraduates and are most commonly offered at nonselective colleges. Colleges could potentially leverage into this untapped resource to improve retention and graduation rates. One important piece to note about their research is that they also suggest in addition to poor academic preparedness, academic momentum can be another indicator of a student dropping out of college. In their study, Douglas and Attewell (2014) utilized the Beyond Postsecondary (BPS) transcript data and found that community colleges and less selective 4-year colleges where students attended bridge programs are 10 percentage points more likely to graduate within six years. The BPS was directed by the National Center for Education Statistics (NCES) and is a longitudinal survey that tracked a sample of college freshmen from 2004 until 2009.

\section{Live Learn Communities}

As stated by Stassen (2013), live learn communities largely emerged as a popular method for improving the quality of the undergraduate experience, particularly during the first year. Live learn communities date back to the 1920s when Alexander Meiklejohn introduced the "Experimental College" at the University of Wisconsin in response to a silo of academic departments and fragmented curriculum. The current live learn communities stem from the 1980s when higher education institutions faced financial constraints and stakeholders focused on maintaining undergraduate enrollment and improving retention rates.

Live learn communities have become an integrated part of the university experience in recent decades. Beginning in the last decades of the twentieth century, live learn communities are structured in a way to bring students together to participate in a 
common learning experience. Tinto (1993) explains that many students experience college as isolated learners where learning is disconnected from their peers and describes the higher education classroom as a "spectator sport" where faculty lecture and students listen, which may lead to disengagement. In recent decades, a growing number of institutions have begun to build live learn communities that focus on bringing students together based on common themes, backgrounds and interests, lending itself to how institutions restructure the classrooms and the way students experience the curriculum and learning within those classrooms. According to Tinto (1993), learning communities in their most basic form, begin with enabling students to take courses together. This may mean that students share a common First-Year Seminar, or even an entire semester of the same classes. Some courses may be linked to others, for example, a First-Year Seminar for undecided students linked with a course about career exploration. Faculty may even reorganize their syllabi and their classroom to promote a collaborative learning experience. Through this structure, learning communities have a few things in common. One is shared knowledge, meaning that because students are taking courses together centered on a common theme, students are connected by a coherent curricular experience. The second commonality is shared knowing. The same students are enrolled in the same classes, so they get acquainted with each other quickly, thus creating a sense of community. The last commonality is shared responsibility. Live learn communities encourage students to become responsible for one another in the learning process. By designing a collaborative curriculum, students learn to be mutually dependent on one another (Tinto, 1993). For institutions that incorporate live learn communities, this means that students not only share similar classes, but also reside in the same residence hall. 
More recently, live learn communities have also incorporated community service or service learning as part of the shared curriculum or as a common theme in the residence hall. Promoting community service within a live learn community stresses the importance of the greater community outside institutional walls and further connects students to a community. Service learning has an underlying pedagogy which may become a shared experience that students and faculty are able to engage. Depending on the theme or objective of a live learn community, the faculty invested in the live learn community usually combine the work of academic and student life professionals to create a holistic experience that touches on most, if not all, student development needs.

Live learn communities were created to foster a sense of belonging and community, and to encourage active learning through a common experience, so it comes to no surprise that institutions began implementing these communities on campus as an attempt to improve not only the undergraduate education experience for students, but also to improve retention and graduation rates. Rocconi (2011) indicated that learning communities are recognized as high impact educational practices that are positively related to students' learning and success in college. Kuh (2008) shares that the interesting find on live learn communities is their indirect impact on student learning. The research from Zhao \& Kuh (2004) found that participating in a live learn community was more strongly related to student engagement than educational outcomes. Although there are different working definitions of student engagement among the academic community, the overarching premise is that learning is related to the way students spend their time and energy (Rocconi, 2011). Therefore, Rocconi's (2011) study on participants of live learn communities versus students who did not participate in a live learn community was based 
on Pace's concept of quality of effort, which suggests that students arrive to college with differing backgrounds and those backgrounds lead to varying amounts of effort, which in turn, determines their perceptions of growth and development. The conceptual model utilized for Rocconi's (2011) study is also based on Pace's work and his model of student development. The model is formulated into three categories. The first category is that the college experience encompasses the events in which a student engages while in college. The second category is the way students make sense of their experiences is impacted by the environment of the college and the third category is the combination of effort and environment that contribute to student growth and development (Rocconi, 2011). Participants in Rocconi's (2011) study included traditional age, first-time, full-time freshmen at a public research university in the United States and all measures were taken from the College Student Experiences Questionnaire (CSEQ). The results of the study revealed that experiences with faculty members, effort in coursework, perceptions of the academic environment, learning community membership and experiences with other students had a significant direct influence on students' perceived gains. Overall, Rocconi's (2011) findings align with previous research around live learn communities in that his findings suggest that live learn community participation is strongly related to student engagement and that is of an indirect nature. Another important finding is that participation in a live learn community was not related to students' perception of the collegiate environment. Rocconi recommends that when developing a live learn community, institutions should develop activities within the community that promote student-faculty interaction and interaction among students and collaborative coursework. 
A study by Eck, Edge and Stephenson (2007) at Rollins College was conducted to determine the impact of live learn communities that were created in the Fall of 2003. It was determined that Rollins College consistently ranked high on measures of students' academic engagement, but measures of social engagement seemed to need improvement. The College decided to implement live learn communities to help combat this issue. The pilot program was open to roughly 20 percent of incoming students and by 2005 was open to nearly half of all first-year students. At the time, the College enrolled roughly 1,719 students. Data from the First-Year Initiative (FYI) provide evidence that the live learn communities at Rollin improved student engagement in and outside the classroom. By the third year of the initiative, results showed that students who had participated in the live learn community were more likely than non-participants to develop critical thinking skills and knowledge of wellness. Eck, et al. (2007) concluded that as the live learn communities at Rollins College continue to extend beyond the classroom, they anticipate that first-year to second-year retention and six-year graduation rates will improve.

A very interesting and timely study by Jehangir, Williams, and Jeske (2012) focused on the influence of multicultural learning communities for first-generation students at a large Midwestern research university. Steeped in the concept of selfauthorship, the live learn community was centered on a multicultural curriculum and critical pedagogy, noting that universities should create learning spaces that invite selfdiscovery and a sense of community for students who are labeled at-risk. Jehangir et al., (2012) noted that, "creating learning environments that draw on first-generation students' strengths as border crossers can serve to facilitate an awareness of potential, which often goes unrecognized" (p. 269). Aligning with Chickering's Theory of Identity 
Development, according to Jehangir, et al. (2012), "learning communities embody elements of curricular design that serve to engage students in the process toward selfauthorship" (p. 270). When a multicultural curriculum is coupled with a learning community structure, this further encourages students to conceptualize their place as a citizen and develop critical thinking and problem solving skills. A common factor in live learn communities that implement multicultural curriculum or other forms of interdisciplinary immersion is the opportunity for students to experience disequilibrium, or dissonance, which aligns with Erikson's Theory of Identity Development. "Learning communities and multicultural curriculum work together to create a space in which students feel valued and heard, but also capitalize on this sense of trust to ask difficult questions of each other and themselves" (Jehanger et al., 2012, p. 271). The findings of this study examined the participation in the learning community and the multicultural curriculum and critical pedagogy influenced the trajectory of first-generation students. The sample consisted of 24 students and after interviews were conducted, the researchers found that students who had participated in the live learn community possessed selfauthorship ways of knowing, although the degree to which self-authorship varied, the students' narratives demonstrated how they moved from crisis/dissonance to the author of one's own life. Students disclosed a sense of growing awareness of their strengths and weaknesses as learners and that the live learn community curriculum intentionally encouraged them to practice self-reflection.

Another qualitative study of the social benefits of live learn communities was conducted by Arensdorf and Naylor-Tincknell (2016). They argue that live learn communities have shown to be successful, however, more studies to reveal this success 
have been quantitative in nature, and their focus is more qualitative to reveal the social benefits of live learn communities. Their study collected data from focus groups from students who participated in a live learn community and students who did not participate in a live learn community to determine if and what social benefits students reported about their live learn community or university experience. Using a phenomenological approach, the findings revealed although both groups do experience similar university life experiences, students who participated in a live learn community had deeper connections with faculty and peers as well as more social and academic opportunities.

Stassen (2013) conducted a study on the impact of three different live learn community models at the same university. The study took place at a large, Research I university in the northeast. The three live learn communities at the institution that were included in this study were the Residential Academic Program where students live in a common residence hall and enroll in a freshman-writing course. The Talent Advancement Program is a selective community designed for students within specific majors. The last is the Honors College Learning Community where Honors students co-enroll in two Honors classes. All three models follow the linked course model typically associated with learning communities. Other components varied among each live learn community. The results indicated that overall GPA was higher for students participating in all three live learn communities compared to students who did not participate in a live learn community. Results also revealed that all three live learn communities had significant effects on one-year retention rates. The results also showed that students who participated in all three live learn communities were more likely to have contact with peers in regard 
to academic work, engage in group projects, report positive academic behaviors, study more and perceive a positive learning environment. (Stassen, 2013)

\section{First-Year Seminar}

First-Year Seminars hold a space in the college experience to help students transition from high school to college. Aligning with Sanford's theory of challenge and support, Strayhorn (2009), believes that "first-year seminars were largely established to provide students with appropriate levels of challenge matched with the academic and social support necessary for student success" (p. 11). First-Year Seminars are not new in higher education. They date back to the early 1900s and were originally designed to ease the transition from high school to college, especially for those students considered at-risk. While First-Year Seminars vary in structure and content, much like summer bridge programs, their reason for existence is similar- to promote student success. Depending on the content of a particular First-Year Seminar class, students could be learning the "language" of higher education like what office hours are, how to send a proper email to a professor, what credit hours are and resources offered to help students. First-Year Seminars could be designed so students in the same major are taking the course together allowing for the content to be tailored to major specific information. Strayhorn (2009) states that First-Year Seminars that bring students in regular contact with their academic advisor are believed to be the most effective for promoting student success because it provides a direct connection with a resourceful person on campus. Like live learn communities, First-Year Seminars are also designed to help students form connections with peers and with faculty members to help build academic skills and make social 
connections. Strayhorn (2009) also states that First-Year Seminars where peer mentors serve as role models and guide first-year students are also successful.

Documenting what students learn in First-Year Seminars and measuring the effect First-Year Seminars have on student persistence are important for universities to assess given the current academic climate. According to Pittendrigh, Borkowski, Swinford \& Plumb (2016):

....empirical evidence about how well First-Year Seminars deliver on the promise to integrate students into the social and academic life of the university and improve student persistence can provide crucial information for administrators and faculty to help guide decision making and improve the firstyear experience for students. (p. 48)

Barton and Donahue (2009) state that students' grades in First-Year Seminars correlated directly with the likelihood of persistence and the grade a student earns in a First-Year Seminar course is a more accurate predictor of success than a student's SAT score or rank in high school. Although the literature demonstrates that First-Year Seminars are associated with increased retention and is positively correlated with graduation rates, Barton and Donahue (2009) cite a few concerns about measuring outcomes of First-Year Seminars. First, success may be defined differently for each researcher and those definitions have not been differentiated among types of first-year students. Second, outcomes have primarily been retention, persistence to graduation and academic performance primarily for at-risk students with only a small number of studies looking at student satisfaction or student/faculty connections. Lastly, Barton and Donahue (2009) note that many students enrolled in First-Year Seminars are not 
randomly assigned, making it difficult to attribute outcomes to the content of the Seminars themselves.

For Strayhorn's (2009) study, the purpose was to measure the impact of FirstYear Seminar participation on three correlates of student retention. The first is academic integration, followed by social integration and finally satisfaction with college. Strayhorn developed specific research questions that compared participants of First-Year Seminars to non-participants of First-Year Seminars. An ex post facto survey design was used to measure student's participation and the sample was drawn from the population of firsttime, full-time first-year students enrolled at a large, public, research-extensive, predominately White institution located in the southeast region of the United States. The study revealed that mere participation in a First-Year Seminar does not necessarily mean better outcomes in terms of academic or social integration, or satisfaction with college. However, the benefits that are likely to ensue from participating in a First-Year Seminar may stem from the type of First-Year Seminar offered and the content of the Seminar. Other findings revealed the same trends in prior research, such as women reporting being more satisfied with college than men and students with higher grades in college were more satisfied with college. Strayhorn (2009) suggests that providing the assistance students need to excel academically, educators can effectively alter students' opinions about college which can lead to a more engaging experience that may lead to persistence and ultimately, graduation.

The study conducted by Pittendrigh et al. (2016) focused on an academic FirstYear Seminar open to all first-year students regardless of major or academic preparation. The researchers were particularly interested in outcomes for students considered at-risk 
and therefore measured outcomes for the cohort, identified at-risk students within the cohort (roughly $25 \%$ of the whole group), and measured outcomes for those students. The study was conducted at a mid-size, research intensive university in the Rocky Mountain West. The university requires a First-Year Seminar for all students and supports a variety of designs for First-Year Seminars offered. Two surveys were used in this study, the first being the College Student Inventory (CSI) where a set of index scores on factors determining student persistence were identified. The second survey was developed by the researchers and administered to students enrolled in the academic First-Year Seminar selected for the study. The second instrument measured a series of learning outcomes and attitudinal changes related to the course. The results of the CSI survey indicated that the primary predictor of persistence or non-persistence for the population of the institution was college motivation. The overall persistence rate for students enrolled in the academic First-Year Seminar was 11.8 percentage points higher than students who were just administered the CSI survey. The researchers also determined that students who were atrisk within the group benefited in regard to persistence in the academic First-Year Seminar.

A study by Barton and Donahue (2009) focused on assessing multiple First-Year Seminars at the same institution. The initial purpose of the study at the University of Maine at Farmington (UMF) was to, "assess the effect of First-Year Seminars on student success and retention in comparison to the effect of previously established first-year transition courses at UMF" (Barton \& Donahue, 2009, p. 263). UMF is an undergraduateonly public liberal arts college where eighty percent of students are from in-state. Students had three options when choosing a First-Year Seminar upon entering college. 
When registering for classes, they had the option of signing up for the new First-Year Seminar that taught on a wide range of topics by faculty or to enroll in the previously existing one-week, one-credit Summer Experience or the one-credit orientation course called Exploration in Learning. Differences in student retention, academic performance, intellectual development during the first semester and student expectations and attitudes about college were measured. The results showed that retention of students was not associated with any of the groups. However, students enrolled in the new First-Year Seminar earned significantly higher GPAs at the end of the academic year compared to students who enrolled in the Explorations in Learning orientation course. Using the Perry intellectual development test as a pre-posttest, no statistically significant differences were found. Students who took the new First-Year Seminar reported significantly higher outcomes regarding whether they spent a substantial amount of time on academic work. Students enrolled in the new First-Year Seminar course had higher expectations for obtaining academic help than in the other orientation courses. Students enrolled in the new First-Year Seminar course also reported higher outcomes regarding involvement on campus. It should be noted that students who opted to enroll in the new First-Year Seminar course had higher SAT scores and higher school rankings than students who opted to enroll in the other orientation options.

A study by Ewing-Cooper and Parker (2013) reported on data assessing whether a first-year orientation course taught by academic advisors influenced Family and Consumer Sciences students' perceptions of preparedness for success in college and their major. The study was conducted in the School of Family and Consumer Sciences in the College of Agriculture and Life Sciences at a major southwestern university. Students 
enrolled in the school were required to take the orientation course which was developed by academic advisors in consultation with faculty. Course topics included career opportunities, communication skills, registration for courses and using campus wide computer systems, problem-solving, critical-thinking and campus resources. The study evaluated students' perceptions of preparedness before and after taking the orientation course. A total of 231 students were enrolled in the orientation course and results from the pre-post survey analysis revealed that six out of the seven items included in the survey were significantly different. Students rated greater agreement on post-test knowledge of major, confidence in quality of resume, confidence with professional communication, knowledge about resources on campus, and knowledge of pre-major requirements. The only non-significant item was comfort using university online systems. Students also rated their likeliness to graduate and return the following semester in the same major, none of which were significant.

\section{Academic Advising}

Academic advising has been defined numerous times in the history of America's institutions of higher education. (Coll \& Zalaquett, 2008) It has been referred to as a process where students realize their potential to an educational activity that assists in decision making. The role of the academic advisor is to assist students with individual academic plans that align with their academic interests and to provide accurate information about the curriculum and pathways for completion. Vianden (2016) suggests that academic advisors should act as agents of student relationship management by strengthening the connection between students and their institutions to affect college retention. 
Schwebel, Walburn, Klyce and Jerrolds (2012) conducted a longitudinal study to evaluate the efficacy of advising outreach on student retention, academic performance and frequency of advising contacts. Using a case-control longitudinal research design, students were randomly selected to be in either a group where students were strongly encouraged to attend advising sessions or another group that received university announcements about advising only. All students began in pre-nursing, psychology or undecided. Both groups were followed over 4 years. The study conducted at the University of Alabama at Birmingham (UAB) looked at three outcomes: retention and attrition, academic progress and achievement, and frequency of advising contacts. Although available data indicate advising outreach and proactive advising usually help students, particularly at-risk students, this study showed no significant differences among the two groups in terms of retention and attrition or academic progress and achievement. Young-Jones, Burt, Dixon and Hawthorne (2013) conducted a study to evaluate academic advising in terms of student needs, expectations and success, rather than student satisfaction with their advising experiences. Participants for the study included 611 undergraduate students enrolled in a range of courses from Introductory Psychology to Senior Seminar in Psychology at a Midwestern University. Information was collected using assessment instruments that included a student self-assessment, student expectations of advising and a student demographic information form. The results revealed correlations between student study skills and student self-efficacy with higher GPAs. Meeting with an advisor and advisor accountability contributed to student responsibility and perceived support. The levels to which advisors are available to students to meet and provide assistance are linked to factors demonstrated to predict 
student success. (Young-Jones, et al., 2013). From the findings, another important variable to consider was gender. The results suggested that students who identify as female take more responsibility for their academic success, which aligns with data showing that females graduate at higher rates than males. (National Bureau of Labor Statistics, 2011). Differences were also found in first versus second generation students on levels of student-efficacy. Overall, the study concluded that meeting with an advisor predicts higher levels of responsibility and study skills in first-year students, suggesting that students with these skills are more likely to succeed.

On the contrary, Vianden's (2016) study concentrated on student satisfaction with academic advising. Vianden states, "where no satisfaction exists, little learning or success follows" (p.19). Academic advisors serve as a resource for students seeking information about a plethora of possible things offered on campus. It's important for academic advisors to have a depth and breadth of knowledge about major course requirements, be approachable and have concern for their students' success, and be able to help students set goals. For this study, data from three Midwestern institutions were collected. All three institutions provided a random sample of 1,000 undergraduates where all were invited to participate in the study. Surveys focusing on students' perspectives of critical incidents in the student university relationship served as the method for data collection. An important limitation of this study to consider is that the academic structure at each institution was not considered. Respondents reported academic advisors instilled a sense of belonging if they were perceived as caring or supportive who listened or provided reliable advice. Respondents reported that academic advisors who were unresponsive or provided uninformed or incorrect advice led them to lose faith in the institution, leading to students 
not seeking future help or feeling a lack of respect when incorrect information was shared with them. The findings point to the following conclusions: positive advising experiences enhanced student's satisfaction with academic advising and impacted the way students felt about being part of the institution. Unsatisfactory advising led students to forego seeking future help and doubts about whether they mattered to the institution.

The input-environment-output concept was at the forefront for a study conducted by Kot (2014). Astin's conceptual model conceptualizes the college as comprising three components: student inputs, the college environment, and student outputs. Student inputs consist of individual qualities a student brings to college. The college environment is the students' experience during their college career and student outputs are aspects in which their experience influenced them. The study focused on the impact of centralized advising on first to second year retention rates and hypothesized that students who used centralized advising during their first and second term will have higher term and cumulative GPAs and there would be enrollment difference between students who utilized centralized advising and students who did not. The study used data on 2,745 firsttime full-time freshmen as a large metropolitan public research institution. Results supported the hypotheses that students who utilized centralized advising had higher term and cumulative GPAs compared to their counterparts who did not use advising. Results partially support that there was a difference in enrollment behavior between students who used centralized advising compared to those who did not.

A multi-institutional study by Smith and Allen (2014) examined self-evaluations of advising knowledge and advising attitudes in over 22,000 students from nine institutions. The researchers measured frequency of student contact with faculty and 
professional advisors and asked students if after the advising session, did they know the requirements they must fulfill for their major, understand how things work, know about resources, understand connections between their choices in major and their career, have an educational plan (p.56). All areas measured were significantly higher for students who had met with an advisor than those who had not.

\section{Academic Success Coaching}

According to Barkley (2010), academic coaching refers to a relationship between instructors and students that is proactive, responsive to student learning outcomes, and committed to student success. Not only can a coaching relationship be established between instructor and student, but also peers, graduate students or professional staff who serve as academic success coaches. Capstick, Harrell-Williams, Cockrun and West (2019) states that coaching is a collaborative relationship between an individual serving as an academic coach and a student where both focus on the student's personal and professional goals. Allen and Lester (2012) declare that "the role of a success coach is to encourage students to be self-motivated, responsible and self-managed" (p.10). Assigning students to coaches may help with early identification of students who are struggling and provide ways to help them at the appropriate time. Academic coaches can help students with self-regulated learning like time management and academic, study and social skills at the college level. According to Robinson and Gahagan (2010), academic coaching focuses on three main steps which are self-assessment, reflection and goal setting. Students can identify their interests, motivations and resources by following these steps.

Coaching began as an athletic concept and has evolved into a type of relationship in academia. Therefore, academic coaching can be defined as using a coaching style 
relationship to enhance student learning. There are even companies that provide coaching to students for profit. One such program that WVU has used and currently uses is alcohol.edu. The premise for these companies is that some students don't have the necessary skills for adjusting to college life (Barkley, 2010). Similarly, academic coaching for college instructors starts with the same assumption and retention rates could be improved through intervention and changes in teaching style. Interestingly, Barkley's premise for adapting his own teaching style came after researching how different generations of students learn and he states that coaching Generation Y students is a tool that helps students become more engaged. Barkley (2010) states that:

The main idea of academic coaching is for the instructor to switch from a dispassionate, disinterested lecturer to an engaged, interested academic coach who is enthusiastic, proactive, and intentional about student success. The most important characteristic of academic coaching is to seek and develop a relationship with students. The more teachers learn and know about their students, the better they are able to meet their educational and academic needs (p. 11). A study conducted by Capstick et al. (2019) over the course of five semesters at one institution determined the effectiveness of a program called Academic Coaching for Excellence (ACE) for at-risk students. The program was implemented as an academic support program for undergraduate students who resided on-campus with a GPA below 2.0. Students were required to meet bi-weekly with their designated success coach for 4560 minutes. The university were the study was conducted is located in an area with a high poverty level and high percentage of minority residents. The results revealed that full and part-time students who participated in the program had significant increases in GPA and 
were more likely to earn at least a 2.0 GPA during the intervention semester and were more likely to be retained at the university the following semester than students who did not participate in the program.

Allen and Lester (2012) conducted a study to determine the impact of a support course and success coaching program at a two-year institution. A pre-post survey was created to determine if students enrolled in the success course and met with their success coach had developed deeper connections and had more knowledge about their academic program compared to students who did not enroll in the success course or have a success coach. Students replied to eight statements on the survey that ranged from questions like: I know the name of my chair of my program" to "I feel connected to my program." The results revealed that improvements were seen in each of the eight statements.

Docherty, Gullan and Philips (2018) state that the presence of a mentor or coach is correlated with positive outcomes for students. Coaching relationships are often associated with increased academic achievement and helping with the transition to college. For their study, 254 participants at a small satellite campus of a public 4-year school in the Northeast were asked to identify an employee at the university who they saw as their coach or mentor. Participants complete the Mentor Relationship Assessment (MRA), which is an internally reliable 24-item measure through exploratory factor analysis. The MRA consisted of questions like how a student feels challenged by the mentor, how connected a student feels to the mentor, how committed the mentee and mentor are to the relationship and how the mentor encourages student engagement in extracurricular activities. Results showed that these four factors are in line with previous theory and qualitative research on characteristics of effective mentoring. The importance 
of this study is that a single theory-driven quantitative measure of a mentor/mentee relationship has yet to be identified, however, an assessment like the MRA may be able to help strengthen the mentor/mentee relationship.

\section{Resources for Career Exploration}

Hansen and Pedersen (2012) state that "the importance of addressing the career development needs of students early in their college experience is receiving increased attention for a wide range of reasons" (p. 33). Even with the transition to a global economy and technological advances, along with the pressures students feel to declare a major, students still lack an understanding of how to navigate their career aspirations in a practical plan. Hansen and Pedersen (2012) insist that "in developing effective interventions designed to improve career decision making, it is essential to ensure that students are able to integrate and apply what they have learned" (p. 36). By participating in interventions that assist with the career decision process, students may apply what they have learned when engaging in career-decision tasks. For Hansen and Pedersen's study, the effects of career development courses on career decision-making self-efficacy (CDMSE), college adjustment, learning integration, academic achievement, and retention among undecided undergraduates were investigated. Several other factors were explored in this study including the impact of career course format on students' CDMSE and academic success outcomes and the effects of CDMSE on college student adjustment, learning integration, retention, and academic achievement. A pretest-posttest design and comparison group were used in this study. The study took place at a four-year, large, urban, public, commuter university in the Midwest. The intervention was a semesterlong, two-credit career development course offered during the 2055-2008 fall semesters. 
First-Year students who were undecided voluntarily enrolled in the course. Two hundred and thirty-six students were included in the study. Five subscales, self-appraisal, goal selection, planning, occupational information, and problem solving were part of the CDMSE short form. The results revealed that students who completed the career course showed significant increases in CDMSE for all domains, college adjustment and learning integration. The course had the most influence on the domains of gathering occupational information. The results also revealed that students enrolled in the career development course had significantly higher levels of academic achievement and retention rates compared to undecided students who did not participate in the course.

A study conducted by Peterson, Wardwell, Will and Campana (2014) focused on a career preparation seminar with an embedded service-learning internship for undergraduate psychology students. The purpose was to determine if undergraduate psychology students were able to articulate the knowledge, skills and abilities (KSAs) needed for their major and career path in the field of psychology. The course was designed for students to engage in class discussions, talk with guest speakers, building a resume, writing occupational summaries, keeping a journal and completing a twenty-hour service learning internship. The study took place at a mid-sized private liberal arts university in a metropolitan area. The course enrolls 15 students per semester and because the undergraduate college is a woman's college, all the participants were female. The students' journals were collected after grades were submitted and were de-identified. The journals were analyzed to gain a better understanding of the impact of the course and if students had a better understanding of the KSAs. Results revealed that students gained a wide range of knowledge about diverse groups of people, developed skills in 
communication, specifically giving clear directions, rephrasing information, talking with others and listening. An ability students gained was acting quickly and flexibly.

Freeman, Lenz and Reardon (2017) studied the impact of a career course intervention on students' career decision and affective states. Freeman, et al. (2017) state that "college is a time of exploration and maturation for many students, and one of their first tasks is determining their educational and career goals" (p. 1). They go on to say that "learning how to effectively make career decisions and develop appropriate goals are important like skills for all student” (p. 2) and that when students enroll in a career course, they vary in their career decision state status, which is defined as one's level of certainty about a career. For this particular study, a sample of 108 students from five undergraduate career course sections in a large public university were given five extra credit points for participating. The participants' career decision state was assessed by the occupational alternatives questionnaire $(\mathrm{OAQ})$ and the satisfaction with choice question. Questions in the OAQ included list all of the occupations you are considering right now and which occupation is your first choice. The satisfaction with choice question includes a single item, how well satisfied are you with your first choice. The course was comprised of three units across a 16-week semester. Unit I consisted of participants learning about career theories and explored self-knowledge. Unit II focused on how social conditions can impact career development. Unit III focused on how to implement a strategic career plan, developing a job search strategy, writing resume and cover letters, preparing for interviews, negotiating job offers and starting a new job. Results indicated a career course can positively influence students' ability to navigate the career decisionmaking process. Participants reported a higher level of satisfaction with their choice upon 
completion of the course and their career affective state was positively impacted by the course. The course helped participants become more focused and motivated in their career plans.

Johnson, Schamuhn, Nelson and Buboltz (2014) based their study on attachment theory and state that healthy psychosocial development is associated with secure parental attachment which means that children feel safe enough to explore their environment while knowing their parental figures are accessible. Johnson, et al. (2014) state that research on the attachment and separation process in relation to young adult career development has produced mixed results and report that "young adults who are attached to their parents and are able to separate with low levels of emotional reactivity may exhibit successful career development" (p. 71). This study focuses on the family systems theory concept of differentiation of self. This concept refers to a person's ability to function in an autonomous manner and still staying connected to significant relationships. Young adults often make career decisions while in the midst of the differentiation process. Therefore, the purpose of this study was to assess the effects of differentiation levels on the career development of young adults. Two hundred and thirty-one college students participated in the study and completed the differentiation of self inventory (DSI) instrument which consisted of four subscales. The subscales were emotional reactivity, I position, emotional cutoff and fusion with others. The study suggests a link between differentiation of self and young adult career development. The study reveals the higher levels of differentiation predict higher levels of vocational identity and higher levels on all four subscales. 
Tirpak and Schlosser (2013) evaluated FOCUS-2 effectiveness in enhancing students' career development. Traditionally, career services at college usually encompass career counseling and career workshops. Because current students are increasingly using the internet and computer as tools for career decision-making, the researchers wanted to evaluate the FOUCS-2, a major and career assessment tools also utilized at WVU, on social cognitive career variables. The study consisted of 420 participants in their first year at a small, 4-year, private, Catholic university in the Northeast. The assessment of attributions for career decision making (AACDM) and the Career Decision Self-Efficacy (CDSE) were used to measure participants' attributed style toward making career decisions and measure self-efficacy expectations for completing tasks in order to make good career decisions. Participants were given a pretest survey, FOCUS-2, and the posttest survey. Results of the study reveal that utilizing FOCUS-2 as a career intervention tool was associated with statistically significant gains in CDSE but not for

\section{AACDM.}

\section{Summary}

Research shows that there are many support initiatives utilized by several institutions to help students be successful and matriculate and ultimately graduate from an institution. There is no one size fits all strategy; depending on a student's background, abilities, motivation, needs and drive can determine what resources should be offered and how those resources are structured and provided. Some studies were shown to be successful, however success was defined for that institution, while others were not. 


\section{CHAPTER III}

\section{Methodology}

The West Virginia University Mountaineer Success Academy was established in 2012 to support students who were either undecided about their major or were not directly admitted into their desired major. The goal of the program was to support undecided students by building a live learn community where students could feel a sense of belonging at West Virginia University and provide academic support by offering smaller class sizes ( 25 students or less) in sections of courses that were part of the General Education Curriculum, designated academic advisors, and student success coaching, as well as a class devoted to helping students choose a major through exploration opportunities. The purpose of this study was to examine the West Virginia University Mountaineer Success Academy participants' graduation rates and academic

performance (GPA) upon graduation and compare the results to eligible non-participants and non-eligible students at West Virginia University. This chapter will outline the methodology utilized for this research study.

\section{Research Questions}

The following research questions were formulated to guide this study:

1. What were the demographic characteristics of WVU Mountaineer Success Academy participants, WVU Mountaineer Success Academy participants who participated in MSA Links, WVU Mountaineer Success Academy participants who did not participate in MSA Links, eligible non-participants and noneligible students entering West Virginia University in the fall semesters 2012, 2013, 2014 and 2015? 
2. What were the within 8 semester (within 4 year) graduation rates of the West Virginia University Mountaineer Success Academy participants compared to those of eligible non-participants and non-eligible students entering West Virginia University in the fall semesters 2012, 2013, 2014 and 2015?

3. What were the more than 8 semester (more than 4 year) graduation rates of the West Virginia Mountaineer Success Academy participants compared to those of eligible non-participants and non-eligible students entering West Virginia University in the fall semesters 2012, 2013 and 2014?

4. What was the academic performance (GPA) upon graduation of the West Virginia University Mountaineer Success Academy participants compared to that of eligible non-participants and non-eligible students entering West Virginia University in the fall semesters of 2012, 2013, 2014, and 2015 ?

5. What were the graduation rates of students who participated in the West Virginia University Mountaineer Success Academy compared to students who participated in the Mountaineer Success Academy, but not MSA Links for fall semesters 2014 and 2015?

6. What was the academic performance (GPA) of students who participated in the Mountaineer Success Academy compared to students who participated in the Mountaineer Success Academy, but not MSA Links for fall semesters 2014 and $2015 ?$

7. What attributes contributed to the successful completion of college degrees for participants of the West Virginia University Mountaineer Success Academy? 


\section{Hypothesis Statements}

\section{Null hypothesis}

Seven null hypotheses were identified for this study:

1. There was no significant difference among the within 8 semester (within 4 year) graduation rates for students who participated in the Mountaineer Success Academy and the within 8 semester (within 4 year) graduation rates for eligible non-participants or non-eligible students.

2. There was no significant difference among the more than 8 semester (more than 4 year) graduation rates for students who participated in the Mountaineer Success Academy and the more than 8 semester (more than 4 year) graduation rates for eligible non-participants or non-eligible students for the 2012, 2013 and 2014 cohorts.

3. There was no significant difference among academic performance (GPA) upon graduation for students who participated in the Mountaineer Success Academy and eligible non-participants and non-eligible students.

4. Among students who participated in the Mountaineer Success Academy, there was no significant difference in graduation rates for those students who participated in MSA Links and graduation rates for students who participated in the Mountaineer Success Academy, but not MSA Links for fall semesters 2014 and 2015.

5. Among students who participated in the Mountaineer Success Academy, there was no significant difference in academic performance (GPA) for those students who participated in MSA Links and academic performance (GPA) for students 
who participated in the Mountaineer Success Academy, but not MSA Links for fall semesters 2014 and 2015.

6. The identified variables: ethnicity, gender, high school GPA, state residency, and SAT/ACT scores were not able to discriminate between participants of the Mountaineer Success Academy who graduated within 8 semesters (within 4 years) and participants of the Mountaineer Success Academy who did not graduate within 8 semesters (within 4 years).

7. The identified variables: ethnicity, gender, high school GPA, state residency, and SAT/ACT scores were not able to discriminate between participants of the Mountaineer Success Academy who graduated in more than 8 semesters (more than 4 years) and participants of the Mountaineer Success Academy who did not graduate in more than 8 semesters (more than 4 years) for the 2012, 2013 and 2014 cohorts.

\section{Alternate Hypothesis}

Based on the seven identified null hypotheses the following alternative hypotheses statements were identified to reflect the initial predictions of this research study:

1. There was a significant difference among the within 8 semester (within 4 year) graduation rates for students who participated in the Mountaineer Success Academy and eligible non-participants and non-eligible students.

2. There was a significant difference among the more than 8 semester (more than 4 year) graduation rates for students who participated in the Mountaineer Success 
Academy and eligible non-participants and non-eligible students for the 2012, 2013 and 2014 cohorts.

3. There was a significant difference among academic performance (GPA) upon graduation for students who participated in the Mountaineer Success Academy and eligible non-participants and non-eligible students.

4. Among students who participated in the Mountaineer Success Academy, there was a significant difference in graduation rates for those students who participated in MSA Links and graduation rates for students who participated in the Mountaineer Success Academy, but not MSA Links for fall semesters 2014 and 2015.

5. Among students who participated in the Mountaineer Success Academy, there was a significant difference in academic performance (GPA) for those students who participated in MSA Links and academic performance (GPA) for students who participated in the Mountaineer Success Academy, but not MSA Links for fall 2014 and 2015.

6. The identified variables: ethnicity, gender, high school GPA, state residency, and SAT/ACT scores were able to discriminate between participants of the Mountaineer Success Academy who graduated in within 8 semesters (within 4 years) and participants of the Mountaineer Success Academy who did not graduate in within 8 semesters (within 4 years).

7. The identified variables: ethnicity, gender, high school GPA, state residency, and SAT/ACT scores were able to discriminate between participants of the Mountaineer Success Academy who graduated in more than 8 semester (more 
than 4 years) and participants of the Mountaineer Success Academy who did not graduate in more than 8 semesters (more than 4 years) for the 2012, 2013 and 2014 cohorts.

\section{Research Design}

This study was designed to examine the West Virginia University Mountaineer Success Academy participants' graduation rates and academic performance (GPA) upon graduation in comparison to randomly selected control groups of eligible non-participants and non-eligible students at West Virginia University. This study utilized a casualcomparative retroactive ex post facto analysis. According to Gay, Mills, and Airasian (2012) in casual-comparative research the researcher attempts to determine the cause, or reason, for existing differences in the behavior or status of groups or individuals. "The basic causal-comparative design involves selecting two groups that differ on some variable of interest and comparing them on some dependent variable" (p. 227). Ary, Jacobs, and Sorensen (2012) state that

the technique, ex post facto research, is conducted after a variation in the variable of interest has already been determined in the natural course of events. Its purpose is to investigate cause and effect relationships between independent and dependent variables and is used in situations that do not permit the randomization and manipulation of variables characteristic of experimental research. (p. 332) According to Ary, Jacobs, and Sorenson (2012), “ex post facto research does not provide safeguards that are necessary for making strong inferences about causal relationships. Mistakenly attributing causation based on a relationship between two variables is called the post hoc fallacy" (p. 333). If a researcher wants to reach a 
conclusion that one variable (x) is the cause of another variable (y), then a statistical relationship between $\mathrm{x}$ and $\mathrm{y}$ must be established (a change in one variable can be predicted from a change in the other), $\mathrm{x}$ precedes $\mathrm{y}$ in time (times series) and other factors did not determine y. Another important thing to note about ex post facto designs for research is that of spurious relationships, which is where two variables really have no effect on each other but are related because other variables influence both.

There may be several threats to internal and external validity when using ex post facto designs for research because, according to Ary, Jacobs and Sorensen, "ex post facto research lacks control of the independent variable and thus has lower internal validity" ( $p$. 335). Gay, Mills, and Airasian (2012) define internal validity as "the degree to which observed differences on the dependent variable are a direct result of manipulation of the independent variable, not some other variable" (p.627). According to Ary, Jacobs and Sorenson (2012), differential (subject) selections pose a major threat to internal validity of ex post facto research because a researcher has no control over the selection of subjects into the two groups. Whenever an assignment is not random, there is always an opening for other variables to enter to explain the observed difference between groups. So how can researchers account for this threat? Researchers can collect data to show that the groups are similar on other extraneous variables that might affect the variable of interest. This is important because ex post facto research lacks control of the independent variable(s) and therefore has lower internal validity. If researchers cannot control (x) they may be led to inappropriate conclusions. When interpreting ex post facto research, one should consider alternative explanations, like common cause, reverse causality, and the presence of other independent variables. 
Reverse causality reverses the hypothesis. If the hypothesis is $\mathrm{X}$ causes $\mathrm{Y}$, reverse causality suggests that perhaps $\mathrm{Y}$ causes $\mathrm{X}$. To decrease the threat to validity, a method of establishing the time order of variables is to obtain measurements of the same subjects at different times (Ary, Jacobs \& Sorenson, 2012). In a situation where $\mathrm{X}$ always precedes $\mathrm{Y}$ in time, the very nature of the data rules out the possibility of reverse causality. The hypothesis of common cause is harder to manage than reverse causality because numerous common causes in each case could produce a spurious relationship (two variables really have no effect on each other but are related because other variables influence both). To help combat a decrease in validity in regard to other possible independent variables, a researcher should attempt to list all the possible alternative independent variables. By holding the others constant, you can test in turn each variable to determine if it is related to $\mathrm{Y}$. A researcher can eliminate the alternative independent variables by showing that they are not related to $Y$, one can gain support for the original hypothesis of a relationship between $\mathrm{X}$ and $\mathrm{Y}$.

Strategies for improving credibility provide partial control of internal validity problems of common cause and other possible independent variables. One of those strategies is matching, where a researcher can match subjects in experimental and control groups on as many extraneous variables as possible (Ary, Jacobs, \& Sorenson, 2012). This may, however, greatly reduce the number of subjects that can be used in the final analysis. Matching provides partial control because even if a researcher can match some variable, other unmatched variables may affect the dependent variable. Another issue with matching is the role of regression, which can be a bigger problem than loss of subjects because when two matched groups are drawn from different populations, 
regression toward the original population means will be expected to create spurious results, whenever the two populations are not equal. Matching pairs from within a single population is often a useful strategy.

Homogeneous groups reduce external validity by controlling a variable by including in the sample only subjects who are homogeneous on that variable. Using homogeneous groups restricts the generalizability of findings only to the specific homogeneous group, thus reduces external validity.

\section{Population}

The target population for this study was all first-time, full-time students at West Virginia University entering the fall semesters of 2012, 2013, 2014 and 2015. The Mountaineer Success Academy emerged as a new retention program under the Associate Provost's Office for Undergraduate Education in 2012. A director, two program coordinators, a resident faculty leader and residence hall coordinator and several graduate assistants were hired to build and lead the program. After a change in leadership in 2015, the Mountaineer Success Academy was discontinued so resources could be reallocated to a different population of students.

The Mountaineer Success Academy had a total of 538 first-time, full-time students entering in the years $2012(\mathrm{n}=60), 2013(\mathrm{n}=236), 2014(\mathrm{n}=128), 2015(\mathrm{n}=$ 114). Students who were considered eligible for the program were first-time, full-time students at WVU who were undecided on a major or were not accepted into their desired major. High school GPA and ACT/SAT scores were also a factor in determining if students were eligible for the program. Students who were considered eligible nonparticipants were students who automatically enrolled in the program because they were 
undecided and opted out of the program. Non-eligible students were all other first-time, full-time students at WVU.

Because the researcher has access to the entire population for this study, it has been determined that the researcher will work with the Office of Institutional Research to pull the data for the population of this study instead of determining an appropriate sample size. The data will be kept on one file.

Table 1

Enrollment of Mountaineer Success Academy participants, Eligible Non-Participants, and Non-Eligible Student Groups for the 2012, 2013, 2014, and 2015 Cohorts.

\begin{tabular}{|c|c|c|c|c|c|}
\hline & 2012 & 2013 & 2014 & 2015 & Tota \\
\hline MSA & & & & & \\
\hline Participants & 60 & 236 & 128 & 114 & 538 \\
\hline $\begin{array}{l}\text { Eligible Non- } \\
\text { Participants }\end{array}$ & 216 & 143 & 107 & 127 & 593 \\
\hline $\begin{array}{l}\text { Non-Eligible } \\
\text { Students }\end{array}$ & 5269 & 4766 & 4738 & 2835 & 17608 \\
\hline
\end{tabular}

\section{Instrumentation}

The instrument used to collect data was developed by the researcher. The boundaries for data collection included:

- The population was identified as first-time, full-time students entering West Virginia University during the fall semesters of 2012, 2013, 2014, and 2015.

- The population was divided into students participating in MSA, students eligible for MSA but who elected not to participate and students ineligible for MSA. 
- For the secondary analysis, the MSA group was further divided into students who participated in MSA Links, and students who did not participate in the early move in component of MSA for fall semesters 2014 and 2015.

- The demographic variables were identified as age, ethnicity, gender, high school GPA, state residency, and SAT/ACT scores.

- Data were analyzed to determine which students graduated within 8 semesters or 4 years. Due to the timing of when this study occurred, only 8 semester (4 year) graduation rates were available for the 2014 and 2015 cohorts.

- Data were analyzed to determine which students graduated within 12 semesters or 6 years. Due to the timing of when this study occurred, 8 semester (4 year) and 12 semester (6 year) graduation rates were available for the 2012 and 2013 cohorts. The variables ethnicity, gender, high school GPA and SAT/ACT scores, state residency, and first-generation student were selected for this study. The state residency was a specific area of interest to the research and was therefore included in the study.

\section{Date Collection Procedures}

The researcher identified the groups to be included in the study as West Virginia University Mountaineer Success Academy participants, Mountaineer Success Academy MSA Links participants, eligible non-participant, and non-eligible students who were first-time, fulltime students entering West Virginia University during the fall semester of 2012, 2013, 2014, and 2015. The researcher collaborated with the WVU Office of Institutional Research to access and collect the data via official records. The WVU Office of Institutional Research was able to pull the official records by identifying students who had an MSA code number of "20." The researcher worked with the Associate Vice 
President for Planning \& Treasury Operations at the West Virginia University

Institutional Research Office. Institutional Research was able to pull official numbers of students who participated in the Mountaineer Success Academy by compiling a list of rosters for the First-Year Seminar class MSA participants were required to take. All other students with a code " 20 " on their record were reported as eligible non-participants. Students with no code " 20 " on their records were not invited to join the program and were therefore reported as non-eligible students. GPA for MSA participants who did not graduate was not reported. The Institutional Research office worked with the WVU Housing office to pull data for MSA participants who moved in early to participate in the MSA Links program. Data were available for the 2014 and 2015 cohorts only.

The Institutional Research office also provided the researcher with the conversion table that converts SAT scores to ACT scores. This table can be found in Appendix B. It is important to note that prior research has been conducted for this group and is housed in the Institutional Research office. An unpublished manuscript titled "West Virginia University Mountaineer Success Academy (MSA) Program Report Executive Summary" dated April 8, 2016 reported on first to second year retention rates for MSA participants. The numbers calculated for this unpublished document are different from the official numbers reported for this study. The researcher elected to use only the official data supplied by the Office of Institutional Research for this research study.

The researcher contacted the Office of Institutional Research prior to data collection to develop the best approach for data collection. Upon identifying the variables to be pulled, it was determined to include the entire population for this study and the process to proceed with data collection was reviewed with the researcher. The data 
request submitted to the Office of Institutional Research can be found in Appendix C. Data were collected for each of the fall, spring, summer I, summer II semesters during the 2012-2013, 2013-2014, 2014-2015, 2015-2016 academic years. Once data were collected, they were placed on a file by the Office of Institutional Research staff and provided to the researcher.

\section{Data Analysis}

The study examined the West Virginia University Mountaineer Success Academy participants' graduation rate and academic performance (GPA) upon graduation. This study also examined the relationship of the data to randomly chosen control groups of eligible non-participants and non-eligible students at West Virginia University.

The data collected by the Office Institutional Research using the identified boundaries were analyzed by the researcher using the Statistical Package for Social Sciences (SPSS). SPSS was most appropriate to use given the research questions and hypotheses.

Descriptive statistics were used to report the profile and demographics of participants using the variables, age, ethnicity, gender, high school GPA, state residency, first-generation student, and ACT/SAT scores. Chi square was used to analyze the difference in graduation rates among the groups. F test was used to account for homogeneous groups. Analysis of covariance was used to partially adjust for pre-existing differences between groups in an ex post facto design. ANCOVA adjusts scores on the dependent variable for any initial differences on the extraneous variable. A .05 alpha level of significance was used for all data analysis. 
Inferential statistics such as chi-square and ANCOVA are limited to research where samples of populations have been utilized. While a census of the population was used for years 2012, 2013, 2014, and 2015, the researcher assumed that these groups were samples of WVU student populations for past and present cohorts. Since the data were samples of other populations, the use of inferential statistics was in order (Ritter \& Sue, 2007).

The findings from the data collection and analysis of this research are presented in Chapter IV. Data are presented in both written and table format. 


\section{CHAPTER IV}

\section{Findings}

The purpose of this study was to examine the West Virginia University Mountaineer Success Academy (MSA) participants' graduation rates and academic performance (GPA) upon graduation in comparison to eligible non-participants and noneligible students at West Virginia University entering the fall semesters of 2012, 2013, 2014 and 2015.

The first cohort entered in 2012 and were projected to graduate in 2016 . The second cohort entered in 2013 and were projected to graduate in 2017. The third cohort entered in 2014 and were projected to graduate in 2018 and the last cohort entered in 2015 and were projected to graduate in 2019. For consistency, hereafter, the cohorts will be referred to as either the 2012, 2013, 2014 or 2015 cohort. This chapter presents the findings from the data collection and analysis following the procedures outlined in Chapter III.

\section{Hypothesis Statements}

\section{Null hypothesis}

Seven null hypotheses were identified for this study:

1. There was no significant difference among the within 8 semester (within 4 year) graduation rates for students who participated in the Mountaineer Success Academy and the within 8 semester (within 4 year) graduation rates for eligible non-participants or non-eligible students.

2. There was no significant difference among the more than 8 semester (more than 4 year) graduation rates for students who participated in the Mountaineer Success 
Academy and the more than 8 semester (more than 4 year) graduation rates for eligible non-participants or non-eligible students for the 2012, 2013 and 2014 cohorts.

3. There was no significant difference among academic performance (GPA) upon graduation for students who participated in the Mountaineer Success Academy and eligible non-participants and non-eligible students.

4. Among students who participated in the Mountaineer Success Academy, there was no significant difference in graduation rates for those students who participated in MSA Links and graduation rates for students who participated in the Mountaineer Success Academy, but not MSA Links for fall semesters 2014 and 2015.

5. Among students who participated in the Mountaineer Success Academy, there was no significant difference in academic performance (GPA) for those students who participated in MSA Links and academic performance (GPA) for students who participated in the Mountaineer Success Academy, but not MSA Links for fall semesters 2014 and 2015.

6. The identified variables: ethnicity, gender, high school GPA, state residency, and SAT/ACT scores were not able to discriminate between participants of the Mountaineer Success Academy who graduated within 8 semesters (within 4 years) and participants of the Mountaineer Success Academy who did not graduate within 8 semesters (within 4 years).

7. The identified variables: ethnicity, gender, high school GPA, state residency, and SAT/ACT scores were not able to discriminate between participants of the 
Mountaineer Success Academy who graduated in more than 8 semesters (more than 4 years) and participants of the Mountaineer Success Academy who did not graduate in more than 8 semesters (more than 4 years) for the 2012, 2013 and 2014 cohorts.

\section{Alternate Hypothesis}

Based on the seven identified null hypotheses the following alternative hypotheses statements were identified to reflect the initial predictions of this research study:

1. There was a significant difference among the within 8 semester (within 4 year) graduation rates for students who participated in the Mountaineer Success Academy and eligible non-participants and non-eligible students.

2. There was a significant difference among the more than 8 semester (more than 4 year) graduation rates for students who participated in the Mountaineer Success Academy and eligible non-participants and non-eligible students for the 2012, 2013 and 2014 cohorts.

3. There was a significant difference among academic performance (GPA) upon graduation for students who participated in the Mountaineer Success Academy and eligible non-participants and non-eligible students.

4. Among students who participated in the Mountaineer Success Academy, there was a significant difference in graduation rates for those students who participated in MSA Links and graduation rates for students who participated in the Mountaineer Success Academy, but not MSA Links for fall semesters 2014 and 2015. 
5. Among students who participated in the Mountaineer Success Academy, there was a significant difference in academic performance (GPA) for those students who participated in MSA Links and academic performance (GPA) for students who participated in the Mountaineer Success Academy, but not MSA Links for fall 2014 and 2015.

6. The identified variables: ethnicity, gender, high school GPA, state residency, and SAT/ACT scores were able to discriminate between participants of the Mountaineer Success Academy who graduated in within 8 semesters (within 4 years) and participants of the Mountaineer Success Academy who did not graduate in within 8 semesters (within 4 years).

7. The identified variables: ethnicity, gender, high school GPA, state residency, and SAT/ACT scores were able to discriminate between participants of the Mountaineer Success Academy who graduated in more than 8 semester (more than 4 years) and participants of the Mountaineer Success Academy who did not graduate in more than 8 semesters (more than 4 years) for the 2012, 2013 and 2014 cohorts.

\section{Research questions}

The following research questions were formulated to guide this study:

1. What were the demographic characteristics of WVU Mountaineer Success Academy participants, WVU Mountaineer Success Academy participants who participated in MSA Links, WVU Mountaineer Success Academy participants who did not participate in MSA Links, eligible non-participants and non-eligible 
students entering West Virginia University in the fall semesters 2012, 2013, 2014 and $2015 ?$

2. What were the within 8 semester (within 4 year) graduation rates of the West Virginia University Mountaineer Success Academy participants compared to those of eligible non-participants and non-eligible students entering West Virginia University in the fall semesters 2012, 2013, 2014 and 2015?

3. What were the more than 8 semester (more than 4 year) graduation rates of the West Virginia Mountaineer Success Academy participants compared to those of eligible non-participants and non-eligible students entering West Virginia University in the fall semesters 2012, 2013 and 2014?

4. What was the academic performance (GPA) upon graduation of the West Virginia University Mountaineer Success Academy participants compared to that of eligible non-participants and non-eligible students entering West Virginia University in the fall semesters of 2012, 2013, 2014, and 2015?

5. What were the graduation rates of students who participated in the West Virginia University Mountaineer Success Academy compared to students who participated in the Mountaineer Success Academy, but not MSA Links for fall semesters 2014 and $2015 ?$

6. What was the academic performance (GPA) of students who participated in the Mountaineer Success Academy compared to students who participated in the Mountaineer Success Academy, but not MSA Links for fall semesters 2014 and $2015 ?$ 
7. What attributes contributed to the successful completion of college degrees for participants of the West Virginia University Mountaineer Success Academy?

\section{Target Population}

The target population for this study was all first-time full-time freshmen entering West Virginia University during the fall semesters of 2012, 2013, 2014 and 2015. Findings reported for each group by cohort as 1) ethnicity percentage, 2) gender percentage, 3) mean high school GPA, 4) percentage resident/non-resident, 5) mean ACT scores, 6) graduation rates, and 7) performance (GPA) upon graduation.

For the 2012 cohort, there were 60 MSA participants, 216 eligible nonparticipants and 5,269 non-eligible students. There were 236 MSA participants, 143 eligible non-participants and 4,766 non-eligible students in the 2013 cohort. For the 2014 cohort, there were 128 MSA participants, 107 eligible non-participants and 4738 noneligible students. There were 114 MSA participants, 127 eligible non-participants and 2,835 non-eligible students in the 2015 cohort (see Table 2). 
Table 2

Number of Participants in the Mountaineer Success Academy, Eligible Non-Participants and Non-Eligible Students for the 2012, 2013, 2014 and 2015 Cohorts

\begin{tabular}{lrrrrrc}
\hline & \multicolumn{9}{c}{ Participation } \\
\cline { 2 - 7 } Cohort & \multicolumn{2}{c}{ Yes } & \multicolumn{2}{c}{ No } & \multicolumn{2}{c}{ Not Eligible } \\
\cline { 2 - 7 } 2012 & $\mathrm{~N}$ & $\%$ & $\mathrm{~N}$ & $\%$ & $\mathrm{~N}$ & $\%$ \\
2013 & 60 & 11.15 & 216 & 36.42 & 5269 & 29.92 \\
2014 & 236 & 43.87 & 143 & 24.11 & 4766 & 27.07 \\
2015 & 128 & 23.79 & 107 & 18.04 & 4738 & 26.91 \\
\hline
\end{tabular}

For the 2014 and 2015 cohorts, 198 Mountaineer Success Academy Participants also participated in MSA Links while 340 Mountaineer Success Academy Participants did not participate in MSA Links. Data were not available for the 2012 and 2013 cohorts (see Table 3). 
Table 3

Number of Mountaineer Success Academy Participants who participated in MSA Links for the 2014 and 2015 Cohorts

\begin{tabular}{|c|c|c|c|c|c|c|c|c|}
\hline & \multicolumn{8}{|c|}{ MSA Participation } \\
\hline & \multicolumn{2}{|c|}{ Yes } & \multicolumn{2}{|c|}{ No } & \multicolumn{2}{|c|}{ Not Eligible } & \multicolumn{2}{|c|}{ Total } \\
\hline & $\mathrm{N}$ & $\%$ & $\mathrm{~N}$ & $\%$ & $\mathrm{~N}$ & $\%$ & $\mathrm{~N}$ & $\%$ \\
\hline Yes & 198 & 36.80 & 5 & .84 & 0 & .00 & 203 & 1.08 \\
\hline No & 340 & 63.20 & 588 & 99.16 & 0 & .00 & 928 & 4.95 \\
\hline Not Eligible & 0 & .00 & 0 & .00 & 17608 & 100.00 & 17608 & 93.96 \\
\hline Total & 538 & 100.00 & 593 & 100.00 & 17608 & 100.00 & 18739 & 100.00 \\
\hline
\end{tabular}

\section{Participants' Profile}

Research Question \#1: What were the demographic characteristics of WVU Mountaineer Success Academy participants, WVU Mountaineer Success Academy participants who participated in MSA Links, WVU Mountaineer Success Academy participants who did not participate in MSA Links, eligible non-participants and non-eligible students entering West Virginia University in the fall semesters 2012, 2013, 2014 and $2015 ?$

\section{Ethnicity}

Combining all four cohorts, the Mountaineer Success Academy had more minority students participate in the program than eligible non-participants. African Americans constituted $4.6 \%$ of MSA participants while $6.4 \%$ of eligible nonparticipants were African American. There were 4.4\% African Americans among the non-eligible students. MSA participants who identified as two or more races were $2.8 \%$ 
while $4.4 \%$ of eligible non-participants identified as two or more races. There were $3.9 \%$ of non-eligible students who identified as two or more races. There were $6.9 \%$ of MSA participants who identified as Hispanic while $3.4 \%$ of eligible non-participants identified as Hispanic. Hispanics constituted $3.7 \%$ of non-eligible students. Of the MSA participants $83.4 \%$ identified as White while $84 \%$ of eligible non-participants were White. The non-eligible student group was composed of $84.0 \%$ White (see Table 4). Ethnicity of Mountaineer Success Academy participants who participated in MSA Links was also captured. Data were not available for the 2012 and 2013 cohorts. For the 2014 cohort, 86\% of MSA participants who participated in MSA Links were White. Of those that participated in MSA Links, $1.0 \%$ identified as Asian, 3.0\% identified as African American, 8.0\% identified as Hispanic and 3.0\% identified as two or more races. In the 2015 cohort, $87.6 \%$ of MSA Links participants identified as White while 1.0\% identified as Asian, 3.0\% identified as African American, 5.2\% identified as Hispanic, $1 \%$ identified as Native Hawaiian/Pacific Islander, $1.0 \%$ identified as two or more races and 1.0\% marked unknown (see Table 5). 
Table 4

Ethnicity of Mountaineer Success Academy Participants, Eligible Non-Participants and Non-Eligible Students for the 2012, 2013, 2014 and 2015 Cohorts

\begin{tabular}{|c|c|c|c|c|c|c|c|c|}
\hline & \multicolumn{8}{|c|}{ Participation } \\
\hline & \multicolumn{2}{|c|}{ Yes } & \multicolumn{2}{|c|}{ No } & \multicolumn{2}{|c|}{ Not Eligible } & \multicolumn{2}{|c|}{ Total } \\
\hline & $\mathrm{N}$ & $\%$ & $\mathrm{~N}$ & $\%$ & $\mathrm{~N}$ & $\%$ & $\mathrm{~N}$ & $\%$ \\
\hline American Indian or Alaskan & & & & & & & & \\
\hline Native & 2 & .37 & 1 & .17 & 17 & .10 & 20 & .11 \\
\hline Asian & 6 & 1.12 & 6 & 1.01 & 454 & 2.58 & 466 & 2.49 \\
\hline Black - Not of Hispanic Origin & 25 & 4.65 & 38 & 6.41 & 775 & 4.40 & 838 & 4.47 \\
\hline Hispanic & 37 & 6.88 & 20 & 3.37 & 653 & 3.71 & 710 & 3.79 \\
\hline $\begin{array}{l}\text { Native Hawaiian or Pacific } \\
\text { Islander }\end{array}$ & 1 & .19 & 1 & .17 & 18 & .10 & 20 & .11 \\
\hline Two or More Races & 15 & 2.79 & 26 & 4.38 & 697 & 3.96 & 738 & 3.94 \\
\hline Unknown & 3 & .56 & 3 & .51 & 144 & .82 & 150 & .80 \\
\hline White - Not of Hispanic Origin & 449 & 83.46 & 498 & 83.98 & 14850 & 84.34 & 15797 & 84.30 \\
\hline Total & 538 & 100.00 & 593 & 100.00 & 17608 & 100.00 & 18739 & 100.00 \\
\hline
\end{tabular}


Table 5

Ethnicity of Mountaineer Success Academy Participants who participated in MSA Links

\begin{tabular}{|c|c|c|c|c|c|c|c|}
\hline & & \multicolumn{6}{|c|}{ Links } \\
\hline & & \multicolumn{2}{|c|}{ Yes } & \multicolumn{2}{|c|}{ No } & \multicolumn{2}{|c|}{ Not Eligible } \\
\hline & & $\mathrm{N}$ & $\%$ & $\mathrm{~N}$ & $\%$ & $\mathrm{~N}$ & $\%$ \\
\hline \multirow[t]{8}{*}{2012} & $\begin{array}{l}\text { American Indian or } \\
\text { Alaskan Native }\end{array}$ & 0 & .00 & 0 & .00 & 0 & .00 \\
\hline & Asian & 0 & .00 & 1 & 1.67 & 0 & .00 \\
\hline & $\begin{array}{l}\text { Black - Not of Hispanic } \\
\text { Origin }\end{array}$ & 0 & .00 & 1 & 1.67 & 0 & .00 \\
\hline & Hispanic & 0 & .00 & 4 & 6.67 & 0 & .00 \\
\hline & $\begin{array}{l}\text { Native Hawaiian or Pacific } \\
\text { Islander }\end{array}$ & 0 & .00 & 0 & .00 & 0 & .00 \\
\hline & Two or More Races & 0 & .00 & 1 & 1.67 & 0 & .00 \\
\hline & Unknown & 0 & .00 & 0 & .00 & 0 & .00 \\
\hline & $\begin{array}{l}\text { White - Not of Hispanic } \\
\text { Origin }\end{array}$ & 0 & .00 & 53 & 88.33 & 0 & .00 \\
\hline
\end{tabular}


Table 5 (continued)

Ethnicity of Mountaineer Success Academy Participants who participated in MSA Links

\begin{tabular}{|c|c|c|c|c|c|c|c|}
\hline & & \multicolumn{6}{|c|}{ Links } \\
\hline & & \multicolumn{2}{|c|}{ Yes } & \multicolumn{2}{|c|}{ No } & \multicolumn{2}{|c|}{ Not Eligible } \\
\hline & & $\mathrm{N}$ & $\%$ & $\mathrm{~N}$ & $\%$ & $\mathrm{~N}$ & $\%$ \\
\hline \multirow[t]{8}{*}{2013} & $\begin{array}{l}\text { American Indian or } \\
\text { Alaskan Native }\end{array}$ & 0 & .00 & 2 & .85 & 0 & .00 \\
\hline & Asian & 0 & .00 & 3 & 1.28 & 0 & .00 \\
\hline & $\begin{array}{l}\text { Black - Not of Hispanic } \\
\text { Origin }\end{array}$ & 0 & .00 & 15 & 6.38 & 0 & .00 \\
\hline & Hispanic & 0 & .00 & 16 & 6.81 & 0 & .00 \\
\hline & $\begin{array}{l}\text { Native Hawaiian or Pacific } \\
\text { Islander }\end{array}$ & 0 & .00 & 0 & .00 & 0 & .00 \\
\hline & Two or More Races & 0 & .00 & 9 & 3.83 & 0 & .00 \\
\hline & Unknown & 0 & .00 & 2 & .85 & 0 & .00 \\
\hline & $\begin{array}{l}\text { White - Not of Hispanic } \\
\text { Origin }\end{array}$ & 1 & 100.00 & 188 & 80.00 & 0 & .00 \\
\hline
\end{tabular}


Table 5 (continued)

Ethnicity of Mountaineer Success Academy Participants who participated in MSA Links

\begin{tabular}{|c|c|c|c|c|c|c|c|}
\hline & & \multicolumn{6}{|c|}{ Links } \\
\hline & & \multicolumn{2}{|c|}{ Yes } & \multicolumn{2}{|c|}{ No } & \multicolumn{2}{|c|}{ Not Eligible } \\
\hline & & $\mathrm{N}$ & $\%$ & $\mathrm{~N}$ & $\%$ & $\mathrm{~N}$ & $\%$ \\
\hline \multirow[t]{8}{*}{2014} & $\begin{array}{l}\text { American Indian or } \\
\text { Alaskan Native }\end{array}$ & 0 & .00 & 0 & .00 & 0 & .00 \\
\hline & Asian & 1 & 1.00 & 0 & .00 & 0 & .00 \\
\hline & $\begin{array}{l}\text { Black - Not of Hispanic } \\
\text { Origin }\end{array}$ & 2 & 2.00 & 3 & 10.71 & 0 & .00 \\
\hline & Hispanic & 8 & 8.00 & 1 & 3.57 & 0 & .00 \\
\hline & $\begin{array}{l}\text { Native Hawaiian or Pacific } \\
\text { Islander }\end{array}$ & 0 & .00 & 0 & .00 & 0 & .00 \\
\hline & Two or More Races & 3 & 3.00 & 0 & .00 & 0 & .00 \\
\hline & Unknown & 0 & .00 & 0 & .00 & 0 & .00 \\
\hline & $\begin{array}{l}\text { White - Not of Hispanic } \\
\text { Origin }\end{array}$ & 86 & 86.00 & 24 & 85.71 & 0 & .00 \\
\hline
\end{tabular}


Table 5 (continued)

Ethnicity of Mountaineer Success Academy Participants who participated in MSA Links

\begin{tabular}{|c|c|c|c|c|c|c|c|}
\hline & & \multicolumn{6}{|c|}{ Links } \\
\hline & & \multicolumn{2}{|c|}{ Yes } & \multicolumn{2}{|c|}{ No } & \multicolumn{2}{|c|}{ Not Eligible } \\
\hline & & $\mathrm{N}$ & $\%$ & $\mathrm{~N}$ & $\%$ & $\mathrm{~N}$ & $\%$ \\
\hline \multirow[t]{8}{*}{2015} & $\begin{array}{l}\text { American Indian or } \\
\text { Alaskan Native }\end{array}$ & 0 & .00 & 0 & .00 & 0 & .00 \\
\hline & Asian & 1 & 1.03 & 0 & .00 & 0 & .00 \\
\hline & $\begin{array}{l}\text { Black - Not of Hispanic } \\
\text { Origin }\end{array}$ & 3 & 3.09 & 1 & 5.88 & 0 & .00 \\
\hline & Hispanic & 5 & 5.15 & 3 & 17.65 & 0 & .00 \\
\hline & $\begin{array}{l}\text { Native Hawaiian or Pacific } \\
\text { Islander }\end{array}$ & 1 & 1.03 & 0 & .00 & 0 & .00 \\
\hline & Two or More Races & 1 & 1.03 & 1 & 5.88 & 0 & .00 \\
\hline & Unknown & 1 & 1.03 & 0 & .00 & 0 & .00 \\
\hline & $\begin{array}{l}\text { White - Not of Hispanic } \\
\text { Origin }\end{array}$ & 85 & 87.63 & 12 & 70.59 & 0 & .00 \\
\hline
\end{tabular}




\section{Gender}

The Mountaineer Success Academy had the largest percentage of males enrolled for the 2012 cohort while the 2013 cohort was roughly the same percentage of males and females. The 2014 and 2015 cohorts enrolled more females than males, respectively. In the 2012 cohort $60.0 \%$ of MSA participants were males while $40.0 \%$ were females. Likewise, $51.9 \%$ of non-participants were males while $48.2 \%$ were females. In the non-eligible group, $53.4 \%$ were males and $46.6 \%$ were females.

In the 2013 cohort, $49.6 \%$ of MSA participants were male while $50.4 \%$ were female. Of non-participants $49.0 \%$ were males while $51.0 \%$ were female. Of the noneligible students $52.7 \%$ of were male while $47.3 \%$ were female for the 2013 cohort.

Of the MSA participants for the 2014 cohort, $54.0 \%$ were female and $46.0 \%$ were male. Of the eligible non-participants, $42.0 \%$ were female and $58.0 \%$ were male. Of the non-eligible students, $51.0 \%$ were female and $49.0 \%$ were male.

Of the MSA participants for the 2015 cohort, $66.0 \%$ were female and $34.0 \%$ were male. Of the eligible non-participants, $53.0 \%$ were female and $46.0 \%$ were male. Of the non-eligible students, $51.0 \%$ were female and $49.0 \%$ were male (see Table 6 ). 
Table 6

Gender of Mountaineer Success Academy Participants, Eligible Non-Participants, and Non-Eligible Students for Cohorts 2012, 2013,

2014 and 2015

\begin{tabular}{|c|c|c|c|c|c|c|c|c|c|}
\hline & & \multicolumn{8}{|c|}{ Participation } \\
\hline & & \multicolumn{2}{|c|}{ Yes } & \multicolumn{2}{|c|}{ No } & \multicolumn{2}{|c|}{ Not Eligible } & \multicolumn{2}{|c|}{ Total } \\
\hline & & $\mathrm{N}$ & $\%$ & $\mathrm{~N}$ & $\%$ & $\mathrm{~N}$ & $\%$ & $\mathrm{~N}$ & $\%$ \\
\hline \multirow[t]{3}{*}{2012} & Female & 24 & 40.00 & 104 & 48.15 & 2457 & 46.63 & 2585 & 46.62 \\
\hline & Male & 36 & 60.00 & 112 & 51.85 & 2812 & 53.37 & 2960 & 53.38 \\
\hline & Total & 60 & 100.00 & 216 & 100.00 & 5269 & 100.00 & 5545 & 100.00 \\
\hline \multirow[t]{3}{*}{2013} & Female & 119 & 50.42 & 73 & 51.05 & 2254 & 47.29 & 2446 & 47.54 \\
\hline & Male & 117 & 49.58 & 70 & 48.95 & 2512 & 52.71 & 2699 & 52.46 \\
\hline & Total & 236 & 100.00 & 143 & 100.00 & 4766 & 100.00 & 5145 & 100.00 \\
\hline \multirow[t]{3}{*}{2014} & Female & 69 & 53.91 & 45 & 42.06 & 2171 & 45.82 & 2285 & 45.95 \\
\hline & Male & 59 & 46.09 & 62 & 57.94 & 2567 & 54.18 & 2688 & 54.05 \\
\hline & Total & 128 & 100.00 & 107 & 100.00 & 4738 & 100.00 & 4973 & 100.00 \\
\hline \multirow[t]{3}{*}{2015} & Female & 75 & 65.79 & 68 & 53.54 & 1438 & 50.72 & 1581 & 51.40 \\
\hline & Male & 39 & 34.21 & 59 & 46.46 & 1397 & 49.28 & 1495 & 48.60 \\
\hline & Total & 114 & 100.00 & 127 & 100.00 & 2835 & 100.00 & 3076 & 100.00 \\
\hline
\end{tabular}


Gender was captured for participants in MSA Links. Data were not available for the 2012 and 2013 cohorts. For the 2014 cohort, 57.0\% of MSA Links participants identified as female while $43.0 \%$ were male. For the 2015 cohort $66.0 \%$ of MSA Links participants identified as female while $34.0 \%$ were male (see Table 7).

Table 7

Gender of Mountaineer Success Academy Participants who participated in MSA Links

\begin{tabular}{|c|c|c|c|c|c|c|c|}
\hline & & \multicolumn{6}{|c|}{ Links } \\
\hline & & \multicolumn{2}{|c|}{ Yes } & \multicolumn{2}{|c|}{ No } & \multicolumn{2}{|c|}{ Not Eligible } \\
\hline & & $\mathrm{N}$ & $\%$ & $\mathrm{~N}$ & $\%$ & $\mathrm{~N}$ & $\%$ \\
\hline \multirow[t]{2}{*}{2012} & Female & 0 & .00 & 24 & 40.00 & 0 & .00 \\
\hline & Male & 0 & .00 & 36 & 60.00 & 0 & .00 \\
\hline \multirow[t]{2}{*}{2013} & Female & 1 & 100.00 & 118 & 50.21 & 0 & .00 \\
\hline & Male & 0 & .00 & 117 & 49.79 & 0 & .00 \\
\hline \multirow[t]{2}{*}{2014} & Female & 57 & 57.00 & 12 & 42.86 & 0 & .00 \\
\hline & Male & 43 & 43.00 & 16 & 57.14 & 0 & .00 \\
\hline \multirow[t]{2}{*}{2015} & Female & 64 & 65.98 & 11 & 64.71 & 0 & .00 \\
\hline & Male & 33 & 34.02 & 6 & 35.29 & 0 & .00 \\
\hline
\end{tabular}




\section{High School GPA}

High School GPA was categorized by students who graduated in 4 years, more than 4 years and did not graduate. Non-eligible students had an overall higher average GPA than MSA participants and eligible non-participants. The average GPA for noneligible students who graduated in 4 years was 3.71 while non-eligible students who graduated in more than 4 years had an average GPA of 3.42. Non-eligible students who did not graduate had an average 3.28 GPA.

The average GPA for MSA participants who graduated in more than 4 years was 3.19 while the average GPA for MSA participants who graduated in 4 years was 3.26. MSA participants who did not graduate had an average GPA of 3.09.

The average GPA for eligible non-participants who graduated in more than 4 years was 3.08 while the average GPA for eligible non-participants who graduated in 4 years was 3.26. Eligible non-participants who did not graduate had an average GPA of 3.08. Results are shown in Table 8 . 
Table 8

Mean High School GPA of Mountaineer Success Academy Participants, Eligible Non-Participants and Non-Eligible Students for the 2012, 2013, 2014 and 2015 Cohorts

\begin{tabular}{|c|c|c|c|c|c|c|c|c|}
\hline & \multicolumn{8}{|c|}{ Participation } \\
\hline & \multicolumn{2}{|c|}{ Yes } & \multicolumn{2}{|c|}{ No } & \multicolumn{2}{|c|}{ Not Eligible } & \multicolumn{2}{|c|}{ Total } \\
\hline & M & SD & M & SD & M & SD & M & SD \\
\hline More than Four Years & 3.19 & .40 & 3.08 & .34 & 3.42 & .51 & 3.40 & .50 \\
\hline Graduated Four Years & 3.26 & .37 & 3.26 & .39 & 3.71 & 3.65 & 3.70 & 3.58 \\
\hline Did not Graduate & 3.09 & .40 & 3.08 & .42 & 3.28 & .52 & 3.27 & .52 \\
\hline
\end{tabular}


Mountaineer Success Academy participants who participated in MSA Links had an average high school GPA of 3.17 for the 2014 cohort. Participants of the 2015 cohort had an average high school GPA of 3.23. The average GPA of MSA participants who did not participant in MSA 3.20 for the 2014 cohort and 3.22 for the 2015 cohort (see Table 9).

Table 9

High School GPA of Mountaineer Success Academy participants who participated in MSA Links

\begin{tabular}{lccccc}
\hline & \multicolumn{5}{c}{ Links } \\
\cline { 2 - 5 } & \multicolumn{3}{c}{ Yes } & \multicolumn{3}{c}{ No } \\
\cline { 2 - 5 } & $\mathrm{M}$ & $\mathrm{SD}$ & 3.00 & SD \\
\hline 2012 &. &. & 3.13 & .44 \\
2013 & 2.58 &. & 3.20 & .39 \\
2014 & 3.17 & .38 & .37 \\
2015 & 3.23 & .40 & 3.22 & .45 \\
\hline
\end{tabular}

\section{ACT/SAT Scores}

The majority of students entering West Virginia University completed the ACT exam. For student who completed the SAT, a conversion formula was used to convert SAT scores into ACT scores for students. The conversion table can be found in Appendix B. Except for the 2012 cohort, MSA participants had lower or similar ACT/SAT scores compared to eligible non-participants. Non- eligible participants had a higher ACT/SAT scores for all four cohorts. 
The 2012 cohort of MSA participants had an average ACT/SAT score of 20.48 while the eligible non-participants had an average ACT/SAT score of 19.80. The noneligible students had an average ACT/SAT score of 23.24.

The 2013 cohort of MSA participants had an average ACT/SAT score of 19.61 while the eligible non-participants had an average ACT/SAT score of 20.02. The noneligible students had an average ACT/SAT score of 23.51.

The 2014 cohort of MSA participants had an average ACT/SAT score of 21.33 while the eligible non-participants had an average ACT/SAT score of 21.30. The noneligible students had an average ACT/SAT score of 23.50.

The 2015 cohort of MSA participants had an average ACT/SAT score of 20.27 while the eligible non-participants had an average ACT/SAT score of 20.56 and the noneligible students had an average ACT/SAT score of 24.19 (see Table 10).

Table 10

ACT scores of Mountaineer Success Academy Participants, Eligible Non-Participants, and Non-Eligible Students for the 2012, 2013, 2014 and 2015 Cohorts

\begin{tabular}{lcccccc}
\hline & \multicolumn{5}{c}{ Participation } \\
\cline { 2 - 7 } & \multicolumn{2}{c}{ MSA } & \multicolumn{2}{c}{ MSA Eligible } & \multicolumn{2}{c}{ Not Eligible } \\
\cline { 2 - 7 } & M & SD & M & SD & M & SD \\
\hline 2012 & 20.48 & 3.08 & 19.80 & 2.56 & 23.24 & 3.84 \\
2013 & 19.61 & 2.25 & 20.02 & 2.55 & 23.51 & 3.80 \\
2014 & 21.32 & 2.89 & 21.30 & 2.86 & 23.50 & 4.00 \\
2015 & 20.27 & 2.78 & 20.56 & 2.75 & 24.19 & 3.95 \\
\hline
\end{tabular}


ACT/SAT scores for Mountaineer Success Academy participants who participated in MSA Links were available for the 2014 and 2015 cohorts. One student graduated early who participated in MSA Links and the ACT/SAT score was captured under the 2014 cohort. The average ACT/SAT score for the 2014 cohort of MSA participants who participated in MSA Links and graduated was 21.48 while the average ACT/SAT score for non-participants was 20.79. The average ACT/SAT score for the 2015 cohort of MSA participants who participated in MSA Links and graduated was 20.22 while the average ACT/SAT score for non-participants was 20.50 . Results can be found in Table 11.

Table 11

ACT/SAT Scores of Mountaineer Success Academy Participants Who Participated in MSA Links

\begin{tabular}{lcccc}
\hline & \multicolumn{5}{c}{ Links } \\
\cline { 2 - 5 } & \multicolumn{2}{c}{ Yes } & M & SD \\
\cline { 2 - 5 } & M & SD & 20.48 & 3.08 \\
2012 & $\cdot$ & $\cdot$ & 19.60 & 2.25 \\
2013 & 21.00 &. & 20.79 & 3.24 \\
2014 & 21.48 & 2.78 & 20.50 & 2.80 \\
2015 & 20.22 & 2.79 & & \\
\hline
\end{tabular}

\section{In-State/Out-of-State Residency}

For all four cohorts, there were more out-of-state participants than in-state participants. For the 2012 and 2013 cohorts, there were more in-state eligible nonparticipants than out-of-state eligible non-participants. Of the 2012 MSA participants 
$80.0 \%$ were out-of-state students while $20.0 \%$ were in-state students. Of the eligible nonparticipants $49.1 \%$ were out-of-state students while $50.9 \%$ were in-state students for the 2012 cohort. Non-eligible students were split evenly where $50.2 \%$ of students were outof-state and $49.7 \%$ of students were in-state for the 2012 cohort.

For the 2013 cohort, $63.1 \%$ of MSA participants were out-of-state students while $36.9 \%$ were in-state students. For the eligible non-participants $47.2 \%$ were out-of-state students while $52.7 \%$ were in-state students. Of the 2013 non-eligible students $47.2 \%$ were out-of-state students and $52.7 \%$ were residents.

For the 2014 cohort, $58.6 \%$ of MSA participants were out-of-state students while $41.4 \%$ were in-state students. Of the eligible non-participants $67.3 \%$ were out-of-state students while $32.7 \%$ were in-state students. Of the non-eligible students $47.9 \%$ were out-of-state and $52.1 \%$ were in-state for the 2014 cohort.

For the 2015 cohort, $76.3 \%$ of MSA participants were out-of-state students while $23.7 \%$ were in-state students. For the eligible non-participants $62.2 \%$ were out-of-state students and $37.8 \%$ were in-state. Of the non-eligible students $51.9 \%$ were out-of-state while $47.7 \%$ were in-state students. Results are shown in Table 12. 
Table 12

Residency of Mountaineer Success Academy Participants, Eligible Non-Participants and Non-Eligible Students for the 2012, 2013, 2014 and 2015 Cohorts

\begin{tabular}{|c|c|c|c|c|c|c|c|c|c|}
\hline & & \multicolumn{8}{|c|}{ Participation } \\
\hline & & \multicolumn{2}{|c|}{ Yes } & \multicolumn{2}{|c|}{ No } & \multicolumn{2}{|c|}{ Not Eligible } & \multicolumn{2}{|c|}{ Total } \\
\hline & & $\mathrm{N}$ & $\%$ & $\mathrm{~N}$ & $\%$ & $\mathrm{~N}$ & $\%$ & $\mathrm{~N}$ & $\%$ \\
\hline \multirow[t]{5}{*}{2012} & Non-Resident & 48 & 80.00 & 106 & 49.07 & 2644 & 50.18 & 2798 & 50.46 \\
\hline & Resident & 12 & 20.00 & 110 & 50.93 & 2619 & 49.71 & 2741 & 49.43 \\
\hline & Metro & 0 & .00 & 0 & .00 & 6 & .11 & 6 & .11 \\
\hline & Undeclared & 0 & .00 & 0 & .00 & 0 & .00 & 0 & .00 \\
\hline & Total & 60 & 100.00 & 216 & 100.00 & 5269 & 100.00 & 5545 & 100.00 \\
\hline \multirow[t]{5}{*}{2013} & Non-Resident & 149 & 63.14 & 68 & 47.55 & 2248 & 47.17 & 2465 & 47.91 \\
\hline & Resident & 87 & 36.86 & 75 & 52.45 & 2513 & 52.73 & 2675 & 51.99 \\
\hline & Metro & 0 & .00 & 0 & .00 & 4 & .08 & 4 & .08 \\
\hline & Undeclared & 0 & .00 & 0 & .00 & 1 & .02 & 1 & .02 \\
\hline & Total & 236 & 100.00 & 143 & 100.00 & 4766 & 100.00 & 5145 & 100.00 \\
\hline
\end{tabular}


Table 12 (continued)

Residency of Mountaineer Success Academy Participants, Eligible Non-Participants and Non-Eligible Students for the 2012, 2013, 2014 and 2015 Cohorts

\begin{tabular}{|c|c|c|c|c|c|c|c|c|c|}
\hline & & \multicolumn{8}{|c|}{ Participation } \\
\hline & & \multicolumn{2}{|c|}{ Yes } & \multicolumn{2}{|c|}{ No } & \multicolumn{2}{|c|}{ Not Eligible } & \multicolumn{2}{|c|}{ Total } \\
\hline & & $\mathrm{N}$ & $\%$ & $\mathrm{~N}$ & $\%$ & $\mathrm{~N}$ & $\%$ & $\mathrm{~N}$ & $\%$ \\
\hline \multirow[t]{5}{*}{2014} & Non-Resident & 75 & 58.59 & 72 & 67.29 & 2269 & 47.89 & 2416 & 48.58 \\
\hline & Resident & 53 & 41.41 & 35 & 32.71 & 2467 & 52.07 & 2555 & 51.38 \\
\hline & Metro & 0 & .00 & 0 & .00 & 2 & .04 & 2 & .04 \\
\hline & Undeclared & 0 & .00 & 0 & .00 & 0 & .00 & 0 & .00 \\
\hline & Total & 128 & 100.00 & 107 & 100.00 & 4738 & 100.00 & 4973 & 100.00 \\
\hline \multirow[t]{5}{*}{2015} & Non-Resident & 87 & 76.32 & 79 & 62.20 & 1472 & 51.92 & 1638 & 53.25 \\
\hline & Resident & 27 & 23.68 & 48 & 37.80 & 1353 & 47.72 & 1428 & 46.42 \\
\hline & Metro & 0 & .00 & 0 & .00 & 0 & .00 & 0 & .00 \\
\hline & Undeclared & 0 & .00 & 0 & .00 & 10 & .35 & 10 & .33 \\
\hline & Total & 114 & 100.00 & 127 & 100.00 & 2835 & 100.00 & 3076 & 100.00 \\
\hline
\end{tabular}


Data for the 2012 and 2013 cohorts were not available when examining the instate and out-of-state Mountaineer Success Academy participants who participated in MSA Links. For the 2014 cohort, $65.0 \%$ of MSA participants who participated in MSA Links were out-of-state students while $35.7 \%$ of out-of-state MSA participants did not participate in MSA Links. Of MSA participants who participated in MSA Links 35.0\% were in-state students while $64.3 \%$ of in-state MSA participants did not participate in MSA Links.

For the 2015 cohort, $79.4 \%$ of out-of-state MSA participants participated in MSA Links while $58.8 \%$ of out-of-state MSA participants did not participate in MSA Links. Of in-state MSA participants $20.6 \%$ participated in MSA Links while $41.2 \%$ of in-state MSA participants did not participate in MSA Links. Residency of MSA participants who participated in MSA Links can be found in Table 13. 
Table 13

Residency of Mountaineer Success Academy Participants Who Participated in MSA Links

\begin{tabular}{|c|c|c|c|c|c|c|c|}
\hline & & \multicolumn{6}{|c|}{ Links } \\
\hline & & \multicolumn{2}{|c|}{ Yes } & \multicolumn{2}{|c|}{ No } & \multicolumn{2}{|c|}{ Not Eligible } \\
\hline & & $\mathrm{N}$ & $\%$ & $\mathrm{~N}$ & $\%$ & $\mathrm{~N}$ & $\%$ \\
\hline \multirow[t]{4}{*}{2012} & Non-Resident & 0 & .00 & 48 & 80.00 & 0 & .00 \\
\hline & Resident & 0 & .00 & 12 & 20.00 & 0 & .00 \\
\hline & Metro & 0 & .00 & 0 & .00 & 0 & .00 \\
\hline & Undeclared & 0 & .00 & 0 & .00 & 0 & .00 \\
\hline \multirow[t]{4}{*}{2013} & Non-Resident & 1 & 100.00 & 148 & 62.98 & 0 & .00 \\
\hline & Resident & 0 & .00 & 87 & 37.02 & 0 & .00 \\
\hline & Metro & 0 & .00 & 0 & .00 & 0 & .00 \\
\hline & Undeclared & 0 & .00 & 0 & .00 & 0 & .00 \\
\hline
\end{tabular}


Table 13 (continued)

Residency of Mountaineer Success Academy Participants Who Participated in MSA Links

\begin{tabular}{|c|c|c|c|c|c|c|c|}
\hline & & \multicolumn{6}{|c|}{ Links } \\
\hline & & \multicolumn{2}{|c|}{ Yes } & \multicolumn{2}{|c|}{ No } & \multicolumn{2}{|c|}{ Not Eligible } \\
\hline & & $\mathrm{N}$ & $\%$ & $\mathrm{~N}$ & $\%$ & $\mathrm{~N}$ & $\%$ \\
\hline \multirow[t]{4}{*}{2014} & Non-Resident & 65 & 65.00 & 10 & 35.71 & 0 & .00 \\
\hline & Resident & 35 & 35.00 & 18 & 64.29 & 0 & .00 \\
\hline & Metro & 0 & .00 & 0 & .00 & 0 & .00 \\
\hline & Undeclared & 0 & .00 & 0 & .00 & 0 & .00 \\
\hline \multirow[t]{4}{*}{2015} & Non-Resident & 77 & 79.38 & 10 & 58.82 & 0 & .00 \\
\hline & Resident & 20 & 20.62 & 7 & 41.18 & 0 & .00 \\
\hline & Metro & 0 & .00 & 0 & .00 & 0 & .00 \\
\hline & Undeclared & 0 & .00 & 0 & .00 & 0 & .00 \\
\hline
\end{tabular}


Residency by state was calculated for this study. More students who were residents of West Virginia opted out of the Mountaineer Success Academy than participated. States to highlight for MSA participants are Connecticut at 1.7\%, Delaware at $2.2 \%$, Maryland at 9.3\%, Massachusetts at $1.0 \%$, New Jersey at $10.8 \%$, New York at $6.3 \%$, Ohio at $2.8 \%$ Pennsylvania at $20.5 \%$, Virginia at $8.9 \%$ and West Virginia at $33.5 \%$. Eligible non-participants were mostly represented by Florida at 1.0\%, Maryland at $7.5 \%$, Massachusetts at $2.2 \%$, New Jersey at $8.3 \%$, New York at $5.3 \%$, Ohio at $2.4 \%$, Pennsylvania at $14.2 \%$, Texas at $1.5 \%$, Virginia at $7.0 \%$, and West Virginia at $45.4 \%$. For non-eligible students, the states that were most represented were Connecticut at $0.9 \%$, Delaware at $0.9 \%$, Maryland at $9.4 \%$, New Jersey at $5.9 \%$, New York at $3.8 \%$, Ohio at 4.7\%, Pennsylvania at $14.2 \%$, Virginia at $8.0 \%$ and West Virginia at $46.2 \%$ (see Table 14).

Table 14

Residency by State of Mountaineer Success Academy Participants, Eligible NonParticipants and Non-Eligible Students for the 2012, 2013, 2014 and 2015 Cohorts

\begin{tabular}{lccccccccc}
\hline & \multicolumn{7}{c}{ Participation } \\
\cline { 2 - 9 } & \multicolumn{2}{c}{ Yes } & \multicolumn{2}{c}{ No } & \multicolumn{2}{c}{ Not Eligible } & \multicolumn{2}{c}{ Total } \\
\cline { 2 - 9 } & & $\mathrm{N}$ & $\%$ & $\mathrm{~N}$ & $\%$ & $\mathrm{~N}$ & $\%$ & $\mathrm{~N}$ & $\%$ \\
\hline $\mathrm{AL}$ & 0 & .00 & 0 & .00 & 6 & .03 & 6 & .03 \\
$\mathrm{AK}$ & 0 & .00 & 0 & .00 & 3 & .02 & 3 & .02 \\
$\mathrm{AZ}$ & 0 & .00 & 0 & .00 & 7 & .04 & 7 & .04 \\
$\mathrm{AR}$ & 0 & .00 & 0 & .00 & 3 & .02 & 3 & .02 \\
$\mathrm{CA}$ & 3 & .56 & 1 & .17 & 75 & .44 & 79 & .43 \\
\hline
\end{tabular}


Table 14 (continued)

Residency by State of Mountaineer Success Academy Participants, Eligible Non-

Participants and Non-Eligible Students for the 2012, 2013, 2014 and 2015 Cohorts

\begin{tabular}{|c|c|c|c|c|c|c|c|c|}
\hline & \multicolumn{8}{|c|}{ Participation } \\
\hline & \multicolumn{2}{|c|}{ Yes } & \multicolumn{2}{|c|}{ No } & \multicolumn{2}{|c|}{ Not Eligible } & \multicolumn{2}{|c|}{ Total } \\
\hline & $\mathrm{N}$ & $\%$ & $\mathrm{~N}$ & $\%$ & $\mathrm{~N}$ & $\%$ & $\mathrm{~N}$ & $\%$ \\
\hline $\mathrm{CO}$ & 0 & .00 & 1 & .17 & 23 & .13 & 24 & .13 \\
\hline $\mathrm{CT}$ & 9 & 1.67 & 5 & .85 & 161 & .94 & 175 & .96 \\
\hline $\mathrm{DE}$ & 12 & 2.23 & 5 & .85 & 158 & .92 & 175 & .96 \\
\hline FL & 3 & .56 & 6 & 1.02 & 107 & .62 & 116 & .63 \\
\hline GA & 0 & .00 & 3 & .51 & 48 & .28 & 51 & .28 \\
\hline HI & 0 & .00 & 0 & .00 & 1 & .01 & 1 & .01 \\
\hline ID & 0 & .00 & 0 & .00 & 3 & .02 & 3 & .02 \\
\hline IL & 2 & .37 & 4 & .68 & 67 & .39 & 73 & .40 \\
\hline $\mathrm{IN}$ & 0 & .00 & 0 & .00 & 20 & .12 & 20 & .11 \\
\hline IA & 0 & .00 & 0 & .00 & 4 & .02 & 4 & .02 \\
\hline $\mathrm{KS}$ & 0 & .00 & 1 & .17 & 5 & .03 & 6 & .03 \\
\hline KY & 0 & .00 & 0 & .00 & 26 & .15 & 26 & .14 \\
\hline LA & 0 & .00 & 0 & .00 & 2 & .01 & 2 & .01 \\
\hline $\mathrm{ME}$ & 0 & .00 & 0 & .00 & 14 & .08 & 14 & .08 \\
\hline MD & 50 & 9.29 & 44 & 7.46 & 1617 & 9.42 & 1711 & 9.36 \\
\hline MA & 6 & 1.12 & 13 & 2.20 & 129 & .75 & 148 & .81 \\
\hline MI & 0 & .00 & 0 & .00 & 35 & .20 & 35 & .19 \\
\hline $\mathrm{MN}$ & 1 & .19 & 0 & .00 & 13 & .08 & 14 & .08 \\
\hline
\end{tabular}


Table 14 (continued)

Residency by State of Mountaineer Success Academy Participants, Eligible Non-

Participants and Non-Eligible Students for the 2012, 2013, 2014 and 2015 Cohorts

\begin{tabular}{|c|c|c|c|c|c|c|c|c|}
\hline & \multicolumn{8}{|c|}{ Participation } \\
\hline & \multicolumn{2}{|c|}{ Yes } & \multicolumn{2}{|c|}{ No } & \multicolumn{2}{|c|}{ Not Eligible } & \multicolumn{2}{|c|}{ Total } \\
\hline & $\mathrm{N}$ & $\%$ & $\mathrm{~N}$ & $\%$ & $\mathrm{~N}$ & $\%$ & $\mathrm{~N}$ & $\%$ \\
\hline MS & 0 & .00 & 0 & .00 & 1 & .01 & 1 & .01 \\
\hline MO & 1 & .19 & 1 & .17 & 8 & .05 & 10 & .05 \\
\hline MT & 0 & .00 & 0 & .00 & 2 & .01 & 2 & .01 \\
\hline $\mathrm{NV}$ & 0 & .00 & 0 & .00 & 3 & .02 & 3 & .02 \\
\hline $\mathrm{NH}$ & 0 & .00 & 4 & .68 & 31 & .18 & 35 & .19 \\
\hline $\mathrm{NJ}$ & 58 & 10.78 & 49 & 8.31 & 1004 & 5.85 & 1111 & 6.08 \\
\hline NM & 0 & .00 & 0 & .00 & 2 & .01 & 2 & .01 \\
\hline NY & 34 & 6.32 & 31 & 5.25 & 654 & 3.81 & 719 & 3.93 \\
\hline $\mathrm{NC}$ & 4 & .74 & 1 & .17 & 103 & .60 & 108 & .59 \\
\hline $\mathrm{OH}$ & 15 & 2.79 & 14 & 2.37 & 811 & 4.73 & 840 & 4.59 \\
\hline $\mathrm{OK}$ & 0 & .00 & 2 & .34 & 4 & .02 & 6 & .03 \\
\hline OR & 0 & .00 & 0 & .00 & 6 & .03 & 6 & .03 \\
\hline PA & 110 & 20.45 & 84 & 14.24 & 2428 & 14.15 & 2622 & 14.34 \\
\hline RI & 0 & .00 & 1 & .17 & 14 & .08 & 15 & .08 \\
\hline $\mathrm{SC}$ & 0 & .00 & 0 & .00 & 32 & .19 & 32 & .17 \\
\hline $\mathrm{TN}$ & 1 & .19 & 0 & .00 & 21 & .12 & 22 & .12 \\
\hline $\mathrm{TX}$ & 1 & .19 & 9 & 1.53 & 102 & .59 & 112 & .61 \\
\hline UT & 0 & .00 & 0 & .00 & 3 & .02 & 3 & .02 \\
\hline
\end{tabular}


Table 14 (continued)

Residency by State of Mountaineer Success Academy Participants, Eligible Non-

Participants and Non-Eligible Students for the 2012, 2013, 2014 and 2015 Cohorts

\begin{tabular}{|c|c|c|c|c|c|c|c|c|}
\hline & \multicolumn{8}{|c|}{ Participation } \\
\hline & \multicolumn{2}{|c|}{ Yes } & \multicolumn{2}{|c|}{ No } & \multicolumn{2}{|c|}{ Not Eligible } & \multicolumn{2}{|c|}{ Total } \\
\hline & $\mathrm{N}$ & $\%$ & $\mathrm{~N}$ & $\%$ & $\mathrm{~N}$ & $\%$ & $\mathrm{~N}$ & $\%$ \\
\hline VT & 0 & .00 & 1 & .17 & 17 & .10 & 18 & .10 \\
\hline VA & 48 & 8.92 & 41 & 6.95 & 1373 & 8.00 & 1462 & 7.99 \\
\hline WA & 0 & .00 & 0 & .00 & 9 & .05 & 9 & .05 \\
\hline WV & 180 & 33.46 & 268 & 45.42 & 7928 & 46.20 & 8376 & 45.80 \\
\hline WI & 0 & .00 & 1 & .17 & 13 & .08 & 14 & .08 \\
\hline WY & 0 & .00 & 0 & .00 & 1 & .01 & 1 & .01 \\
\hline $\mathrm{DC}$ & 0 & .00 & 0 & .00 & 38 & .22 & 38 & .21 \\
\hline GU & 0 & .00 & 0 & .00 & 1 & .01 & 1 & .01 \\
\hline PR & 0 & .00 & 0 & .00 & 1 & .01 & 1 & .01 \\
\hline $\mathrm{AE}$ & 0 & .00 & 0 & .00 & 6 & .03 & 6 & .03 \\
\hline PQ & 0 & .00 & 0 & .00 & 1 & .01 & 1 & .01 \\
\hline AP & 0 & .00 & 0 & .00 & 3 & .02 & 3 & .02 \\
\hline $\mathrm{BC}$ & 0 & .00 & 0 & .00 & 2 & .01 & 2 & .01 \\
\hline $\mathrm{AB}$ & 0 & .00 & 0 & .00 & 1 & .01 & 1 & .01 \\
\hline $\mathrm{ON}$ & 0 & .00 & 0 & .00 & 10 & .06 & 10 & .05 \\
\hline Total & 538 & 100.00 & 590 & 100.00 & 17160 & 100.00 & 18288 & 100.00 \\
\hline
\end{tabular}


Residency by state for Mountaineer Success Academy participants who participated in MSA Links was captured. Data for the 2012 and 2013 cohorts was not available. More students from West Virginia opted out of the MSA Links portion of the program for both the 2014 and 2015 cohorts. For the 2014 cohort, MSA participants who participated in MSA Links were represented by California at $1.0 \%$, Connecticut at 3.0\%, Florida at $1.0 \%$, Maryland at 7.0\%, Massachusetts at 1.0\%, New Jersey at $17.0 \%$, New York at 2.0\%, North Carolina at 2.0\%, Ohio at 4.0\%, Pennsylvania at 16.0\%, Virginia at $11.0 \%$ and West Virginia at $35.0 \%$. Those that did not participate in MSA Links for the 2014 cohort were represented by New Jersey at 7.1\%, New York at 3.6\%, Pennsylvania at $17.9 \%$, Virginia at $7.1 \%$ and West Virginia at $64.3 \%$.

For the 2015 cohort, MSA participants who participated in MSA Links were represented by Connecticut at 2.0\%, Delaware at 3.0\%, Maryland at 9.3\%, Massachusetts at $1.0 \%$, New Jersey at $10.3 \%$, New York at $7.2 \%$, Ohio at $6.2 \%$, Pennsylvania at $28.9 \%$, Virginia at $10.3 \%$ and $\mathrm{WV}$ at $21.7 \%$.

Those that did not participate in MSA Links for the 2015 cohort were represented by Maryland at $11.7 \%$, Minnesota at $5.9 \%$, New York at $23.5 \%$, Virginia at $11.8 \%$ and West Virginia at 47\%. Results are shown in Table 15. 
Table 15

Residency by State of Mountaineer Success Academy Participants Who Participated in MSA Links

\begin{tabular}{|c|c|c|c|c|c|c|c|}
\hline & & \multicolumn{6}{|c|}{ Links } \\
\hline & & \multicolumn{2}{|c|}{ Yes } & \multicolumn{2}{|c|}{ No } & \multicolumn{2}{|c|}{ Not Eligible } \\
\hline & & $\mathrm{N}$ & $\%$ & $\mathrm{~N}$ & $\%$ & $\mathrm{~N}$ & $\%$ \\
\hline \multirow[t]{18}{*}{2012} & $\mathrm{AL}$ & 0 & .00 & 0 & .00 & 0 & .00 \\
\hline & $\mathrm{AK}$ & 0 & .00 & 0 & .00 & 0 & .00 \\
\hline & $\mathrm{AZ}$ & 0 & .00 & 0 & .00 & 0 & .00 \\
\hline & AR & 0 & .00 & 0 & .00 & 0 & .00 \\
\hline & $\mathrm{CA}$ & 0 & .00 & 0 & .00 & 0 & .00 \\
\hline & $\mathrm{CO}$ & 0 & .00 & 0 & .00 & 0 & .00 \\
\hline & $\mathrm{CT}$ & 0 & .00 & 3 & 5.00 & 0 & .00 \\
\hline & $\mathrm{DE}$ & 0 & .00 & 1 & 1.67 & 0 & .00 \\
\hline & $\mathrm{FL}$ & 0 & .00 & 1 & 1.67 & 0 & .00 \\
\hline & GA & 0 & .00 & 0 & .00 & 0 & .00 \\
\hline & $\mathrm{HI}$ & 0 & .00 & 0 & .00 & 0 & .00 \\
\hline & ID & 0 & .00 & 0 & .00 & 0 & .00 \\
\hline & IL & 0 & .00 & 1 & 1.67 & 0 & .00 \\
\hline & $\mathrm{IN}$ & 0 & .00 & 0 & .00 & 0 & .00 \\
\hline & IA & 0 & .00 & 0 & .00 & 0 & .00 \\
\hline & $\mathrm{KS}$ & 0 & .00 & 0 & .00 & 0 & .00 \\
\hline & KY & 0 & .00 & 0 & .00 & 0 & .00 \\
\hline & LA & 0 & .00 & 0 & .00 & 0 & .00 \\
\hline
\end{tabular}


Table 15 (continued)

Residency by State of Mountaineer Success Academy Participants Who Participated in MSA Links

\begin{tabular}{|c|c|c|c|c|c|c|}
\hline & \multicolumn{6}{|c|}{ Links } \\
\hline & \multicolumn{2}{|c|}{ Yes } & \multicolumn{2}{|c|}{ No } & \multicolumn{2}{|c|}{ Not Eligible } \\
\hline & $\mathrm{N}$ & $\%$ & $\mathrm{~N}$ & $\%$ & $\mathrm{~N}$ & $\%$ \\
\hline $\mathrm{ME}$ & 0 & .00 & 0 & .00 & 0 & .00 \\
\hline MD & 0 & .00 & 9 & 15.00 & 0 & .00 \\
\hline MA & 0 & .00 & 0 & .00 & 0 & .00 \\
\hline MI & 0 & .00 & 0 & .00 & 0 & .00 \\
\hline $\mathrm{MN}$ & 0 & .00 & 0 & .00 & 0 & .00 \\
\hline MS & 0 & .00 & 0 & .00 & 0 & .00 \\
\hline MO & 0 & .00 & 0 & .00 & 0 & .00 \\
\hline MT & 0 & .00 & 0 & .00 & 0 & .00 \\
\hline NV & 0 & .00 & 0 & .00 & 0 & .00 \\
\hline $\mathrm{NH}$ & 0 & .00 & 0 & .00 & 0 & .00 \\
\hline NJ & 0 & .00 & 4 & 6.67 & 0 & .00 \\
\hline NM & 0 & .00 & 0 & .00 & 0 & .00 \\
\hline NY & 0 & .00 & 8 & 13.33 & 0 & .00 \\
\hline $\mathrm{NC}$ & 0 & .00 & 0 & .00 & 0 & .00 \\
\hline $\mathrm{OH}$ & 0 & .00 & 1 & 1.67 & 0 & .00 \\
\hline OK & 0 & .00 & 0 & .00 & 0 & .00 \\
\hline OR & 0 & .00 & 0 & .00 & 0 & .00 \\
\hline PA & 0 & .00 & 12 & 20.00 & 0 & .00 \\
\hline
\end{tabular}


Table 15 (continued)

Residency by State of Mountaineer Success Academy Participants Who Participated in MSA Links

\begin{tabular}{|c|c|c|c|c|c|c|}
\hline & \multicolumn{6}{|c|}{ Links } \\
\hline & \multicolumn{2}{|c|}{ Yes } & \multicolumn{2}{|c|}{ No } & \multicolumn{2}{|c|}{ Not Eligible } \\
\hline & $\mathrm{N}$ & $\%$ & $\mathrm{~N}$ & $\%$ & $\mathrm{~N}$ & $\%$ \\
\hline RI & 0 & .00 & 0 & .00 & 0 & .00 \\
\hline $\mathrm{SC}$ & 0 & .00 & 0 & .00 & 0 & .00 \\
\hline $\mathrm{TN}$ & 0 & .00 & 0 & .00 & 0 & .00 \\
\hline TX & 0 & .00 & 0 & .00 & 0 & .00 \\
\hline UT & 0 & .00 & 0 & .00 & 0 & .00 \\
\hline VT & 0 & .00 & 0 & .00 & 0 & .00 \\
\hline VA & 0 & .00 & 8 & 13.33 & 0 & .00 \\
\hline WA & 0 & .00 & 0 & .00 & 0 & .00 \\
\hline WV & 0 & .00 & 12 & 20.00 & 0 & .00 \\
\hline WI & 0 & .00 & 0 & .00 & 0 & .00 \\
\hline WY & 0 & .00 & 0 & .00 & 0 & .00 \\
\hline $\mathrm{DC}$ & 0 & .00 & 0 & .00 & 0 & .00 \\
\hline GU & 0 & .00 & 0 & .00 & 0 & .00 \\
\hline PR & 0 & .00 & 0 & .00 & 0 & .00 \\
\hline $\mathrm{AE}$ & 0 & .00 & 0 & .00 & 0 & .00 \\
\hline PQ & 0 & .00 & 0 & .00 & 0 & .00 \\
\hline AP & 0 & .00 & 0 & .00 & 0 & .00 \\
\hline $\mathrm{BC}$ & 0 & .00 & 0 & .00 & 0 & .00 \\
\hline
\end{tabular}


Table 15 (continued)

Residency by State of Mountaineer Success Academy Participants Who Participated in MSA Links

\begin{tabular}{|c|c|c|c|c|c|c|c|}
\hline & & \multicolumn{6}{|c|}{ Links } \\
\hline & & \multicolumn{2}{|c|}{ Yes } & \multicolumn{2}{|c|}{ No } & \multicolumn{2}{|c|}{ Not Eligible } \\
\hline & & $\mathrm{N}$ & $\%$ & $\mathrm{~N}$ & $\%$ & $\mathrm{~N}$ & $\%$ \\
\hline & $\mathrm{AB}$ & 0 & .00 & 0 & .00 & 0 & .00 \\
\hline & $\mathrm{ON}$ & 0 & .00 & 0 & .00 & 0 & .00 \\
\hline \multirow[t]{16}{*}{2013} & $\mathrm{AL}$ & 0 & .00 & 0 & .00 & 0 & .00 \\
\hline & $\mathrm{AK}$ & 0 & .00 & 0 & .00 & 0 & .00 \\
\hline & $\mathrm{AZ}$ & 0 & .00 & 0 & .00 & 0 & .00 \\
\hline & AR & 0 & .00 & 0 & .00 & 0 & .00 \\
\hline & $\mathrm{CA}$ & 1 & 100.00 & 1 & .43 & 0 & .00 \\
\hline & $\mathrm{CO}$ & 0 & .00 & 0 & .00 & 0 & .00 \\
\hline & $\mathrm{CT}$ & 0 & .00 & 1 & .43 & 0 & .00 \\
\hline & $\mathrm{DE}$ & 0 & .00 & 8 & 3.40 & 0 & .00 \\
\hline & FL & 0 & .00 & 1 & .43 & 0 & .00 \\
\hline & GA & 0 & .00 & 0 & .00 & 0 & .00 \\
\hline & $\mathrm{HI}$ & 0 & .00 & 0 & .00 & 0 & .00 \\
\hline & ID & 0 & .00 & 0 & .00 & 0 & .00 \\
\hline & IL & 0 & .00 & 1 & .43 & 0 & .00 \\
\hline & $\mathrm{IN}$ & 0 & .00 & 0 & .00 & 0 & .00 \\
\hline & IA & 0 & .00 & 0 & .00 & 0 & .00 \\
\hline & $\mathrm{KS}$ & 0 & .00 & 0 & .00 & 0 & .00 \\
\hline
\end{tabular}


Table 15 (continued)

Residency by State of Mountaineer Success Academy Participants Who Participated in MSA Links

\begin{tabular}{|c|c|c|c|c|c|c|}
\hline & \multicolumn{6}{|c|}{ Links } \\
\hline & \multicolumn{2}{|c|}{ Yes } & \multicolumn{2}{|c|}{ No } & \multicolumn{2}{|c|}{ Not Eligible } \\
\hline & $\mathrm{N}$ & $\%$ & $\mathrm{~N}$ & $\%$ & $\mathrm{~N}$ & $\%$ \\
\hline KY & 0 & .00 & 0 & .00 & 0 & .00 \\
\hline LA & 0 & .00 & 0 & .00 & 0 & .00 \\
\hline $\mathrm{ME}$ & 0 & .00 & 0 & .00 & 0 & .00 \\
\hline MD & 0 & .00 & 23 & 9.79 & 0 & .00 \\
\hline MA & 0 & .00 & 4 & 1.70 & 0 & .00 \\
\hline MI & 0 & .00 & 0 & .00 & 0 & .00 \\
\hline $\mathrm{MN}$ & 0 & .00 & 0 & .00 & 0 & .00 \\
\hline MS & 0 & .00 & 0 & .00 & 0 & .00 \\
\hline MO & 0 & .00 & 1 & .43 & 0 & .00 \\
\hline MT & 0 & .00 & 0 & .00 & 0 & .00 \\
\hline NV & 0 & .00 & 0 & .00 & 0 & .00 \\
\hline $\mathrm{NH}$ & 0 & .00 & 0 & .00 & 0 & .00 \\
\hline NJ & 0 & .00 & 25 & 10.64 & 0 & .00 \\
\hline NM & 0 & .00 & 0 & .00 & 0 & .00 \\
\hline NY & 0 & .00 & 12 & 5.11 & 0 & .00 \\
\hline $\mathrm{NC}$ & 0 & .00 & 2 & .85 & 0 & .00 \\
\hline $\mathrm{OH}$ & 0 & .00 & 4 & 1.70 & 0 & .00 \\
\hline OK & 0 & .00 & 0 & .00 & 0 & .00 \\
\hline
\end{tabular}


Table 15 (continued)

Residency by State of Mountaineer Success Academy Participants Who Participated in MSA Links

\begin{tabular}{|c|c|c|c|c|c|c|}
\hline & \multicolumn{6}{|c|}{ Links } \\
\hline & \multicolumn{2}{|c|}{ Yes } & \multicolumn{2}{|c|}{ No } & \multicolumn{2}{|c|}{ Not Eligible } \\
\hline & $\mathrm{N}$ & $\%$ & $\mathrm{~N}$ & $\%$ & $\mathrm{~N}$ & $\%$ \\
\hline OR & 0 & .00 & 0 & .00 & 0 & .00 \\
\hline $\mathrm{PA}$ & 0 & .00 & 49 & 20.85 & 0 & .00 \\
\hline RI & 0 & .00 & 0 & .00 & 0 & .00 \\
\hline $\mathrm{SC}$ & 0 & .00 & 0 & .00 & 0 & .00 \\
\hline $\mathrm{TN}$ & 0 & .00 & 1 & .43 & 0 & .00 \\
\hline $\mathrm{TX}$ & 0 & .00 & 1 & .43 & 0 & .00 \\
\hline UT & 0 & .00 & 0 & .00 & 0 & .00 \\
\hline VT & 0 & .00 & 0 & .00 & 0 & .00 \\
\hline VA & 0 & .00 & 15 & 6.38 & 0 & .00 \\
\hline WA & 0 & .00 & 0 & .00 & 0 & .00 \\
\hline WV & 0 & .00 & 86 & 36.60 & 0 & .00 \\
\hline WI & 0 & .00 & 0 & .00 & 0 & .00 \\
\hline WY & 0 & .00 & 0 & .00 & 0 & .00 \\
\hline $\mathrm{DC}$ & 0 & .00 & 0 & .00 & 0 & .00 \\
\hline GU & 0 & .00 & 0 & .00 & 0 & .00 \\
\hline PR & 0 & .00 & 0 & .00 & 0 & .00 \\
\hline $\mathrm{AE}$ & 0 & .00 & 0 & .00 & 0 & .00 \\
\hline PQ & 0 & .00 & 0 & .00 & 0 & .00 \\
\hline
\end{tabular}


Table 15 (continued)

Residency by State of Mountaineer Success Academy Participants Who Participated in MSA Links

\begin{tabular}{|c|c|c|c|c|c|c|c|}
\hline & & \multicolumn{6}{|c|}{ Links } \\
\hline & & \multicolumn{2}{|c|}{ Yes } & \multicolumn{2}{|c|}{ No } & \multicolumn{2}{|c|}{ Not Eligible } \\
\hline & & $\mathrm{N}$ & $\%$ & $\mathrm{~N}$ & $\%$ & $\mathrm{~N}$ & $\%$ \\
\hline & AP & 0 & .00 & 0 & .00 & 0 & .00 \\
\hline & $\mathrm{BC}$ & 0 & .00 & 0 & .00 & 0 & .00 \\
\hline & $\mathrm{AB}$ & 0 & .00 & 0 & .00 & 0 & .00 \\
\hline & $\mathrm{ON}$ & 0 & .00 & 0 & .00 & 0 & .00 \\
\hline \multirow[t]{14}{*}{2014} & $\mathrm{AL}$ & 0 & .00 & 0 & .00 & 0 & .00 \\
\hline & $\mathrm{AK}$ & 0 & .00 & 0 & .00 & 0 & .00 \\
\hline & $\mathrm{AZ}$ & 0 & .00 & 0 & .00 & 0 & .00 \\
\hline & $\mathrm{AR}$ & 0 & .00 & 0 & .00 & 0 & .00 \\
\hline & $\mathrm{CA}$ & 1 & 1.00 & 0 & .00 & 0 & .00 \\
\hline & $\mathrm{CO}$ & 0 & .00 & 0 & .00 & 0 & .00 \\
\hline & $\mathrm{CT}$ & 3 & 3.00 & 0 & .00 & 0 & .00 \\
\hline & $\mathrm{DE}$ & 0 & .00 & 0 & .00 & 0 & .00 \\
\hline & FL & 1 & 1.00 & 0 & .00 & 0 & .00 \\
\hline & GA & 0 & .00 & 0 & .00 & 0 & .00 \\
\hline & $\mathrm{HI}$ & 0 & .00 & 0 & .00 & 0 & .00 \\
\hline & ID & 0 & .00 & 0 & .00 & 0 & .00 \\
\hline & IL & 0 & .00 & 0 & .00 & 0 & .00 \\
\hline & IN & 0 & .00 & 0 & .00 & 0 & .00 \\
\hline
\end{tabular}


Table 15 (continued)

Residency by State of Mountaineer Success Academy Participants Who Participated in MSA Links

\begin{tabular}{|c|c|c|c|c|c|c|}
\hline & \multicolumn{6}{|c|}{ Links } \\
\hline & \multicolumn{2}{|c|}{ Yes } & \multicolumn{2}{|c|}{ No } & \multicolumn{2}{|c|}{ Not Eligible } \\
\hline & $\mathrm{N}$ & $\%$ & $\mathrm{~N}$ & $\%$ & $\mathrm{~N}$ & $\%$ \\
\hline IA & 0 & .00 & 0 & .00 & 0 & .00 \\
\hline $\mathrm{KS}$ & 0 & .00 & 0 & .00 & 0 & .00 \\
\hline KY & 0 & .00 & 0 & .00 & 0 & .00 \\
\hline LA & 0 & .00 & 0 & .00 & 0 & .00 \\
\hline ME & 0 & .00 & 0 & .00 & 0 & .00 \\
\hline MD & 7 & 7.00 & 0 & .00 & 0 & .00 \\
\hline MA & 1 & 1.00 & 0 & .00 & 0 & .00 \\
\hline MI & 0 & .00 & 0 & .00 & 0 & .00 \\
\hline $\mathrm{MN}$ & 0 & .00 & 0 & .00 & 0 & .00 \\
\hline MS & 0 & .00 & 0 & .00 & 0 & .00 \\
\hline MO & 0 & .00 & 0 & .00 & 0 & .00 \\
\hline MT & 0 & .00 & 0 & .00 & 0 & .00 \\
\hline NV & 0 & .00 & 0 & .00 & 0 & .00 \\
\hline $\mathrm{NH}$ & 0 & .00 & 0 & .00 & 0 & .00 \\
\hline $\mathrm{NJ}$ & 17 & 17.00 & 2 & 7.14 & 0 & .00 \\
\hline NM & 0 & .00 & 0 & .00 & 0 & .00 \\
\hline NY & 2 & 2.00 & 1 & 3.57 & 0 & .00 \\
\hline $\mathrm{NC}$ & 2 & 2.00 & 0 & .00 & 0 & .00 \\
\hline
\end{tabular}


Table 15 (continued)

Residency by State of Mountaineer Success Academy Participants Who Participated in MSA Links

\begin{tabular}{|c|c|c|c|c|c|c|}
\hline & \multicolumn{6}{|c|}{ Links } \\
\hline & \multicolumn{2}{|c|}{ Yes } & \multicolumn{2}{|c|}{ No } & \multicolumn{2}{|c|}{ Not Eligible } \\
\hline & $\mathrm{N}$ & $\%$ & $\mathrm{~N}$ & $\%$ & $\mathrm{~N}$ & $\%$ \\
\hline $\mathrm{OH}$ & 4 & 4.00 & 0 & .00 & 0 & .00 \\
\hline $\mathrm{OK}$ & 0 & .00 & 0 & .00 & 0 & .00 \\
\hline OR & 0 & .00 & 0 & .00 & 0 & .00 \\
\hline PA & 16 & 16.00 & 5 & 17.86 & 0 & .00 \\
\hline RI & 0 & .00 & 0 & .00 & 0 & .00 \\
\hline $\mathrm{SC}$ & 0 & .00 & 0 & .00 & 0 & .00 \\
\hline $\mathrm{TN}$ & 0 & .00 & 0 & .00 & 0 & .00 \\
\hline $\mathrm{TX}$ & 0 & .00 & 0 & .00 & 0 & .00 \\
\hline UT & 0 & .00 & 0 & .00 & 0 & .00 \\
\hline VT & 0 & .00 & 0 & .00 & 0 & .00 \\
\hline VA & 11 & 11.00 & 2 & 7.14 & 0 & .00 \\
\hline WA & 0 & .00 & 0 & .00 & 0 & .00 \\
\hline WV & 35 & 35.00 & 18 & 64.29 & 0 & .00 \\
\hline WI & 0 & .00 & 0 & .00 & 0 & .00 \\
\hline WY & 0 & .00 & 0 & .00 & 0 & .00 \\
\hline $\mathrm{DC}$ & 0 & .00 & 0 & .00 & 0 & .00 \\
\hline $\mathrm{GU}$ & 0 & .00 & 0 & .00 & 0 & .00 \\
\hline PR & 0 & .00 & 0 & .00 & 0 & .00 \\
\hline
\end{tabular}


Table 15 (continued)

Residency by State of Mountaineer Success Academy Participants Who Participated in MSA Links

\begin{tabular}{|c|c|c|c|c|c|c|c|}
\hline & & \multicolumn{6}{|c|}{ Links } \\
\hline & & \multicolumn{2}{|c|}{ Yes } & \multicolumn{2}{|c|}{ No } & \multicolumn{2}{|c|}{ Not Eligible } \\
\hline & & $\mathrm{N}$ & $\%$ & $\mathrm{~N}$ & $\%$ & $\mathrm{~N}$ & $\%$ \\
\hline & $\mathrm{AE}$ & 0 & .00 & 0 & .00 & 0 & .00 \\
\hline & PQ & 0 & .00 & 0 & .00 & 0 & .00 \\
\hline & AP & 0 & .00 & 0 & .00 & 0 & .00 \\
\hline & $\mathrm{BC}$ & 0 & .00 & 0 & .00 & 0 & .00 \\
\hline & $\mathrm{AB}$ & 0 & .00 & 0 & .00 & 0 & .00 \\
\hline & $\mathrm{ON}$ & 0 & .00 & 0 & .00 & 0 & .00 \\
\hline \multirow[t]{12}{*}{2015} & $\mathrm{AL}$ & 0 & .00 & 0 & .00 & 0 & .00 \\
\hline & $\mathrm{AK}$ & 0 & .00 & 0 & .00 & 0 & .00 \\
\hline & $\mathrm{AZ}$ & 0 & .00 & 0 & .00 & 0 & .00 \\
\hline & AR & 0 & .00 & 0 & .00 & 0 & .00 \\
\hline & $\mathrm{CA}$ & 0 & .00 & 0 & .00 & 0 & .00 \\
\hline & $\mathrm{CO}$ & 0 & .00 & 0 & .00 & 0 & .00 \\
\hline & $\mathrm{CT}$ & 2 & 2.06 & 0 & .00 & 0 & .00 \\
\hline & $\mathrm{DE}$ & 3 & 3.09 & 0 & .00 & 0 & .00 \\
\hline & FL & 0 & .00 & 0 & .00 & 0 & .00 \\
\hline & GA & 0 & .00 & 0 & .00 & 0 & .00 \\
\hline & HI & 0 & .00 & 0 & .00 & 0 & .00 \\
\hline & ID & 0 & .00 & 0 & .00 & 0 & .00 \\
\hline
\end{tabular}


Table 15 (continued)

Residency by State of Mountaineer Success Academy Participants Who Participated in MSA Links

\begin{tabular}{|c|c|c|c|c|c|c|}
\hline & \multicolumn{6}{|c|}{ Links } \\
\hline & \multicolumn{2}{|c|}{ Yes } & \multicolumn{2}{|c|}{ No } & \multicolumn{2}{|c|}{ Not Eligible } \\
\hline & $\mathrm{N}$ & $\%$ & $\mathrm{~N}$ & $\%$ & $\mathrm{~N}$ & $\%$ \\
\hline IL & 0 & .00 & 0 & .00 & 0 & .00 \\
\hline IN & 0 & .00 & 0 & .00 & 0 & .00 \\
\hline IA & 0 & .00 & 0 & .00 & 0 & .00 \\
\hline $\mathrm{KS}$ & 0 & .00 & 0 & .00 & 0 & .00 \\
\hline KY & 0 & .00 & 0 & .00 & 0 & .00 \\
\hline LA & 0 & .00 & 0 & .00 & 0 & .00 \\
\hline ME & 0 & .00 & 0 & .00 & 0 & .00 \\
\hline MD & 9 & 9.28 & 2 & 11.76 & 0 & .00 \\
\hline MA & 1 & 1.03 & 0 & .00 & 0 & .00 \\
\hline MI & 0 & .00 & 0 & .00 & 0 & .00 \\
\hline $\mathrm{MN}$ & 0 & .00 & 1 & 5.88 & 0 & .00 \\
\hline MS & 0 & .00 & 0 & .00 & 0 & .00 \\
\hline MO & 0 & .00 & 0 & .00 & 0 & .00 \\
\hline MT & 0 & .00 & 0 & .00 & 0 & .00 \\
\hline NV & 0 & .00 & 0 & .00 & 0 & .00 \\
\hline $\mathrm{NH}$ & 0 & .00 & 0 & .00 & 0 & .00 \\
\hline NJ & 10 & 10.31 & 0 & .00 & 0 & .00 \\
\hline NM & 0 & .00 & 0 & .00 & 0 & .00 \\
\hline
\end{tabular}


Table 15 (continued)

Residency by State of Mountaineer Success Academy Participants Who Participated in MSA Links

\begin{tabular}{|c|c|c|c|c|c|c|}
\hline & \multicolumn{6}{|c|}{ Links } \\
\hline & \multicolumn{2}{|c|}{ Yes } & \multicolumn{2}{|c|}{ No } & \multicolumn{2}{|c|}{ Not Eligible } \\
\hline & $\mathrm{N}$ & $\%$ & $\mathrm{~N}$ & $\%$ & $\mathrm{~N}$ & $\%$ \\
\hline NY & 7 & 7.22 & 4 & 23.53 & 0 & .00 \\
\hline $\mathrm{NC}$ & 0 & .00 & 0 & .00 & 0 & .00 \\
\hline $\mathrm{OH}$ & 6 & 6.19 & 0 & .00 & 0 & .00 \\
\hline OK & 0 & .00 & 0 & .00 & 0 & .00 \\
\hline OR & 0 & .00 & 0 & .00 & 0 & .00 \\
\hline PA & 28 & 28.87 & 0 & .00 & 0 & .00 \\
\hline RI & 0 & .00 & 0 & .00 & 0 & .00 \\
\hline $\mathrm{SC}$ & 0 & .00 & 0 & .00 & 0 & .00 \\
\hline $\mathrm{TN}$ & 0 & .00 & 0 & .00 & 0 & .00 \\
\hline $\mathrm{TX}$ & 0 & .00 & 0 & .00 & 0 & .00 \\
\hline UT & 0 & .00 & 0 & .00 & 0 & .00 \\
\hline VT & 0 & .00 & 0 & .00 & 0 & .00 \\
\hline VA & 10 & 10.31 & 2 & 11.76 & 0 & .00 \\
\hline WA & 0 & .00 & 0 & .00 & 0 & .00 \\
\hline WV & 21 & 21.65 & 8 & 47.06 & 0 & .00 \\
\hline WI & 0 & .00 & 0 & .00 & 0 & .00 \\
\hline WY & 0 & .00 & 0 & .00 & 0 & .00 \\
\hline $\mathrm{DC}$ & 0 & .00 & 0 & .00 & 0 & .00 \\
\hline GU & 0 & .00 & 0 & .00 & 0 & .00 \\
\hline
\end{tabular}


Table 15 (continued)

Residency by State of Mountaineer Success Academy Participants Who Participated in MSA Links

\begin{tabular}{|c|c|c|c|c|c|c|}
\hline & \multicolumn{6}{|c|}{ Links } \\
\hline & \multicolumn{2}{|c|}{ Yes } & \multicolumn{2}{|c|}{ No } & \multicolumn{2}{|c|}{ Not Eligible } \\
\hline & $\mathrm{N}$ & $\%$ & $\mathrm{~N}$ & $\%$ & $\mathrm{~N}$ & $\%$ \\
\hline PR & 0 & .00 & 0 & .00 & 0 & .00 \\
\hline $\mathrm{AE}$ & 0 & .00 & 0 & .00 & 0 & .00 \\
\hline PQ & 0 & .00 & 0 & .00 & 0 & .00 \\
\hline AP & 0 & .00 & 0 & .00 & 0 & .00 \\
\hline $\mathrm{BC}$ & 0 & .00 & 0 & .00 & 0 & .00 \\
\hline $\mathrm{AB}$ & 0 & .00 & 0 & .00 & 0 & .00 \\
\hline ON & 0 & .00 & 0 & .00 & 0 & .00 \\
\hline
\end{tabular}


Of the MSA participants $99.4 \%$ were US citizens while $100.0 \%$ of eligible nonparticipants were US citizens. Of the non-eligible students 96.0\% were US citizens (see Table 16).

Table 16

Citizenship of Mountaineer Success Academy Participants, Eligible Non-Participants and Non-Eligible Students for the 2012, 2013, 2014 and 2015 Cohorts

\begin{tabular}{lrrrrrrrrr}
\hline & \multicolumn{8}{c}{ Participation } \\
\cline { 2 - 10 } & \multicolumn{2}{c}{ Yes } & \multicolumn{1}{c}{ No } & \multicolumn{2}{c}{ Not Eligible } & \multicolumn{2}{c}{ Total } \\
\cline { 2 - 10 } & $\mathrm{N}$ & $\%$ & $\mathrm{~N}$ & $\%$ & $\mathrm{~N}$ & $\%$ & $\mathrm{~N}$ & $\%$ \\
\hline Permanent & & & .56 & 0 & .00 & 91 & .52 & 94 & .50 \\
Resident & 3 & & & & & & & \\
US Citizen & 535 & 99.44 & 593 & 100.00 & 16897 & 95.96 & 18025 & 96.19 \\
Non-Immigrant & 0 & .00 & 0 & .00 & 616 & 3.50 & 616 & 3.29 \\
Refugee & 0 & .00 & 0 & .00 & 4 & .02 & 4 & .02 \\
Total & 538 & 100.00 & 593 & 100.00 & 17608 & 100.00 & 18739 & 100.00 \\
\hline
\end{tabular}

One hundred percent of Mountaineer Success Academy participants who participated in MSA Links for the 2014 cohort were US citizens. For the 2015 cohort, $10.0 \%$ of Mountaineer Success Academy participants who participated in MSA Links were permanent residents while $99.0 \%$ were US citizens. For both cohorts, $100.0 \%$ of students who did not participate in MSA were US citizens. Data for the 2012 and 2013 cohorts was not available. Results are shown in Table 17. 
Table 17

Citizenship of Mountaineer Success Academy Participants Who Participated in MSA Links

\begin{tabular}{|c|c|c|c|c|c|c|c|}
\hline & & \multicolumn{6}{|c|}{ Links } \\
\hline & & \multicolumn{2}{|c|}{ Yes } & \multicolumn{2}{|c|}{ No } & \multicolumn{2}{|c|}{ Not Eligible } \\
\hline & & $\mathrm{N}$ & $\%$ & $\mathrm{~N}$ & $\%$ & $\mathrm{~N}$ & $\%$ \\
\hline \multirow[t]{5}{*}{2012} & Permanent & & & & & & \\
\hline & Resident & 0 & .00 & 0 & .00 & 0 & .00 \\
\hline & US Citizen & 0 & .00 & 60 & 100.00 & 0 & .00 \\
\hline & $\begin{array}{l}\text { Non- } \\
\text { Immigrant }\end{array}$ & 0 & .00 & 0 & .00 & 0 & .00 \\
\hline & Refugee & 0 & .00 & 0 & .00 & 0 & .00 \\
\hline \multirow[t]{5}{*}{2013} & Permanent & & & & & & \\
\hline & Resident & 0 & .00 & 2 & .85 & 0 & .00 \\
\hline & US Citizen & 1 & 100.00 & 233 & 99.15 & 0 & .00 \\
\hline & $\begin{array}{l}\text { Non- } \\
\text { Immigrant }\end{array}$ & 0 & .00 & 0 & .00 & 0 & .00 \\
\hline & Refugee & 0 & .00 & 0 & .00 & 0 & .00 \\
\hline \multirow[t]{5}{*}{2014} & Permanent & & & & & & \\
\hline & Resident & 0 & .00 & 0 & .00 & 0 & .00 \\
\hline & US Citizen & 100 & 100.00 & 28 & 100.00 & 0 & .00 \\
\hline & $\begin{array}{l}\text { Non- } \\
\text { Immigrant }\end{array}$ & 0 & .00 & 0 & .00 & 0 & .00 \\
\hline & Refugee & 0 & .00 & 0 & .00 & 0 & .00 \\
\hline \multirow[t]{5}{*}{2015} & Permanent & & & & & & \\
\hline & Resident & 1 & 1.03 & 0 & .00 & 0 & .00 \\
\hline & US Citizen & 96 & 98.97 & 17 & 100.00 & 0 & .00 \\
\hline & $\begin{array}{l}\text { Non- } \\
\text { Immigrant }\end{array}$ & 0 & .00 & 0 & .00 & 0 & .00 \\
\hline & Refugee & 0 & .00 & 0 & .00 & 0 & .00 \\
\hline
\end{tabular}




\section{Graduation Rates}

Research Questions \#2 and \#3: What were the within 8 semesters (within 4 years) graduation rates of the West Virginia University Mountaineer Success Academy participants compared to those of eligible non-participants and non-eligible students entering West Virginia University in the fall semesters 2012, 2013, 2014 and 2015? What were the more than 8 semester (more than 4 years) graduation rates of the West Virginia Mountaineer Success Academy participants compared to those of eligible nonparticipants and non-eligible students entering West Virginia University in the fall semesters 2012, 2013 and 2014?

Up to four year and more than four-year graduation rates were computed for 2012, 2013 and 2014 cohorts respectively. Up to four-year graduation rates were computed for the 2015 cohort.

For all three groups, more students graduated within 4 years than more than 4 years. There was no difference between MSA participants that graduated within 4 years or more than 4 years when compared to eligible non-participants. More non-eligible students graduated within 4 years. There was no difference among all three groups for more than 4-year graduation rates. More MSA participants did not graduate when compared to eligible non-participants and non-eligible participants.

There were $25.5 \%$ of MSA participants who graduated within 4 years while $25.6 \%$ of eligible non-participants graduated within 4 years. There were $40.0 \%$ of noneligible students who graduated within 4 years. Of those who participated in MSA, 17.0\% graduated in more than 4 years while $18.7 \%$ of eligible non-participants graduated in more than 4 years. There were $17.0 \%$ of non-eligible students who graduated in more 
than 4 years. There were $57.0 \%$ of MSA participants who did not graduate within 12 semesters while $55.7 \%$ of eligible non-participants did not graduate within 12 semesters. Of the $43.0 \%$ of non-eligible student group $43.9 \%$ did not graduate within 12 semesters. Results are shown in Table 18. 
Table 18

Graduation Rates of Mountaineer Success Academy Participants, Eligible Non-Participants, and Non-Eligible Student Groups for the 2012, 2013, 2014, 2015 Cohorts

\begin{tabular}{|c|c|c|c|c|c|c|c|c|}
\hline & \multicolumn{8}{|c|}{ Participation } \\
\hline & \multicolumn{2}{|c|}{ Yes } & \multicolumn{2}{|c|}{ No } & \multicolumn{2}{|c|}{ Not Eligible } & \multicolumn{2}{|c|}{ Total } \\
\hline & $\mathrm{N}$ & $\%$ & $\mathrm{~N}$ & $\%$ & $\mathrm{~N}$ & $\%$ & $\mathrm{~N}$ & $\%$ \\
\hline $\begin{array}{l}\text { More than Four } \\
\text { Years }\end{array}$ & 92 & 17.10 & 111 & 18.72 & 2992 & 16.99 & 3195 & 17.05 \\
\hline $\begin{array}{l}\text { Graduated Four } \\
\text { Years }\end{array}$ & 137 & 25.46 & 152 & 25.63 & 7086 & 40.24 & 7375 & 39.36 \\
\hline Did not Graduate & 309 & 57.43 & 330 & 55.65 & 7530 & 42.76 & 8169 & 43.59 \\
\hline Total & 538 & 100.00 & 593 & 100.00 & 17608 & 100.00 & 18739 & 100.00 \\
\hline
\end{tabular}


It is important to note that students may still be enrolled at West Virginia University and have not graduated yet, thus graduation rates, especially for the 2014 and 2015 cohorts, may not be complete.

For the 2012 cohort, more non-participants graduated in more than 4 years than MSA participants and non-eligible students. More MSA participants graduated within 4 years than eligible non-participants but not non-eligible students. Over all, more MSA participants did not graduate than eligible non-participants and non-eligible students for the 2012 cohort. Of those that participated in MSA, 20.0\% graduated in more than four years while $30.6 \%$ of eligible non-participants graduated in more than 4 years. Of the non-eligible students, $25.0 \%$ graduated in more than 4 years. Of the MSA participants, $27.0 \%$ graduated in 4 years while $18.0 \%$ of eligible non-participants graduated in 4 years. Of the non-eligible students $36.0 \%$ graduated in 4 years. Of those that participated in MSA, 53.0\% did not graduate within 12 semesters, $51.0 \%$ of eligible non-participants and $40.0 \%$ of non-eligible students did not graduate in 12 semesters for the 2012 cohort.

For the 2013 cohort, there was no difference in more than 4-year graduation rates between MSA participants and eligible non-participants. Non-eligible students had a slightly lower graduation rate then MSA participants and eligible non-participants. More non-eligible participants graduated within 4 years than MSA participants and eligible non-participants. More eligible non-participants did not graduate then MSA participants and non-eligible students for the 2013 cohort. Of the MSA participants 25.0\% graduated in more than 4 years while $23.0 \%$ of eligible non-participants graduated in more than 4 years for the 2013 cohort. Of the non-eligible students $20.0 \%$ graduated in more than 4 years. Of those that participated in MSA, $22.0 \%$ graduated in 4 years while $20.0 \%$ 
eligible non-participants graduated in 4 years and $40.0 \%$ of non-eligible students graduated in 4 years. Of those that participated in MSA, 53.0\% of MSA participants did not graduate in 12 semesters. Of the eligible non-participants, $56.0 \%$ did not graduate in 12 semesters and $40.0 \%$ of non-eligible students did not graduate in 12 semesters for the 2013 cohort. For the 2014 cohort, more MSA students graduated in more than 4 years than eligible non-participants and non-eligible students. More non-eligible students graduated in 4 years than MSA participants and eligible non-participants. There was no difference in MSA participants and eligible non-participants who did not graduate. Of those that participated in MSA $17.0 \%$ and $11.0 \%$ of eligible non-participants graduated in more than 4 years while $15.0 \%$ of non-eligible students graduated in more than 4 years. Of those that participated in MSA $23.0 \%$ and $30.0 \%$ of eligible non-participants graduated within 4 years. Of the non-eligible students $41.0 \%$ graduated in 4 years for the 2014 cohort. No data were available for the more than 4-year graduation rates for the 2015 cohort. There was no difference in MSA participants and eligible non-participants who graduated within 4 years. More non-eligible students graduated in 4 years than MSA participants and eligible non-participants. More MSA participants did not graduate than eligible non-participants and non-eligible students. Of the MSA participants, $25.0 \%$ graduated in 4 years. Of the eligible non-participants $25.0 \%$ graduated in 4 years while $40.0 \%$ of non-eligible students graduated in 4 years. Of those that participated in MSA $65.0 \%$ and $59.0 \%$ of eligible non-participants did not graduate in 12 semesters while $52 \%$ of non-eligible participants did not graduate in 12 semesters for the 2015 cohort (see Table 19). 
Table 19

Graduation Rates of Mountaineer Success Academy Participants, Eligible Non-Participants, and Non-Eligible Student Groups for the 2012, 2013, 2014 and 2015 Cohorts by Year

\begin{tabular}{|c|c|c|c|c|c|c|c|c|c|}
\hline & & \multicolumn{8}{|c|}{ Participation } \\
\hline & & \multicolumn{2}{|c|}{ Yes } & \multicolumn{2}{|c|}{ No } & \multicolumn{2}{|c|}{ Not Eligible } & \multicolumn{2}{|c|}{ Total } \\
\hline & & $\mathrm{N}$ & $\%$ & $\mathrm{~N}$ & $\%$ & $\mathrm{~N}$ & $\%$ & $\mathrm{~N}$ & $\%$ \\
\hline \multirow[t]{4}{*}{2012} & $\begin{array}{l}\text { More than Four } \\
\text { Years }\end{array}$ & 12 & 20.00 & 66 & 30.56 & 1305 & 24.77 & 1383 & 24.94 \\
\hline & $\begin{array}{l}\text { Graduated Four } \\
\text { Years }\end{array}$ & 16 & 26.67 & 39 & 18.06 & 1880 & 35.68 & 1935 & 34.90 \\
\hline & Did not Graduate & 32 & 53.33 & 111 & 51.39 & 2084 & 39.55 & 2227 & 40.16 \\
\hline & Total & 60 & 100.00 & 216 & 100.00 & 5269 & 100.00 & 5545 & 100.00 \\
\hline \multirow[t]{4}{*}{2013} & $\begin{array}{l}\text { More than Four } \\
\text { Years }\end{array}$ & 58 & 24.58 & 33 & 23.08 & 992 & 20.81 & 1083 & 21.05 \\
\hline & $\begin{array}{l}\text { Graduated Four } \\
\text { Years }\end{array}$ & 52 & 22.03 & 29 & 20.28 & 1891 & 39.68 & 1972 & 38.33 \\
\hline & Did not Graduate & 126 & 53.39 & 81 & 56.64 & 1883 & 39.51 & 2090 & 40.62 \\
\hline & Total & 236 & 100.00 & 143 & 100.00 & 4766 & 100.00 & 5145 & 100.00 \\
\hline
\end{tabular}


Table 19

Graduation Rates of Mountaineer Success Academy Participants, Eligible Non-Participants, and Non-Eligible Student Groups for the 2012, 2013, 2014 and 2015 Cohorts by Year

\begin{tabular}{|c|c|c|c|c|c|c|c|c|c|}
\hline & & \multicolumn{8}{|c|}{ Participation } \\
\hline & & \multicolumn{2}{|c|}{ Yes } & \multicolumn{2}{|c|}{ No } & \multicolumn{2}{|c|}{ Not Eligible } & \multicolumn{2}{|c|}{ Total } \\
\hline & & $\mathrm{N}$ & $\%$ & $\mathrm{~N}$ & $\%$ & $\mathrm{~N}$ & $\%$ & $\mathrm{~N}$ & $\%$ \\
\hline \multirow[t]{4}{*}{2014} & $\begin{array}{l}\text { More than Four } \\
\text { Years }\end{array}$ & 22 & 17.19 & 12 & 11.21 & 695 & 14.67 & 729 & 14.66 \\
\hline & $\begin{array}{l}\text { Graduated Four } \\
\text { Years }\end{array}$ & 29 & 22.66 & 32 & 29.91 & 1945 & 41.05 & 2006 & 40.34 \\
\hline & Did not Graduate & 77 & 60.16 & 63 & 58.88 & 2098 & 44.28 & 2238 & 45.00 \\
\hline & Total & 128 & 100.00 & 107 & 100.00 & 4738 & 100.00 & 4973 & 100.00 \\
\hline \multirow[t]{4}{*}{2015} & $\begin{array}{l}\text { More than Four } \\
\text { Years }\end{array}$ & 0 & .00 & 0 & .00 & 0 & .00 & 0 & .00 \\
\hline & $\begin{array}{l}\text { Graduated Four } \\
\text { Years }\end{array}$ & 40 & 35.09 & 52 & 40.94 & 1370 & 48.32 & 1462 & 47.53 \\
\hline & Did not Graduate & 74 & 64.91 & 75 & 59.06 & 1465 & 51.68 & 1614 & 52.47 \\
\hline & Total & 114 & 100.00 & 127 & 100.00 & 2835 & 100.00 & 3076 & 100.00 \\
\hline
\end{tabular}


Table 19 (continued)

Graduation Rates of Mountaineer Success Academy Participants, Eligible Non-Participants, and Non-Eligible Student Groups for the 2012, 2013, 2014 and 2015 Cohorts by Year

\begin{tabular}{|c|c|c|c|c|c|c|c|c|c|}
\hline & & \multicolumn{8}{|c|}{ Participation } \\
\hline & & \multicolumn{2}{|c|}{ Yes } & \multicolumn{2}{|c|}{ No } & \multicolumn{2}{|c|}{ Not Eligible } & \multicolumn{2}{|c|}{ Total } \\
\hline & & $\mathrm{N}$ & $\%$ & $\mathrm{~N}$ & $\%$ & $\mathrm{~N}$ & $\%$ & $\mathrm{~N}$ & $\%$ \\
\hline \multirow[t]{4}{*}{ Total } & $\begin{array}{l}\text { More than Four } \\
\text { Years }\end{array}$ & 92 & 17.10 & 111 & 18.72 & 2992 & 16.99 & 3195 & 17.05 \\
\hline & $\begin{array}{l}\text { Graduated Four } \\
\text { Years }\end{array}$ & 137 & 25.46 & 152 & 25.63 & 7086 & 40.24 & 7375 & 39.36 \\
\hline & Did not Graduate & 309 & 57.43 & 330 & 55.65 & 7530 & 42.76 & 8169 & 43.59 \\
\hline & Total & 538 & 100.00 & 593 & 100.00 & 17608 & 100.00 & 18739 & 100.00 \\
\hline
\end{tabular}


Graduation rates were calculated for first-generation students. For all four cohorts, $15.2 \%$ of MSA participants that were first-generation students graduated within 4 years compared to $11.7 \%$ of eligible non-participants who were first-generation students. $10.4 \%$ of non-eligible students who were first-generation students graduated within 4 years. Of the MSA participants who were first-generation students $6.0 \%$ graduated in more than 4 years and $16.5 \%$ of eligible non-participants who were first-generation students graduated in more than 4 years while $12.0 \%$ of non-eligible students who were first-generation students graduated in more than 4 years. Of the MSA participants who were first-generation students $18.0 \%$ did not graduate in 12 semesters while $15.5 \%$ of eligible non-participants and $17.0 \%$ of non-eligible students did not graduate in 12 semesters (see Table 20). 
Table 20

Graduation Rates of First-Generation Mountaineer Success Academy Participants, Eligible Non-Participants and Non-Eligible Students for the 2012, 2013, 2014 and 2015 Cohorts

\begin{tabular}{|c|c|c|c|c|c|c|c|c|c|}
\hline & & \multicolumn{8}{|c|}{ Participation } \\
\hline & & \multicolumn{2}{|c|}{ Yes } & \multicolumn{2}{|c|}{ No } & \multicolumn{2}{|c|}{ Not Eligible } & \multicolumn{2}{|c|}{ Total } \\
\hline & & $\mathrm{N}$ & $\%$ & $\mathrm{~N}$ & $\%$ & $\mathrm{~N}$ & $\%$ & $\mathrm{~N}$ & $\%$ \\
\hline \multirow{3}{*}{$\begin{array}{l}\text { More than } \\
\text { Four Years }\end{array}$} & Yes & 14 & 15.22 & 13 & 11.71 & 312 & 10.43 & 339 & 10.61 \\
\hline & No & 78 & 84.78 & 98 & 88.29 & 2680 & 89.57 & 2856 & 89.39 \\
\hline & Total & 92 & 100.00 & 111 & 100.00 & 2992 & 100.00 & 3195 & 100.00 \\
\hline \multirow{3}{*}{$\begin{array}{l}\text { Graduated } \\
\text { Four Years }\end{array}$} & Yes & 22 & 16.06 & 25 & 16.45 & 893 & 12.60 & 940 & 12.75 \\
\hline & No & 115 & 83.94 & 127 & 83.55 & 6193 & 87.40 & 6435 & 87.25 \\
\hline & Total & 137 & 100.00 & 152 & 100.00 & 7086 & 100.00 & 7375 & 100.00 \\
\hline \multirow{3}{*}{$\begin{array}{l}\text { Did not } \\
\text { Graduate }\end{array}$} & Yes & 56 & 18.12 & 51 & 15.45 & 1288 & 17.10 & 1395 & 17.08 \\
\hline & No & 253 & 81.88 & 279 & 84.55 & 6242 & 82.90 & 6774 & 82.92 \\
\hline & Total & 309 & 100.00 & 330 & 100.00 & 7530 & 100.00 & 8169 & 100.00 \\
\hline
\end{tabular}


For the 2014 cohort, $26.0 \%$ of MSA participants who also participated in MSA Links and were first-generation students graduated while $8.0 \%$ of MSA participants who also participated in MSA Links and were not first-generation students graduated. For the 2015 cohort, $25.0 \%$ of MSA participants who also participated in MSA Links and were first-generation students graduated while $4.0 \%$ of MSA participants who also participated in MSA Links and were not first-generation students graduated. Data were not available for the 2012 and 2013 cohorts. Results are shown in Table 21.

Table 21

Graduation Rates of First-Generation Mountaineer Success Academy Participants who Participated in MSA Links

\begin{tabular}{|c|c|c|c|c|c|}
\hline & & \multicolumn{4}{|c|}{ Links } \\
\hline & & \multicolumn{2}{|c|}{ Yes } & \multicolumn{2}{|c|}{ No } \\
\hline & & $\mathrm{N}$ & $\%$ & $\mathrm{~N}$ & $\%$ \\
\hline \multirow[t]{2}{*}{2012} & Yes & 0 & .00 & 5 & 8.33 \\
\hline & No & 0 & .00 & 55 & 91.67 \\
\hline \multirow[t]{2}{*}{2013} & Yes & 0 & .00 & 25 & 10.64 \\
\hline & No & 1 & 100.00 & 210 & 89.36 \\
\hline \multirow[t]{2}{*}{2014} & Yes & 26 & 26.00 & 8 & 28.57 \\
\hline & No & 74 & 74.00 & 20 & 71.43 \\
\hline \multirow[t]{2}{*}{2015} & Yes & 24 & 24.74 & 4 & 23.53 \\
\hline & No & 73 & 75.26 & 13 & 76.47 \\
\hline
\end{tabular}


Graduation rates were calculated by ethnicity. For the 2012 cohort, $6.0 \%$ of MSA participants who identified as African American graduated within 4 years while $10.0 \%$ of eligible non-participants who identified as African American and 2.8\% of non-eligible students graduated within 4 years. Of the MSA participants $6.0 \%$ who identified as two more races graduated within four years while $5.0 \%$ of eligible non-participants and $2.0 \%$ of non-eligible students graduated within 4 years. Of those who participated in MSA $87.0 \%$ who identified as White graduated within 4 years while $82.0 \%$ of eligible nonparticipants and $88.0 \%$ of non-eligible students graduated within 4 years. Of MSA participants $16.0 \%$ who identified as Hispanic graduated in more than 4 years while $4.0 \%$ of non-eligible students graduated in more than 4 years. Of those that participated in MSA $83.0 \%$ who identified as White graduated in more than 4 years while $87.0 \%$ of eligible non-participants and $83.0 \%$ of non-eligible students graduated in more than 4 years. Of those who participated in MSA $6.0 \%$ of MSA students who identified as Hispanic did not graduate in 12 semesters while $3.7 \%$ of eligible non-participants and $5.0 \%$ of non-eligible students did not graduate in 12 semesters. Of those that did not graduate in 12 semesters, $90.0 \%$ of MSA participants identified as White, while $82.0 \%$ of eligible non-participants identified as White and $79.0 \%$ of eligible non-participants identified as White. For the 2013 cohort, $2.0 \%$ of MSA participants who identified as African American graduated within 4 years while $17.0 \%$ of eligible non-participants and 2.4\% of non-eligible students who identified as African American graduated within 4 years. There were $8.0 \%$ of MSA participants who identified as Hispanic who graduated within 4 years while $3.0 \%$ of eligible non-participants and $11.0 \%$ of non-eligible students who identified as Hispanic graduated within 4 years. Of those who participated in MSA, 
$90.0 \%$ who identified as White graduated within 4 years while $76.0 \%$ of eligible nonparticipants and $87.0 \%$ of non-eligible students who identified as White graduated within 4 years. There were $7.0 \%$ of MSA participants who identified as African American who graduated in more than 4 years while $9.0 \%$ of eligible non-participants and $4.0 \%$ of noneligible students graduated in more than 4 years. There were 5.0\% of MSA participants who identified as Hispanic who graduated in more than 4 years while $3.0 \%$ of eligible non-participants and $3.7 \%$ of non-eligible students graduated in more than years. There were $78 \%$ of MSA participants who graduated in more than 4 years who identified as White while $81.0 \%$ of eligible non-participants who identified as White graduated in more than 4 years. Of the non-eligible student group, $83.0 \%$ who identified as White graduated in more than 4 years. There were $7.0 \%$ of MSA participants who identified as African American who did not graduate in 12 semesters while $8.6 \%$ of eligible nonparticipants and $5.0 \%$ of non-eligible students who identified as African American did not graduate in 12 semesters. Of those who did not graduate, $77.0 \%$ of MSA participants identified as White while $74.0 \%$ of eligible non-participants and $81.0 \%$ of non-eligible students were White. For the 2014 cohort, 7.0\% of MSA students who graduated within 4 years identified as African American while 3.0\% of eligible non-participants who graduated within 4 years identified as African American. There were $2.8 \%$ of noneligible students who graduated within 4 years who identified as African American. There were $86.0 \%$ of MSA participants who graduated within 4 years who identifies as White while $90.0 \%$ of eligible non-participants who graduated within 4 years were White. Of the non-eligible student group, $88.0 \%$ who graduated within 4 years were White. There were $14.0 \%$ of MSA participants who identified as Hispanic who graduated 
in more than 4 years while $8.0 \%$ of eligible non-participants and $2.0 \%$ of non-eligible students who identified as Hispanic graduated in more the 4 years. There were $82.0 \%$ of MSA participants who identified as White who graduated in more than 4 years while $83.0 \%$ of eligible non-participants and $86.0 \%$ of non-eligible students who identified as White graduated in more than 4 years. Of the MSA participants, $4.0 \%$ who identified as African American did not graduate in 12 semesters while $8.0 \%$ of eligible nonparticipants and $7.0 \%$ of non-eligible students who identified as African American did not graduate in 12 semesters. There were $6.5 \%$ of MSA participants who identified as Hispanic who did not graduate in 12 semesters while $3.0 \%$ of eligible non-participants and $4.5 \%$ of non-eligible students who identified as Hispanic did not graduate. Of those who did not graduate in 12 semesters, $87.0 \%$ of MSA participants identified as White while $83.0 \%$ of eligible non-participants and $78.0 \%$ of non-eligible students who identified as White. For the 2015 cohort, $97.0 \%$ of MSA participants who identified as White graduated within 4 years while $92.0 \%$ of eligible non-participants and $91.0 \%$ of non-eligible students who identified as White graduated within 4 years. There were $78.0 \%$ of MSA participants who identify as White who have not graduated while $90.0 \%$ of eligible non-participants and $85.0 \%$ of non-eligible students have not yet graduated. Data were not available for more than 4-year graduation rates for the 2015 cohort (see Table 22). 
Table 22

Graduation Rates by Ethnicity

\begin{tabular}{|c|c|c|c|c|c|c|c|c|}
\hline & & & \multicolumn{6}{|c|}{ Participation } \\
\hline & & & \multicolumn{2}{|c|}{ Yes } & \multicolumn{2}{|c|}{ No } & \multicolumn{2}{|c|}{ Not Eligible } \\
\hline & & & $\mathrm{N}$ & $\%$ & $\mathrm{~N}$ & $\%$ & $\mathrm{~N}$ & $\%$ \\
\hline \multirow[t]{12}{*}{2012} & Graduated & American Indian or Alaskan Native & 0 & .00 & 0 & .00 & 1 & .05 \\
\hline & $\begin{array}{l}\text { Four } \\
\text { Years }\end{array}$ & Asian & 0 & .00 & 0 & .00 & 42 & 2.23 \\
\hline & & Black - Not of Hispanic Origin & 1 & 6.25 & 4 & 10.26 & 53 & 2.82 \\
\hline & & Hispanic & 0 & .00 & 1 & 2.56 & 54 & 2.87 \\
\hline & & Native Hawaiian or Pacific Islander & 0 & .00 & 0 & .00 & 0 & .00 \\
\hline & & Two or More Races & 1 & 6.25 & 2 & 5.13 & 42 & 2.23 \\
\hline & & Unknown & 0 & .00 & 0 & .00 & 19 & 1.01 \\
\hline & & White - Not of Hispanic Origin & 14 & 87.50 & 32 & 82.05 & 1669 & 88.78 \\
\hline & More than & American Indian or Alaskan Native & 0 & .00 & 1 & 1.52 & 1 & .08 \\
\hline & $\begin{array}{l}\text { Four } \\
\text { Years }\end{array}$ & Asian & 0 & .00 & 1 & 1.52 & 44 & 3.37 \\
\hline & & Black - Not of Hispanic Origin & 0 & .00 & 4 & 6.06 & 71 & 5.44 \\
\hline & & Hispanic & 2 & 16.67 & 0 & .00 & 52 & 3.98 \\
\hline
\end{tabular}


Table 22 (continued)

Graduation Rates by Ethnicity

\begin{tabular}{|c|c|c|c|c|c|c|c|}
\hline & & \multicolumn{6}{|c|}{ Participation } \\
\hline & & \multicolumn{2}{|c|}{ Yes } & \multicolumn{2}{|c|}{ No } & \multicolumn{2}{|c|}{ Not Eligible } \\
\hline & & $\mathrm{N}$ & $\%$ & $\mathrm{~N}$ & $\%$ & $\mathrm{~N}$ & $\%$ \\
\hline \multirow{12}{*}{$\begin{array}{l}\text { Did not } \\
\text { Graduate }\end{array}$} & Native Hawaiian or Pacific Islander & 0 & .00 & 0 & .00 & 3 & .23 \\
\hline & Two or More Races & 0 & .00 & 2 & 3.03 & 44 & 3.37 \\
\hline & Unknown & 0 & .00 & 0 & .00 & 11 & .84 \\
\hline & White - Not of Hispanic Origin & 10 & 83.33 & 58 & 87.88 & 1079 & 82.68 \\
\hline & American Indian or Alaskan Native & 0 & .00 & 0 & .00 & 5 & .24 \\
\hline & Asian & 1 & 3.13 & 1 & .90 & 64 & 3.07 \\
\hline & Black - Not of Hispanic Origin & 0 & .00 & 7 & 6.31 & 142 & 6.81 \\
\hline & Hispanic & 2 & 6.25 & 4 & 3.60 & 104 & 4.99 \\
\hline & Native Hawaiian or Pacific Islander & 0 & .00 & 0 & .00 & 3 & .14 \\
\hline & Two or More Races & 0 & .00 & 5 & 4.50 & 89 & 4.27 \\
\hline & Unknown & 0 & .00 & 2 & 1.80 & 15 & .72 \\
\hline & White - Not of Hispanic Origin & 29 & 90.63 & 92 & 82.88 & 1662 & 79.75 \\
\hline
\end{tabular}


Table 22 (continued)

Graduation Rates by Ethnicity

\begin{tabular}{|c|c|c|c|c|c|c|c|c|}
\hline & & & & & & ation & & \\
\hline & & & & & & & & ible \\
\hline & & & $\mathrm{N}$ & $\%$ & $\mathrm{~N}$ & $\%$ & $\mathrm{~N}$ & $\%$ \\
\hline 2013 & Graduated & American Indian or Alaskan Native & 0 & .00 & 0 & .00 & 2 & .11 \\
\hline & $\begin{array}{l}\text { Four } \\
\text { Years }\end{array}$ & Asian & 0 & .00 & 0 & .00 & 38 & 2.01 \\
\hline & & Black - Not of Hispanic Origin & 1 & 1.92 & 5 & 17.24 & 45 & 2.38 \\
\hline & & Hispanic & 4 & 7.69 & 1 & 3.45 & 69 & 3.65 \\
\hline & & Native Hawaiian or Pacific Islander & 0 & .00 & 0 & .00 & 2 & .11 \\
\hline & & Two or More Races & 0 & .00 & 1 & 3.45 & 69 & 3.65 \\
\hline & & Unknown & 0 & .00 & 0 & .00 & 12 & .63 \\
\hline & & White - Not of Hispanic Origin & 47 & 90.38 & 22 & 75.86 & 1654 & 87.47 \\
\hline & More than & American Indian or Alaskan Native & 0 & .00 & 0 & .00 & 1 & .10 \\
\hline & $\begin{array}{l}\text { Four } \\
\text { Years }\end{array}$ & Asian & 2 & 3.45 & 1 & 3.03 & 33 & 3.33 \\
\hline & & Black - Not of Hispanic Origin & 4 & 6.90 & 3 & 9.09 & 44 & 4.44 \\
\hline & & Hispanic & 3 & 5.17 & 1 & 3.03 & 37 & 3.73 \\
\hline
\end{tabular}


Table 22 (continued)

Graduation Rates by Ethnicity

\begin{tabular}{|c|c|c|c|c|c|c|c|}
\hline & & \multicolumn{6}{|c|}{ Participation } \\
\hline & & \multicolumn{2}{|c|}{ Yes } & \multicolumn{2}{|c|}{ No } & \multicolumn{2}{|c|}{ Not Eligible } \\
\hline & & $\mathrm{N}$ & $\%$ & $\mathrm{~N}$ & $\%$ & $\mathrm{~N}$ & $\%$ \\
\hline \multirow{12}{*}{$\begin{array}{l}\text { Did not } \\
\text { Graduate }\end{array}$} & Native Hawaiian or Pacific Islander & 0 & .00 & 0 & .00 & 1 & .10 \\
\hline & Two or More Races & 2 & 3.45 & 1 & 3.03 & 44 & 4.44 \\
\hline & Unknown & 2 & 3.45 & 0 & .00 & 9 & .91 \\
\hline & White - Not of Hispanic Origin & 45 & 77.59 & 27 & 81.82 & 823 & 82.96 \\
\hline & American Indian or Alaskan Native & 2 & 1.59 & 0 & .00 & 1 & .05 \\
\hline & Asian & 1 & .79 & 0 & .00 & 47 & 2.50 \\
\hline & Black - Not of Hispanic Origin & 10 & 7.94 & 7 & 8.64 & 112 & 5.95 \\
\hline & Hispanic & 9 & 7.14 & 7 & 8.64 & 97 & 5.15 \\
\hline & Native Hawaiian or Pacific Islander & 0 & .00 & 0 & .00 & 1 & .05 \\
\hline & Two or More Races & 7 & 5.56 & 7 & 8.64 & 95 & 5.05 \\
\hline & Unknown & 0 & .00 & 0 & .00 & 11 & .58 \\
\hline & White - Not of Hispanic Origin & 97 & 76.98 & 60 & 74.07 & 1519 & 80.67 \\
\hline
\end{tabular}


Table 22 (continued)

Graduation Rates by Ethnicity

\begin{tabular}{|c|c|c|c|c|c|c|c|c|}
\hline & & & & & & ation & & \\
\hline & & & & & & & & ible \\
\hline & & & $\mathrm{N}$ & $\%$ & $\mathrm{~N}$ & $\%$ & $\mathrm{~N}$ & $\%$ \\
\hline 2014 & Graduated & American Indian or Alaskan Native & 0 & .00 & 0 & .00 & 1 & .05 \\
\hline & $\begin{array}{l}\text { Four } \\
\text { Years }\end{array}$ & Asian & 0 & .00 & 1 & 3.13 & 50 & 2.57 \\
\hline & & Black - Not of Hispanic Origin & 2 & 6.90 & 1 & 3.13 & 55 & 2.83 \\
\hline & & Hispanic & 1 & 3.45 & 0 & .00 & 47 & 2.42 \\
\hline & & Native Hawaiian or Pacific Islander & 0 & .00 & 1 & 3.13 & 0 & .00 \\
\hline & & Two or More Races & 1 & 3.45 & 0 & .00 & 73 & 3.75 \\
\hline & & Unknown & 0 & .00 & 0 & .00 & 16 & .82 \\
\hline & & White - Not of Hispanic Origin & 25 & 86.21 & 29 & 90.63 & 1703 & 87.56 \\
\hline & More than & American Indian or Alaskan Native & 0 & .00 & 0 & .00 & 0 & .00 \\
\hline & $\begin{array}{l}\text { Four } \\
\text { Years }\end{array}$ & Asian & 0 & .00 & 0 & .00 & 18 & 2.59 \\
\hline & & Black - Not of Hispanic Origin & 0 & .00 & 0 & .00 & 28 & 4.03 \\
\hline & & Hispanic & 3 & 13.64 & 1 & 8.33 & 15 & 2.16 \\
\hline
\end{tabular}


Table 22 (continued)

Graduation Rates by Ethnicity

\begin{tabular}{|c|c|c|c|c|c|c|c|}
\hline & & \multicolumn{6}{|c|}{ Participation } \\
\hline & & \multicolumn{2}{|c|}{ Yes } & \multicolumn{2}{|c|}{ No } & \multicolumn{2}{|c|}{ Not Eligible } \\
\hline & & $\mathrm{N}$ & $\%$ & $\mathrm{~N}$ & $\%$ & $\mathrm{~N}$ & $\%$ \\
\hline \multirow{12}{*}{$\begin{array}{l}\text { Did not } \\
\text { Graduate }\end{array}$} & Native Hawaiian or Pacific Islander & 0 & .00 & 0 & .00 & 2 & .29 \\
\hline & Two or More Races & 1 & 4.55 & 1 & 8.33 & 28 & 4.03 \\
\hline & Unknown & 0 & .00 & 0 & .00 & 4 & .58 \\
\hline & White - Not of Hispanic Origin & 18 & 81.82 & 10 & 83.33 & 600 & 86.33 \\
\hline & American Indian or Alaskan Native & 0 & .00 & 0 & .00 & 4 & .19 \\
\hline & Asian & 1 & 1.30 & 0 & .00 & 75 & 3.57 \\
\hline & Black - Not of Hispanic Origin & 3 & 3.90 & 5 & 7.94 & 151 & 7.20 \\
\hline & Hispanic & 5 & 6.49 & 2 & 3.17 & 95 & 4.53 \\
\hline & Native Hawaiian or Pacific Islander & 0 & .00 & 0 & .00 & 2 & .10 \\
\hline & Two or More Races & 1 & 1.30 & 4 & 6.35 & 116 & 5.53 \\
\hline & Unknown & 0 & .00 & 0 & .00 & 16 & .76 \\
\hline & White - Not of Hispanic Origin & 67 & 87.01 & 52 & 82.54 & 1639 & 78.12 \\
\hline
\end{tabular}


Table 22 (continued)

Graduation Rates by Ethnicity

\begin{tabular}{|c|c|c|c|c|c|c|c|c|}
\hline & & & \multicolumn{6}{|c|}{ Participation } \\
\hline & & & \multicolumn{2}{|c|}{ Yes } & \multicolumn{2}{|c|}{ No } & \multicolumn{2}{|c|}{ Not Eligible } \\
\hline & & & $\mathrm{N}$ & $\%$ & $\mathrm{~N}$ & $\%$ & $\mathrm{~N}$ & $\%$ \\
\hline \multirow[t]{12}{*}{2015} & Graduated & American Indian or Alaskan Native & 0 & .00 & 0 & .00 & 0 & .00 \\
\hline & $\begin{array}{l}\text { Four } \\
\text { Years }\end{array}$ & Asian & 0 & .00 & 1 & 1.92 & 21 & 1.53 \\
\hline & & Black - Not of Hispanic Origin & 0 & .00 & 0 & .00 & 15 & 1.09 \\
\hline & & Hispanic & 0 & .00 & 0 & .00 & 30 & 2.19 \\
\hline & & Native Hawaiian or Pacific Islander & 0 & .00 & 0 & .00 & 3 & .22 \\
\hline & & Two or More Races & 0 & .00 & 2 & 3.85 & 37 & 2.70 \\
\hline & & Unknown & 1 & 2.50 & 1 & 1.92 & 14 & 1.02 \\
\hline & & White - Not of Hispanic Origin & 39 & 97.50 & 48 & 92.31 & 1250 & 91.24 \\
\hline & More than & American Indian or Alaskan Native & 0 & .00 & 0 & .00 & 0 & .00 \\
\hline & Years & Asian & 0 & .00 & 0 & .00 & 0 & .00 \\
\hline & & Black - Not of Hispanic Origin & 0 & .00 & 0 & .00 & 0 & .00 \\
\hline & & Hispanic & 0 & .00 & 0 & .00 & 0 & .00 \\
\hline
\end{tabular}


Table 22 (continued)

Graduation Rates by Ethnicity

\begin{tabular}{|c|c|c|c|c|c|c|c|}
\hline & & \multicolumn{6}{|c|}{ Participation } \\
\hline & & \multicolumn{2}{|c|}{ Yes } & \multicolumn{2}{|c|}{ No } & \multicolumn{2}{|c|}{ Not Eligible } \\
\hline & & $\mathrm{N}$ & $\%$ & $\mathrm{~N}$ & $\%$ & $\mathrm{~N}$ & $\%$ \\
\hline \multirow{12}{*}{$\begin{array}{l}\text { Did not } \\
\text { Graduate }\end{array}$} & Native Hawaiian or Pacific Islander & 0 & .00 & 0 & .00 & 0 & .00 \\
\hline & Two or More Races & 0 & .00 & 0 & .00 & 0 & .00 \\
\hline & Unknown & 0 & .00 & 0 & .00 & 0 & .00 \\
\hline & White - Not of Hispanic Origin & 0 & .00 & 0 & .00 & 0 & .00 \\
\hline & American Indian or Alaskan Native & 0 & .00 & 0 & .00 & 1 & .07 \\
\hline & Asian & 1 & 1.35 & 1 & 1.33 & 22 & 1.50 \\
\hline & Black - Not of Hispanic Origin & 4 & 5.41 & 2 & 2.67 & 59 & 4.03 \\
\hline & Hispanic & 8 & 10.81 & 3 & 4.00 & 53 & 3.62 \\
\hline & Native Hawaiian or Pacific Islander & 1 & 1.35 & 0 & .00 & 1 & .07 \\
\hline & Two or More Races & 2 & 2.70 & 1 & 1.33 & 60 & 4.10 \\
\hline & Unknown & 0 & .00 & 0 & .00 & 17 & 1.16 \\
\hline & White - Not of Hispanic Origin & 58 & 78.38 & 68 & 90.67 & 1252 & 85.46 \\
\hline
\end{tabular}


A chi-square test of independence was performed on graduation rates for all groups to determine the significance of differences among the proportions of graduates. Both observed and expected frequencies are compared. Observed frequencies are the actual count captured in the research and expected frequencies are the predicted frequencies used for comparison in the chi-square test of independence.

\section{Graduation Rates for All Groups}

A chi-square test of independence was used to determine if there was a significant relationship in the graduation rates among the three groups. The chi-square value was $105.470(\mathrm{df}+2)$ and was significant $(\alpha \leq .05)$. The null hypothesis was rejected, and the alternate hypothesis accepted that there was a significant difference in graduation rates among the groups. The non-eligible student group was different.

The MSA participant group 4-year graduation expected count was 211.7 with an actual count of 137. The eligible non-participant group 4-year graduation expected count was 233.4 with a 152 actual count and the non-eligible student group had an expected count of 6929.9 with an actual count of 7086. The MSA participant group more than 4year graduation expected count was 91.7 with an actual count of 92 . The eligible nonparticipant more than 4-year graduation expected count was 101.1 with a 111 actual count and the non-eligible student group had an expected count of 3002.2 with a 2992 actual count. The MSA participant group expected count for those that did not graduate was 234.5 with an actual count of 309 . The eligible non-participant group expected count for those that did not graduate was 258.5 with an actual count of 330 . The non-eligible student group expected count for those that did not graduate was 7676.0 with an actual count of 7530 (see Table 23). 
Table 23

Chi Square Analysis- Graduation Rates of Mountaineer Success Academy Participants, Eligible Non-Participants, and Non-Eligible Student Groups- Cross Tabulations

\begin{tabular}{|c|c|c|c|c|}
\hline \multicolumn{2}{|l|}{ Participation } & \multirow{2}{*}{$\begin{array}{l}\text { Graduated in } \\
\text { Four Years } \\
137\end{array}$} & \multirow{2}{*}{$\begin{array}{l}\text { Graduated in } \\
\text { More than Four } \\
\text { Years } \\
\qquad 92\end{array}$} & \multirow{2}{*}{$\begin{array}{l}\text { Did Not } \\
\text { Graduate } \\
309\end{array}$} \\
\hline Yes & Count & & & \\
\hline & $\begin{array}{l}\text { Expected } \\
\text { Count }\end{array}$ & 211.7 & 91.7 & 234.5 \\
\hline & $\%$ within & & & \\
\hline & Participation & $25.5 \%$ & $17.1 \%$ & $57.4 \%$ \\
\hline \multirow[t]{4}{*}{ No } & Count & 152 & 111 & 330 \\
\hline & $\begin{array}{l}\text { Expected } \\
\text { Count }\end{array}$ & 233.4 & 101.1 & 258.5 \\
\hline & $\%$ within & & 2 & \\
\hline & Participation & $25.6 \%$ & $18.7 \%$ & $55.6 \%$ \\
\hline \multirow[t]{3}{*}{ Not Eligible } & Count & 7086 & 2992 & 7530 \\
\hline & $\begin{array}{l}\text { Expected } \\
\text { Count }\end{array}$ & 6929.9 & 3002.2 & 7676.0 \\
\hline & $\begin{array}{l}\% \text { within } \\
\text { Participation }\end{array}$ & $40.2 \%$ & $17.0 \%$ & $42.8 \%$ \\
\hline \multirow[t]{3}{*}{ Total } & Count & 7375 & 3195 & 8169 \\
\hline & $\begin{array}{l}\text { Expected } \\
\text { Count }\end{array}$ & 7375.0 & 3195.0 & 8169.0 \\
\hline & $\begin{array}{l}\% \text { within } \\
\text { Participation }\end{array}$ & $39.4 \%$ & $17.1 \%$ & $43.6 \%$ \\
\hline
\end{tabular}

Chi-square $=105.4, \mathrm{df}=4, \alpha \leq .05$ 
Graduation Rates of Students Eligible for the Mountaineer Success Academy

A chi-square test of independence was used to determine if there was a significant relationship in the graduation rates among MSA participants and eligible nonparticipants. The chi-square value was $.574(\mathrm{df}=2)$ was not significant $(\alpha \leq .05)$. The research failed to reject the null hypothesis. There was no significant difference in graduation rates among MSA participants and eligible non-participants (see Table 24).

Table 24

Chi-Square Analysis- Graduation Rates of Mountaineer Success Academy Participants and Eligible Non-Participants- Cross Tabulations

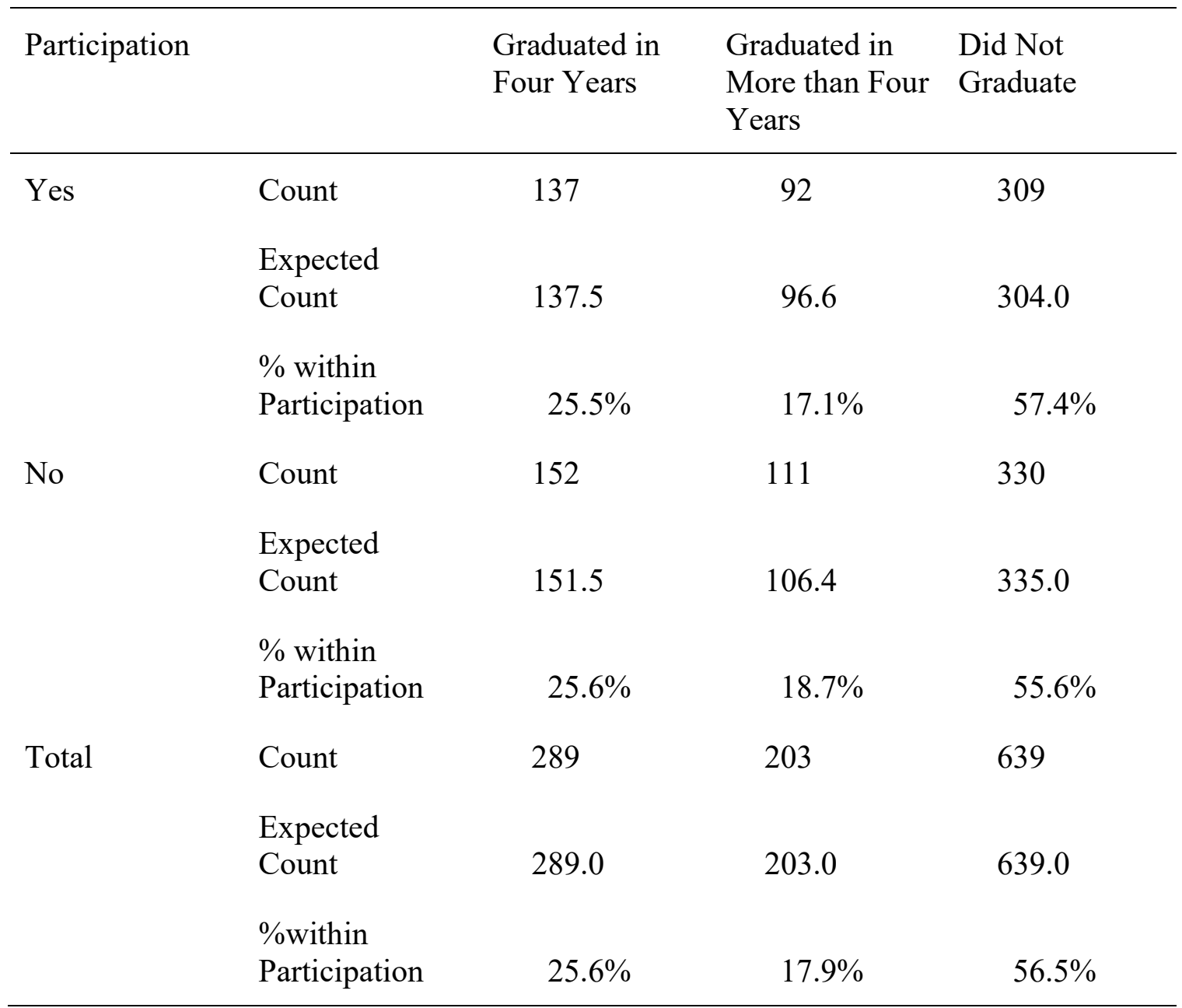

Chi-square $=.574, \mathrm{df}=2, \alpha \leq .05$ 


\section{Academic Performance (GPA) Upon Graduation}

Research Question \#4: What was the academic performance (GPA) upon graduation of the West Virginia University Mountaineer Success Academy participants compared to that of eligible non-participants and non-eligible students entering West Virginia University in the fall semesters of 2012, 2013, 2014, and 2015?

The average GPA of MSA participants who graduated within 4 years was 3.13 while the average GPA of eligible non-participants who graduated within 4 years was 3.15. The average GPA of non-eligible students who graduated within 4 years was 3.36 . The average GPA of non-eligible students who did not graduate was 2.82 . The average GPA of MSA participants who graduated in more than 4 years was 2.97 while the average GPA of eligible non-participants who graduated in more than 4 years was 2.79 . The average GPA of non-eligible students who graduated in more than 4 years was 2.92 . Data were not available for MSA participants or eligible non-participants who did not graduate in 12 semesters (see Table 23). 
Table 25

Academic Performance (GPA) Upon Graduation of Mountaineer Success Academy Participants, Eligible Non-Participants and NonEligible Students for the 2012, 2013, 2014, and 2015 Cohorts

\begin{tabular}{|c|c|c|c|c|c|c|c|c|}
\hline & \multicolumn{8}{|c|}{ Participation } \\
\hline & \multicolumn{2}{|c|}{ Yes } & \multicolumn{2}{|c|}{ No } & \multicolumn{2}{|c|}{ Not Eligible } & \multicolumn{2}{|c|}{ Total } \\
\hline & M & $\mathrm{SD}$ & M & $\mathrm{SD}$ & M & SD & M & SD \\
\hline More than Four Years & 2.97 & .47 & 2.79 & .45 & 2.92 & .45 & 2.91 & .46 \\
\hline Graduated Four Years & 3.13 & .38 & 3.15 & .38 & 3.36 & .41 & 3.35 & .42 \\
\hline Did not Graduate & . & . & . & . & 2.82 & .49 & 2.82 & .49 \\
\hline
\end{tabular}


An Analysis of Covariance (ANCOVA) was performed on the means of the academic performance (GPA) upon graduation to test the null hypothesis that there was no significant difference between the groups. To factor differences in academic abilities into the calculations, high school GPA was used as a covariate. The dependent variable was final college GPA and the factors analyzed were graduation on time and participation in MSA. The ANCOVA showed a significant difference between the groups for final college GPA $(\mathrm{F}=366.55, \mathrm{df}=7,10563, \mathrm{p} \leq .05$. $)$ The null hypothesis was rejected and the alternative hypothesis accepted that there was a significant difference in academic performance (GPA) upon graduation among the groups.

There was a significant main effect for graduating on time $(F=134.26, \mathrm{p} \leq .05)$ and participation in the MSA program $(F=21.46, \mathrm{p} \leq .05)$. There was also a significant interaction between graduating on time and MSA participation $(F=11.773, \mathrm{p}<.05)$ (see Table 26).

Non-eligible students had a higher GPA (3.22) than MSA participants (3.06) and eligible non-participants (3.00). There was a difference between GPAs for non-eligible students. For this group, those that graduated within 4 years had a 3.35 college GPA. Students who graduated in more than 4 years in the non-eligible group had a GPA of 2.91 while non-eligible students who did not graduate had a 2.82 college GPA. Eligible nonparticipants who graduated within 4 years (3.16) had a higher GPA than MSA participants who graduated within 4 years (3.13). MSA participants who graduated in more than 4 years (2.97) had a higher GPA than eligible non-participants (2.79) and noneligible students (2.91) who graduated in more than 4 years. 
Table 26

Descriptive Data for Analysis of Covariance for Academic Performance (GPA) Based on Participation and Time of Graduation Mountaineer Success Academy Participants,

Eligible Non-Participants and Non-Eligible Students

\begin{tabular}{lllll}
\hline \multicolumn{1}{c}{ On Time } & Participation & M & SD & N \\
\hline Graduated Four Years & Yes & 3.1262 & .37751 & 136 \\
& No & 3.1505 & .37825 & 151 \\
& Not Eligible & 3.3592 & .41465 & 7052 \\
& Total & 3.3506 & .41543 & 7339 \\
\hline More than Four Years & Yes & 2.9663 & .46573 & 84 \\
& No & 2.7891 & .45403 & 101 \\
& Not Eligible & 2.9169 & .45441 & 2804 \\
& Total & 2.9140 & .45524 & 2989 \\
\hline Did not Graduate & Not Eligible & 2.8190 & .49149 & 236 \\
& Total & 2.8190 & .49149 & 236 \\
\hline Total & Yes & 3.0651 & .41966 & 220 \\
& No & 3.0056 & .44622 & 252 \\
& Not Eligible & 3.2237 & .47533 & 10092 \\
& Total & 3.2152 & .47519 & 10564 \\
\hline
\end{tabular}


Table 27

Summary Data: Analysis of Covariance for Academic Performance (GPA) Based on Participation and Time of Graduation Mountaineer Success Academy Participants, Eligible Non-Participants and Non-Eligible Students

\begin{tabular}{|c|c|c|c|c|}
\hline Source & $\begin{array}{l}\text { Type III Sum } \\
\text { of Squares }\end{array}$ & $\mathrm{DF}$ & MS & $\mathrm{F}$ \\
\hline \multicolumn{5}{|l|}{ Corrected } \\
\hline Model & 466.405 & 7 & 66.629 & $366.552 *$ \\
\hline Intercept & 7332.845 & 1 & 7332.845 & $40340.646^{*}$ \\
\hline \multicolumn{5}{|l|}{ High School } \\
\hline GPA & 8.393 & 1 & 8.393 & $46.172 *$ \\
\hline On Time & 48.811 & 2 & 24.406 & $134.264 *$ \\
\hline Participation & 7.802 & 2 & 3.901 & $21.460^{*}$ \\
\hline \multicolumn{5}{|l|}{ On Time } \\
\hline Participation & 4.280 & 2 & 2.140 & $11.773 *$ \\
\hline Error & 1918.797 & 10556 & .186 & \\
\hline Total & 111590.522 & 10564 & & \\
\hline Corrected Total & 2385.202 & 10563 & & \\
\hline
\end{tabular}

$* \alpha \leq .05$

\section{Graduation Rates Within the Mountaineer Success Academy Participant Group}

Research Question \#5: What were the graduation rates of students who participated in the West Virginia University Mountaineer Success Academy compared to students who participated in the Mountaineer Success Academy, but not MSA Links for fall semesters 2014 and $2015 ?$

Of the 2014 and 2015 cohort of Mountaineer Success Academy participants who also participated in MSA Links, $17.0 \%$ graduated in more than 4 years while $18.0 \%$ of 
those who did not participate in MSA Links graduated in more than 4 years. There were $25.5 \%$ of Mountaineer Success Academy participants who participated in MSA Links who graduated within 4 years while $25.6 \%$ of those that did not participate in MSA Links graduated within 4 years. There were $57.0 \%$ of Mountaineer Success Academy participants who also participated in MSA Links who did not graduate in 12 semesters, while $55.7 \%$ of those that did not participate in MSA Links did not graduate in 12 semesters (see Table 28). 
Table 28

Graduation Rates of Mountaineer Success Academy Students who also Participated in MSA Links for the 2014 and 2015 Cohorts

\begin{tabular}{|c|c|c|c|c|c|c|c|c|}
\hline & \multicolumn{8}{|c|}{ Participation } \\
\hline & \multicolumn{2}{|c|}{ Yes } & \multicolumn{2}{|c|}{ No } & \multicolumn{2}{|c|}{ Not Eligible } & \multicolumn{2}{|c|}{ Total } \\
\hline & $\mathrm{N}$ & $\%$ & $\mathrm{~N}$ & $\%$ & $\mathrm{~N}$ & $\%$ & $\mathrm{~N}$ & $\%$ \\
\hline $\begin{array}{l}\text { More than Four } \\
\text { Years }\end{array}$ & 92 & 17.10 & 111 & 18.72 & 2992 & 16.99 & 3195 & 17.05 \\
\hline $\begin{array}{l}\text { Graduated Four } \\
\text { Years }\end{array}$ & 137 & 25.46 & 152 & 25.63 & 7086 & 40.24 & 7375 & 39.36 \\
\hline Did not Graduate & 309 & 57.43 & 330 & 55.65 & 7530 & 42.76 & 8169 & 43.59 \\
\hline Total & 538 & 100.00 & 593 & 100.00 & 17608 & 100.00 & 18739 & 100.00 \\
\hline
\end{tabular}


Graduation Rates of Mountaineer Success Academy Participants who also Participated in MSA Links and Mountaineer Success Academy Participants who did not Participate in MSA Links.

A chi-square test of independence was used to determine if there was a significant relationship in the graduation rates among Mountaineer Success Academy participants who also participated in MSA Links and Mountaineer Success Academy participants who did not participate in MSA Links. The chi-square value was $12.642(\mathrm{df}=2)$ and was significant $(\alpha \leq .05)$. The null hypothesis was rejected and the alternate hypothesis accepted that there was a significant difference in graduation rates among Mountaineer Success Academy participants who also participated in MSA Links and Mountaineer Success Academy participants who did not participate in MSA Links.

The Mountaineer Success Academy participants who also participated in MSA Links who graduated within 4 years expected count was 51.9 with an actual count of 60 . The Mountaineer Success Academy participants who did not participate in MSA Links who graduated within 4 years expected count was 237.1 with an actual count of 229 . The Mountaineer Success Academy participants who also participated in MSA Links who graduated in more than 4 years expected count was 36.4 with an actual count of 19 . The Mountaineer Success Academy participants who did not participate in MSA Links who graduated in more than 4 years expected count was 166.6 with an actual count of 184 . The Mountaineer Success Academy participants who also participated in MSA Links who did not graduate in 12 semesters expected count was 114.7 with an actual count of 124. The Mountaineer Success Academy participants who did not participate in MSA 
Links who did not graduate in 12 semesters expected count was 524.3 with an actual count of 515 (see Table 29).

Table 29

Chi-Square Analysis- Graduation Rates of Mountaineer Success Academy Participants who also Participated in MSA Links and Mountaineer Success Academy Participants who did not Participate in MSA Links

\begin{tabular}{|c|c|c|c|c|c|c|}
\hline & & & $\begin{array}{l}\text { Graduated } \\
\text { in For } \\
\text { Years }\end{array}$ & $\begin{array}{l}\text { Graduated } \\
\text { in More } \\
\text { than Years }\end{array}$ & $\begin{array}{l}\text { Did Not } \\
\text { Graduate }\end{array}$ & Total \\
\hline \multirow{6}{*}{$\begin{array}{l}\text { MSA } \\
\text { Links }\end{array}$} & Yes & Count & 60 & 19 & 124 & 203 \\
\hline & & Expected Count & 51.9 & 36.4 & 114.7 & 203.0 \\
\hline & & $\%$ within Links & $29.6 \%$ & $9.4 \%$ & $61.1 \%$ & 100.0 \\
\hline & No & Count & 229 & 184 & 515 & 928 \\
\hline & & Expected Count & 237.1 & 166.6 & 524.3 & 928.0 \\
\hline & & $\%$ within Links & $24 . \%$ & $19.8 \%$ & $55.5 \%$ & $100.0 \%$ \\
\hline \multirow[t]{3}{*}{ Total } & & Count & 289 & 203 & 639 & 1131 \\
\hline & & Expected Count & 289.0 & 203.0 & 639.0 & 1131.0 \\
\hline & & $\%$ within Links & $25.6 \%$ & $17.9 \%$ & $56.5 \%$ & $100.0 \%$ \\
\hline
\end{tabular}

Chi-Square $=12.64, \mathrm{df}=2, \alpha \leq .05$

Academic Performance (GPA) Upon Graduation Within The Mountaineer Success Academy Participant Group

Research Question \#6: What was the academic performance (GPA) of students who participated in the Mountaineer Success Academy compared to students who participated in the Mountaineer Success Academy, but not MSA Links for fall semesters 2014 and $2015 ?$ 
The average GPA of Mountaineer Success Academy participants who also participated in MSA Links for the 2014 cohort was 3.09. The average GPA of Mountaineer Success Academy participants who did not participate in MSA Links was 2.94. The average GPA of Mountaineer Success Academy participants who also participated in MSA Links for the 2015 cohort was 3.13. The average GPA of Mountaineer Success Academy participants who did not participate in MSA Links was 3.41. Data were not available for the 2012 and 2013 cohorts. Results are shown in Table 30.

Table 30

GPA Upon Graduation of Mountaineer Success Academy Participants who also Participated in MSA Links for the 2014 and 2015 Cohorts

\begin{tabular}{|c|c|c|c|c|}
\hline & \multicolumn{4}{|c|}{ Links } \\
\hline & \multicolumn{2}{|c|}{ Yes } & \multicolumn{2}{|c|}{ No } \\
\hline & $\mathrm{M}$ & SD & $\mathrm{M}$ & SD \\
\hline 2012 & . & . & 3.06 & .43 \\
\hline 2013 & . & . & 3.03 & .45 \\
\hline 2014 & 3.09 & .38 & 2.94 & .43 \\
\hline 2015 & 3.13 & .35 & 3.41 & .31 \\
\hline
\end{tabular}




\section{Attributes Contributing to the Successful Completion of College Degrees for \\ Mountaineer Success Academy Participants}

Research Question \#7: What attributes contributed to the successful completion of college degrees for participants of the West Virginia University Mountaineer Success Academy?

Results revealed there was no impact on graduation rates between MSA participants and eligible non-participants but there was a difference in graduation rates for non-eligible students. There was a difference in academic performance for participants. Results revealed that non-eligible students who graduated in 4 years had higher college GPAs than MSA participants and eligible non-participants.

\section{Summary of Findings}

The findings of this study were limited to the target population of West Virginia University Mountaineer Success Academy participants, eligible non-participants, and non-eligible students who were first-time, full-time freshmen entering West Virginia University during the fall semesters of 2012, 2013, 2014 and 2015. Because there were not enough significant differences among and between the groups studied to use discriminative analysis, additional analyses were not warranted. Summary, conclusions and recommendations based on these findings are discussed in Chapter $\mathrm{V}$ of this study. 


\section{CHAPTER V}

\section{Summary, Conclusions, Implications and Recommendations}

This study was conducted to examine the impact of the West Virginia University Mountaineer Success Academy program for the years 2012, 2013, 2014 and 2015. It investigated the graduation rates and academic performance (GPA) upon graduation of the full-time, first-time freshmen in the Mountaineer Success Academy program in comparison to full-time, first-time freshmen eligible non-participants, and full-time, firsttime non-eligible students entering West Virginia University during the fall semesters of 2012, 2013, 2014 and 2015. This study also investigated if attributes including ethnicity, gender, high school GPA, state, residency and ACT/SAT scores appear to have an impact on graduation rates and academic performance (GPA) upon graduation.

The target population for this study was all first-time, full-time freshmen entering West Virginia University during the fall semesters of 2012, 2013, 2014, and 2015. An expost facto research design was used in this study. Data were collected in collaboration with the Institutional Research office. Data collected were analyzed utilizing the Statistical Package for Social Sciences (SPSS).

Descriptive statistics were used to report the profile of participants using the identified characteristics of ethnicity, gender, high school GPA, state residency, and ACT/SAT scores. Chi-square was used to analyze the difference in graduation rates among the three groups. Analysis of covariance was used to partially adjust for preexisting differences between groups in an ex post facto design. ANCOVA adjusts scores on the dependent variable for any initial differences on the extraneous variable. A .05 alpha level of significance was used for all data analysis. 


\section{Hypothesis Statements}

\section{Null hypothesis}

Seven null hypotheses were identified for this study:

1. There was no significant difference among the within 8 semester (within 4 year) graduation rates for students who participated in the Mountaineer Success Academy and the within 8 semester (within 4 year) graduation rates for eligible non-participants or non-eligible students.

2. There was no significant difference among the more than 8 semester (more than 4 year) graduation rates for students who participated in the Mountaineer Success Academy and the more than 8 semester (more than 4 year) graduation rates for eligible non-participants or non-eligible students for the 2012, 2013 and 2014 cohorts.

3. There was no significant difference among academic performance (GPA) upon graduation for students who participated in the Mountaineer Success Academy and eligible non-participants and non-eligible students.

4. Among students who participated in the Mountaineer Success Academy, there was no significant difference in graduation rates for those students who participated in MSA Links and graduation rates for students who participated in the Mountaineer Success Academy, but not MSA Links for fall semesters 2014 and 2015.

5. Among students who participated in the Mountaineer Success Academy, there was no significant difference in academic performance (GPA) for those students who participated in MSA Links and academic performance (GPA) for students 
who participated in the Mountaineer Success Academy, but not MSA Links for fall semesters 2014 and 2015.

6. The identified variables: ethnicity, gender, high school GPA, state residency, and SAT/ACT scores were not able to discriminate between participants of the Mountaineer Success Academy who graduated within 8 semesters (within 4 years) and participants of the Mountaineer Success Academy who did not graduate within 8 semesters (within 4 years).

7. The identified variables: ethnicity, gender, high school GPA, state residency, and SAT/ACT scores were not able to discriminate between participants of the Mountaineer Success Academy who graduated in more than 8 semesters (more than 4 years) and participants of the Mountaineer Success Academy who did not graduate in more than 8 semesters (more than 4 years) for the 2012, 2013 and 2014 cohorts.

\section{Alternate Hypothesis}

Based on the seven identified null hypotheses the following alternative hypotheses statements were identified to reflect the initial predictions of this research study:

1. There was a significant difference among the within 8 semester (within 4 year) graduation rates for students who participated in the Mountaineer Success Academy and eligible non-participants and non-eligible students.

2. There was a significant difference among the more than 8 semester (more than 4 year) graduation rates for students who participated in the Mountaineer Success 
Academy and eligible non-participants and non-eligible students for the 2012, 2013 and 2014 cohorts.

3. There was a significant difference among academic performance (GPA) upon graduation for students who participated in the Mountaineer Success Academy and eligible non-participants and non-eligible students.

4. Among students who participated in the Mountaineer Success Academy, there was a significant difference in graduation rates for those students who participated in MSA Links and graduation rates for students who participated in the Mountaineer Success Academy, but not MSA Links for fall semesters 2014 and 2015.

5. Among students who participated in the Mountaineer Success Academy, there was a significant difference in academic performance (GPA) for those students who participated in MSA Links and academic performance (GPA) for students who participated in the Mountaineer Success Academy, but not MSA Links for fall 2014 and 2015.

6. The identified variables: ethnicity, gender, high school GPA, state residency, and SAT/ACT scores were able to discriminate between participants of the Mountaineer Success Academy who graduated in within 8 semesters (within 4 years) and participants of the Mountaineer Success Academy who did not graduate in within 8 semesters (within 4 years).

7. The identified variables: ethnicity, gender, high school GPA, state residency, and SAT/ACT scores were able to discriminate between participants of the Mountaineer Success Academy who graduated in more than 8 semester (more 
than 4 years) and participants of the Mountaineer Success Academy who did not graduate in more than 8 semesters (more than 4 years) for the 2012, 2013 and 2014 cohorts.

\section{Research Questions}

The following research questions were formulated to guide this study:

1. What were the demographic characteristics of WVU Mountaineer Success Academy participants, WVU Mountaineer Success Academy participants who participated in MSA Links, WVU Mountaineer Success Academy participants who did not participate in MSA Links, eligible non-participants and non-eligible students entering West Virginia University in the fall semesters 2012, 2013, 2014 and $2015 ?$

2. What were the within 8 semester (within 4 year) graduation rates of the West Virginia University Mountaineer Success Academy participants compared to those of eligible non-participants and non-eligible students entering West Virginia University in the fall semesters 2012, 2013, 2014 and 2015?

3. What were the more than 8 semester (more than 4 year) graduation rates of the West Virginia Mountaineer Success Academy participants compared to those of eligible non-participants and non-eligible students entering West Virginia University in the fall semesters 2012, 2013 and 2014?

4. What was the academic performance (GPA) upon graduation of the West Virginia University Mountaineer Success Academy participants compared to that of eligible non-participants and non-eligible students entering West Virginia University in the fall semesters of 2012, 2013, 2014, and $2015 ?$ 
5. What were the graduation rates of students who participated in the West Virginia University Mountaineer Success Academy compared to students who participated in the Mountaineer Success Academy, but not MSA Links for fall semesters 2014 and $2015 ?$

6. What was the academic performance (GPA) of students who participated in the Mountaineer Success Academy compared to students who participated in the Mountaineer Success Academy, but not MSA Links for fall semesters 2014 and $2015 ?$

7. What attributes contributed to the successful completion of college degrees for participants of the West Virginia University Mountaineer Success Academy? One of the most significant limitations of the study is that of self-selection. Students were identified by the WVU Office of Admissions and an invitation was extended to students who met the requirements of the program. All students who received an invitation to join MSA were automatically enrolled in the program. Students had the option to participate in the program and were directed to contact WVU to opt out of the program.

Another limitation of this study is the inability of the researcher to gather information about the extent to which eligible non-participants and non-eligible students were utilizing other campus resources similar to resources that were offered to students through the MSA program. 


\section{Summary and Conclusions}

Summary and conclusions were based on the findings reported in Chapter IV. Summary and conclusions are presented for each research question identified for this study.

\section{Participants Profile}

Research Question \#1: What were the demographic characteristics of WVU Mountaineer Success Academy participants, WVU Mountaineer Success Academy participants who participated in MSA Links, WVU Mountaineer Success Academy participants who did not participate in MSA Links, eligible non-participants and noneligible students entering West Virginia University in the fall semesters 2012, 2013, 2014 and $2015 ?$

Summary. There were more minority students who participated in the Mountaineer Success Academy (16.5\%) than eligible non-participants (16.0\%). Interestingly, there were more MSA participants who identified as Hispanic (6.9\%) than eligible non-participants (3.4\%). The majority of MSA participants (83.6\%), eligible nonparticipants (83.9\%) and non-eligible students $(84.3 \%)$ identified as White. The majority of Mountaineer Success Academy participants who also participated in MSA Links identified as White.

For the 2012 cohort, there were more male MSA participants than females. There were also more male eligible non-participants than female and more male non-eligible students than female. The 2013 cohort consisted of approximately the same number of male and female students in all three groups. For the 2014 cohort, there were more female MSA participants than male participants. There were more male eligible non- 
participants than female as well as more male non-eligible students than female. For the 2015 cohort there were more female MSA participants than male. There were more male eligible non-participants than female. There were more female non-eligible students than male. There were more female Mountaineer Success Academy participants who also participated in MSA Links than male participants.

The non-eligible student group had the highest high school GPA among the groups. MSA participants and eligible non-participants had similar GPAs for those that graduated within 4 years and those that did not graduate. There was no difference in high school GPA among MSA participants and Mountaineer Success Academy participants who also participated in MSA Links.

For the 2012 cohort, MSA participants had slightly higher ACT scores than eligible non-participants. Non-eligible students had the highest ACT scores among the groups. For the 2013 cohort, MSA participants had slightly lower ACT scores than eligible non-participants. Again, non-eligible students had the highest ACT scores among the groups. For the 2014 cohort, there was no difference among ACT scores for the MSA participants and eligible non-participants. Non-eligible students had the highest ACT scores. For the 2015 cohort, MSA participants and eligible non-participants had similar ACT scores while the ACT scores of non-eligible students were the highest. ACT scores of Mountaineer Success Academy participants who also participated in MSA Links were higher than those that did not participate in MSA Links for the 2014 cohort. ACT scores were similar among Mountaineer Success Academy participants who also participated in MSA Links and those that did not participate for the 2015 cohort. 
For all cohorts, there were more non-residents that participated in MSA than residents. For the 2012 cohort, more residents declined to participate in the MSA program than non-residents. Non-eligible students were split 50\% non-residents and 50\% residents. For the 2013 cohort, there were more residents who declined to participate in the MSA program than non-residents. There were also more non-eligible residents than non-residents. For the 2014 cohort, there were more non-residents who declined to participate in the program than residents and there were more non-eligible residents than non-residents. For the 2015 cohort there were more non-residents that declined to participate in the MSA program than residents and there were more non-eligible students who were non-residents than residents. There were more non-resident MSA Links participants than residents for both the 2014 and 2015 cohorts.

The states where most MSA participants were from were West Virginia, Maryland, New Jersey, New York, Ohio, Pennsylvania, and Virginia. The states where most eligible non-participants were from were West Virginia, Virginia, Texas, Pennsylvania, Ohio, New York, New Jersey, Massachusetts, Maryland and Florida. The states where most non-eligible students were from were Maryland, New Jersey, New York, Ohio, Pennsylvania, Virginia and West Virginia. For the 2014 and 2015 cohorts the states where most Mountaineer Success Academy participants who also participated in MSA Links were from were California, Connecticut, Florida, Maryland, Massachusetts, New Jersey, New York, North Carolina, Ohio, Pennsylvania, Virginia, West Virginia, and Delaware. 
The majority of MSA participants, eligible non-participants, and non-eligible students were US citizens. The majority of Mountaineer Success Academy participants who also participated in MSA Links were US citizens.

Conclusion. There was no difference between high school GPA and ACT scores for Mountaineer Success Academy participants and MSA Links participants.

\section{Graduation Rates}

Research Questions 2, 3 and 5: What were the within 8 semester (within 4 year) graduation rates of the West Virginia University Mountaineer Success Academy participants compared to those of eligible non-participants and non-eligible students entering West Virginia University in the fall semesters 2012, 2013, 2014 and 2015? What were the more than 8 semester (more than 4 year) graduation rates of the West Virginia Mountaineer Success Academy participants compared to those of eligible nonparticipants and non-eligible students entering West Virginia University in the fall semesters 2012, 2013 and 2014? What were the graduation rates of students who participated in the West Virginia University Mountaineer Success Academy compared to students who participated in the Mountaineer Success Academy, but not MSA Links for fall semesters 2014 and $2015 ?$

Summary. Graduation rates among all three groups were similar for students who graduated in more than 4 years. Within 4-year graduation rates were higher among all three groups compared to more than 4-year graduation rates. More non-eligible students graduated within 4 years than the other two groups. More MSA participants did not graduate than eligible non-participants and non-eligible students. For the 2012 cohort, more eligible non-participants graduated in more than 4 years than MSA participants. 
More MSA participants graduated within 4 years than eligible non-participants. More MSA participants did not graduate when compared to the other two groups for the 2012 cohort. For the 2013 cohort, there was no significant difference between graduation rates for all three groups who graduated in more than 4 years. For those that graduated within 4 years, more non-eligible students graduated at higher rates. More eligible nonparticipants did not graduate compared to the other two groups for the 2013 cohort. For the 2014 cohort, more MSA participants graduated in more than 4 years compared to the other two groups. More non-eligible students graduated within 4 years. There was no difference between MSA participants and eligible non-participants who did not graduate. For the 2015 cohort, more non-eligible students graduated within 4 years. More MSA participants did not graduate compared to the other two groups. More first-generation MSA participants did not graduate compared to the other two groups. More firstgeneration MSA Links participants graduated compared to MSA participants who did not participate in MSA Links. More MSA participants who identified as Hispanic graduated at higher rates when compared to the other groups. More MSA Links participants graduated than MSA participants who did not participate in MSA Links.

Conclusion. The Mountaineer Success Academy program had no impact on graduation rates. More MSA participants did not graduate compared to the other groups. MSA participants who identified as Hispanic graduated at higher rates than the other two groups. MSA Links participants graduated at higher rates than MSA participants who did not participate in MSA Links. 


\section{Academic Performance (GPA) Upon Graduation}

Research Questions 4 and 6: What was the academic performance (GPA) upon graduation of the West Virginia University Mountaineer Success Academy participants compared to that of eligible non-participants and non-eligible students entering West Virginia University in the fall semesters of 2012, 2013, 2014, and 2015? What was the academic performance (GPA) of students who participated in the Mountaineer Success Academy compared to students who participated in the Mountaineer Success Academy, but not MSA Links for fall semesters 2014 and 2015?

Summary. Mountaineer Success Academy participants, eligible non-participants and non-eligible students who graduated in more than 4 years had similar GPAs upon graduation. Non-eligible students who graduated within 4 years had slightly higher GPAs upon graduation compared to the other two groups. For the 2014 cohort, MSA Links participants had higher GPAs than MSA participants who did not participant in MSA Links. For the 2015 cohort, MSA participants who did not participate in MSA Links had higher GPAs than MSA Links participants.

Conclusion. There was a significant difference between academic performance (GPA) among the three groups. The non-eligible student group who graduated within 4 years (3.36) had higher college GPAs than MSA participants (3.13) and eligible nonparticipants (3.15). Although there was statistical significance differences among the groups, the researcher did not calculate effect size because the differences were not large enough to be meaningful in real life. There was no practical difference between the groups. 


\section{Attributes Impacting Graduation Rates}

Research Question 7: What attributes contributed to the successful completion of college degrees for participants of the West Virginia University Mountaineer Success Academy?

Summary and Conclusion. There was no practical difference between graduation rates and academic performance between Mountaineer Success Academy participants and eligible non-participants, therefore, attributes contributing to the successful completion of college degrees cannot be determined.

\section{Recommendations}

Based on the findings of this study, the following recommendations were suggested by the researcher:

- Although the West Virginia University Mountaineer Success Academy Program did not improve graduation rates, a similar program could be used to improve first to second year retention rates.

- An additional study to determine if the Mountaineer Success Academy Program impacted first to second year retention rates should be conducted.

- The information gathered in this study should be appropriately communicated to groups and individuals that might find the data useful. Groups may include the Center for Learning, Advising and Student Success as well as the WVU Office of the Provost for Undergraduate Education.

In addition to the above recommendations, several possible research studies have been identified that may contribute additional information to the research. The suggestions for further studies are listed below: 
- Further analysis of first-generation students who participated in the Mountaineer Success Academy program.

- Comparison of MSA participants who resided in Brooke Tower, the live learn community designated for MSA participants compared to MSA participants who resided elsewhere.

- Analysis of students who were Pell eligible.

- Analysis of first to second year retention rates.

- Analysis of which students' majors at graduation.

- Analysis of graduation rates for males compared to females.

- Analysis of graduation rates for in-state compared to out-of-state MSA participants.

- For future success programs, capture real-time analysis.

- A qualitative study of the West Virginia University Mountaineer Success Academy program participants should be conducted to identify the participants' perception of the extent to which they feel the program assisted them to graduation.

- Continuing the study to capture the more than 4-year graduation rates, particularly for the 2015 cohort.

- A qualitative study of the West Virginia University Mountaineer Success Academy program participants should be conducted to identify participants who did not graduate to learn why they dropped out or stopped out of college.

- A study following-up the graduates to identify employment/career status and to what extent the Mountaineer Success Academy may have impacted their success. 
- Many other attributes beside those chosen for this study could affect the graduation rates and academic performance (GPA) upon graduation of undecided students. More research needs to be conducted to better understand the attributes and their effect on this population. Some of the attributes that could be investigated include academic advising, student success coaching, campus involvement, estimated family contribution, Pell eligibility, on or off campus residency, rural vs urban residency, in-state and out-of-state residency and family size. 


\section{REFERENCES}

Allen, I. H. \& Lester, S. M. (2012). The impact of a college survival skills course and a success coach on retention and academic performance. Journal of Career and Technical Education, 27, 8-14.

Arensdork, J. (2016). beyond the traditional retention data: A qualitative study of the social benefits of living learning communities. Learning Communities Research and Practice, 4, 1-16.

Ary, D., Jacobs, L. C., \& Sorenson C. (2010). Introduction to research education. Belmont, California: Cengage Learning.

Barkley, A. (2010). “Academic coaching” for enhanced learning, higher levels of student responsibility, and greater retention.

Barton, A., \& Donahue, C. (2009). Multiple assessments of a first-year seminar pilot. The Journal of General Education, 58, 259-278.

Capstick, M. K., Harrell-Williams, L. M., Cockrum, C. D., \& West, S. L. (2019). Exploring effectiveness of academic coaching for academically at-risk college students. Innovative Higher Education, 44, 219-231.

Cole, J.E., \& Zalaquett, C. (2008). The relationship of worldviews of advisors and students and satisfaction with advising: A case of homogenous group impact. $J$. College Student Retention, 9, 273-281.

College Simply. (n.d.). Retrieved from https://www.collegesimply.com/colleges/florida/university-of-florida/admission/

Docherty, M., Gullan, R. L., \& Phillips III, R. E. (2018). Confirming the factor structure of a mentorship measure for college students. Journal of College Student Development, 59, 372-376.

Douglas, D. \& Attwell P. (2014). The bridge and the troll underneath: Summer bridge programs and degree completion. American Journal of Education, 121.

Eck, J. C., Edge, H., \& Stephenson, K., (2007). Investigating types of student engagement through living-learning communities: The perspective from Rollins College. Assessment Update, 19, 6-8.

Ewing-Cooper, A.R., \& Parker, M.V. (2013). Student perceptions of preparedness for academic success: The impact of an advisor taught orientation course in Family and Consumer Sciences. NACTA Journal, December 2013, 2-5.

Freeman, V. F., Lenz, J. G. \& Reardon, R. C. (2017). career course impact on college students' career decision and affective states. VISTAS Online, 32, 1-14. 
Gay, L. R., Mills, G. E., Airasian, P. (2012). Educational research: Competencies for analysis and applications. Upper Saddle River, New Jersey: Pearson Education, Inc.

Hansen, M. J. \& Pederson J. S. (2012). An examination of the effects of career development courses on career decision-making self-efficacy, adjustment to college, learning integration, and academic success. Journal of the First-Year Experience \& Students in Transition, 24, 33-61.

Jehangir, R., Williams, R., \& Jeske, J. (2012). the influence of multicultural learning communities on the intrapersonal development of first-generation college students. Journal of College Student Development, 53, 267-284.

Johnson, P., Schamuhn, T. D., Nelson, D. B. \& Buboltz, W. C. (2014). Differentiation levels of college students: Effects on vocation identity and career decision making. The Career Development Quarterly, 62, 70-80.

Kitchen, J. A., Sadler, P., \& Sonnert, G. (2018). The impact of the summer bridge programs on college students' STEM career aspirations. Journal of College Student Development, 59, 698-715.

Kot, F. C. (2014). The impact of centralized advising on first-year academic performance and second-year enrollment behavior. Research in Higher Education, 55, 527563.

Kuh, G. D. (2008). High-impact educational practices: What are they, who has access to them, and why they matter. Washington, DC: Association of American College and Universities.

McCurrie, M. K. (2009). Measuring success in summer bridge programs: Retention efforts and basic writing. Journal of Basic Writing, 28, 28-49.

Melzer, D.K., \& Grant, R. M. (2016). Investigating the differences in personality traits and academic needs among prepared and underprepared first-year college students. Journal of College Student Development, 57, 99-103.

Peterson, J. J., Wardwell, C., Will, K. \& Campana, K. L. (2014). Pursuing a purpose: The role of career exploration courses and service-learning internships in recognizing and developing knowledge, skills and abilities. Teaching of Psychology, 41, 354259.

Pittendrigh, A., Borkowski, J., Swinford, S., \& Plumb, C. (2016). Knowledge and community: The effect of a first-year seminar on student persistence. The Journal of General Education, 65, 48-65.

Ritter, L. \& Sue, V. (2007). Using online surveys in evaluation. New Directions for Evaluation Journal, 115, 24-28. 
Robinson C. \& Gahagan J. (2010). Coaching students to academic success and engagement on campus. In Practice, 26-29.

Rocconi, L. M., (2011). The impact of learning communities on first-year students' growth and development in college. Research in Higher Education, 52, 178-193.

Schwebel, D. C., Walburn, N. C., Klyce, K., Jerrolds, K. L. (2012). Efficacy of advising outreach on student retention, academic progress and achievement, and frequency of advising contacts: A longitudinal randomized trial. NACADA Journal, 32, 3643.

Smith, C. L., \& Allen, J. M. (2014). Does contact with advisors predict judgements and attitudes consistent with student success? A multi-institutional study. NACADA Journal, 34, 50-63.

Spight, D. B. (n.d.). Undecided-exploratory students and persistence. Retrieved from nacada.ksu.edu/Resources/Academic-Advising-Today/view-Articles/UndecidedExploratory-Students-and-Persistence.aspx

Stassen, M. L. (2003). Student outcomes: The impact of varying living-learning community models. Research in Higher Education, 44, 581-613,

Strayhorn, T.L. (2009). An examination of the impact of first-year seminars on correlates of college student retention. Journal of The First-Year Experience \& Students in Transition, 21, 9-27.

Suzuki, A., Amrein-Beardsley, A., \& Perry, N. (2012). A summer bridge program for underrepresented first-year students: Confidence, community, and re-enrollment. Journal of the First-Year Experience \& Students in Transition, 24, 85-106.

The Chronicle of Higher Education College Completion. (n.d.) Retrieved from collegecompletion.chronicle.com/institution/\#id=238032

Tinto, V. (1993). Leaving college: Rethinking the causes and cures of student attrition $\left(2^{\text {nd }} E d.\right)$. The University of Chicago Press, Chicago.

Tirpak, D. M. \& Schlosser, L. Z. (2013). Evaluating FOCUS-2's effectiveness in enhancing first-year college students' social cognitive career development. The Career Development Quarterly, 61, 110-123.

Vianden, J. (2016). Ties that bind: Academic advisors as agents of student relationship management. NACADA Journal, 36, 19-29.

Young-Jones, A. D., Burt, T. D., Dixon, S., Hawthorne, M. J. (2013). Academic advising: Does it really impact student success? Quality Assurance in Education, 21, 7-19.

Zhao, C., \& Kuh, G.D. (2004). Adding value: Learning communities and student engagement. Research in Higher Education, 45, 115-138. 
APPENDICES 
APPENDIX A

Mountaineer Success Academy Frequently Asked Questions 


\section{What is the Mountaineer Success Academy?}

The MSA is a program for students who are undecided about their major and those who have not been directly admitted to their desired major. You will participate in programs and workshops targeted toward development of an academic plan, selection of a major, and progression toward your bachelor's degree. You will also have an opportunity to get a jump start on your fall semester by beginning a week earlier than most new students. As a Mountaineer Success Academy participant, you will:

- Have a dedicated Living-Learning environment in Brooke Tower

- Move in one week early to your residence hall room

- Get a head start on important first-year courses

- Become familiar with the campus and the resources available to you before the fall semester begins

- Get connected with faculty and staff dedicated to your success

\section{Why does WVU have a Mountaineer Success Academy?}

The MSA is part of our Blueprint for Student Success and demonstrates WVU's commitment to student success. Similar programs have been implemented at other universities and are considered best practices. Students who fully participate in those programs tend to be more successful than those who do not participate. For example, they tend to have higher GPAs, to be more likely to persist, to declare a major, and to be more socially and academically engaged.

\section{What are the benefits of the Mountaineer Success Academy?}

The MSA is designed to help you succeed at WVU. Some of the benefits include:

- $\quad$ Specialized academic advising

- Peer mentoring and/or student success coaching

- Specifically selected curriculum as well as special sections of courses that will lead to first year completion of a large portion of the required General Education Curriculum (GEC)

- Targeted programming and workshops

- Guided career exploration including the development of an academic plan

- The experience of a small Living-Learning Community combined with the benefits afforded by a large research university.

\section{Why was I admitted to the Mountaineer Success Academy?}

You have been selected to participate in this program because you are either undecided about your major or you have not been directly admitted to your desired major. 


\section{How do I prepare for my desired major while enrolled in the Mountaineer Success Academy?}

The MSA provides multiple opportunities for you to develop and hone the academic skills and social engagement necessary to be successful in all majors. By participating fully in the MSA, you can work toward your desired major. It will be up to you, of course, to earn the GPA necessary to be admitted to your desired major; however, the MSA staff will support and mentor you as you work toward this goal.

\section{Are all Undergraduate Studies students in the Mountaineer Success Academy?}

Undergraduate Study students at WVU are served either by the University College or by the MSA based on their current high school GPA and test scores on record.

\section{What will happen if I change my major during the course of the year?}

If you change your major, you can still participate in the Mountaineer Success Academy.

\section{Can I change my major now?}

You are welcome to change your major. If, however, you are not sure about your major, we hope you will participate in the Mountaineer Success Academy because it will help you choose the best major for you and provide you with many opportunities to develop the academic skills and social engagement necessary to be successful in your chosen major.

\section{Does the Mountaineer Success Academy guarantee my success at WVU?}

No program can guarantee a student's success because a large part of your success at WVU is based on the personal effort and motivation you put into the program. We believe the program will increase the likelihood of your success, but you have to do your part.

\section{What is required of me as a Mountaineer Success Academy participant?}

- Take part in all required courses and special programming.

- If living in on-campus housing, reside on dedicated floors in Brooke Tower.

- If commuting from home, participate in special programming.

\section{How do the "required courses" work?}

As a participant, you will be required to take some courses in the fall and the spring semesters. These courses will meet General Education Curriculum requirements 
for all students - regardless of major. You will also have the opportunity, based on your interests, to select some of your courses in conjunction with program staff.

\section{When does the Mountaineer Success Academy start?}

Mountaineer Success Academy participants will be given special permission to move into their residence hall rooms early. You will be able to check in after 4:00 p.m. on Sunday, August 10, 2014. The program will begin that Sunday evening. We will send you more details as that date approaches.

\section{How long does the Mountaineer Success Academy last?}

The MSA will last for two full semesters, fall 2014 and spring 2015.

\section{Is it mandatory to participate in the MSA program?}

Participation to the MSA is not mandatory. However, we highly recommend you participate because the MSA experience will provide you with resources to help you succeed academically and explore major and career opportunities. Given your academic record so far and the challenges we know all students face when transitioning from high school to college, we believe participating in the MSA is the best choice for you.

\section{Where will I live?}

The MSA is based in Brooke Tower in the Evansdale Residential Complex (ERC). Please request a room on the floor of your choice in Brooke Tower. It is up to you to request a room while space is available. For any questions about housing, please contact the Housing Assignments office at 304.293.2811. Be sure to tell them you are a Mountaineer Success Academy scholar and is supposed to live in Brooke Tower.

Can I invite my friend to share a room even if he or she is not an MSA participant?

Your roommate does not need to be an MSA participant, and you can invite your friend to live with you. However, we recommend you find a roommate who is an MSA participant so you can both share the MSA experience.

\section{How much will it cost to be part of the Mountaineer Success Academy?}

Although there is no additional tuition charge, MSA participants are responsible for their room and board for their first week on campus. This charge is eligible for financial aid.

\section{WV?}

Can I participate in both the Mountaineer Success Academy and Adventure 
You are welcome to participate in an Adventure WV summer trip. For more information, please visit: http://adventurewv.wvu.edu/.

\section{What if I am a student-athlete?}

We can talk with you about your individual situation and with Athletics staff about your competition schedule and determine if the MSA is the best choice for you. Please contact us at the email addresses or telephone number listed below.

\section{Is the Mountaineer Success Academy a "remedial" program?}

The MSA is not a remedial program. It is a student success initiative intended to create a smoother academic and social transition from high school to college by providing access to key resources and personnel here at WVU.

Will I be connected to the rest of the university as are other freshmen?

You will be encouraged to participate in many co-curricular and extra-curricular programs - some through the MSA and others based on your interests and personal preferences.

How do I let you know I plan to enroll at WVU and participate in the Mountaineer Success Academy?

Please pay the academic deposit to confirm your enrollment and to receive housing information and registration materials for New Student Orientation. This deposit will be applied to your fall 2014 tuition invoice. Be sure to let Housing know you are an MSA participant by sending an email from your WVU MIX email address to WVUAssign@mail.wvu.edu.

\section{Are there any social networking tools available to me as a Mountaineer Success Academy participant?}

Visit and feel free to join the MSA Facebook page at http://www.facebook.com/pages/WVU-Mountaineer-SuccessAcademy/277869145617547 and the MSA YOU@WVU group at http://you.wvu.edu/group/mountaineer-success-academy.

\section{How do I get additional information?}

For more information on the MSA, please contact either Jacob Sanwidi at Jacob.Sanwidi@mail.wvu.edu or Ashley Watts at Ashley.Watts@mail.wvu.edu or by telephone at (304)293-2316 
APPENDIX B

Conversion Tables from SAT Scores to ACT Score 
New SAT to ACT Concordance Table

\begin{tabular}{|c|c|}
\hline $\begin{array}{l}\text { New SAT } \\
\text { Total } \\
(400-1600)\end{array}$ & $\begin{array}{c}\text { ACT } \\
\text { Composite } \\
\text { Score }\end{array}$ \\
\hline 1600 & 36 \\
\hline 1590 & 36 \\
\hline 1580 & 36 \\
\hline 1570 & 36 \\
\hline 1560 & 35 \\
\hline 1550 & 35 \\
\hline 1540 & 35 \\
\hline 1530 & 35 \\
\hline 1520 & 34 \\
\hline 1510 & 34 \\
\hline 1500 & 34 \\
\hline 1490 & 34 \\
\hline 1480 & 33 \\
\hline 1470 & 33 \\
\hline 1460 & 33 \\
\hline 1450 & 33 \\
\hline 1440 & 32 \\
\hline 1430 & 32 \\
\hline 1420 & 32 \\
\hline 1410 & 31 \\
\hline 1400 & 31 \\
\hline 1390 & 31 \\
\hline 1380 & 30 \\
\hline 1370 & 30 \\
\hline 1360 & 30 \\
\hline 1350 & 29 \\
\hline 1340 & 29 \\
\hline 1330 & 29 \\
\hline 1320 & 28 \\
\hline 1310 & 28 \\
\hline 1300 & 28 \\
\hline 1290 & 27 \\
\hline 1280 & 27 \\
\hline 1270 & 27 \\
\hline
\end{tabular}

\begin{tabular}{|c|c|}
\hline $\begin{array}{l}\text { New SAT } \\
\text { Total } \\
(400-1600)\end{array}$ & $\begin{array}{c}\text { ACT } \\
\text { Composite } \\
\text { Score }\end{array}$ \\
\hline 1260 & 27 \\
\hline 1250 & 26 \\
\hline 1240 & 26 \\
\hline 1230 & 26 \\
\hline 1220 & 25 \\
\hline 1210 & 25 \\
\hline 1200 & 25 \\
\hline 1190 & 24 \\
\hline 1180 & 24 \\
\hline 1170 & 24 \\
\hline 1160 & 24 \\
\hline 1150 & 23 \\
\hline 1140 & 23 \\
\hline 1130 & 23 \\
\hline 1120 & 22 \\
\hline 1110 & 22 \\
\hline 1100 & 22 \\
\hline 1090 & 21 \\
\hline 1080 & 21 \\
\hline 1070 & 21 \\
\hline 1060 & 21 \\
\hline 1050 & 20 \\
\hline 1040 & 20 \\
\hline 1030 & 20 \\
\hline 1020 & 19 \\
\hline 1010 & 19 \\
\hline 1000 & 19 \\
\hline 990 & 19 \\
\hline 980 & 18 \\
\hline 970 & 18 \\
\hline 960 & 18 \\
\hline 950 & 17 \\
\hline 940 & 17 \\
\hline 930 & 17 \\
\hline
\end{tabular}

\begin{tabular}{|c|c|}
\hline $\begin{array}{l}\text { New SAT } \\
\text { Total } \\
(400-1600)\end{array}$ & $\begin{array}{c}\text { ACT } \\
\text { Composite } \\
\text { Score } \\
\end{array}$ \\
\hline 920 & 17 \\
\hline 910 & 16 \\
\hline 900 & 16 \\
\hline 890 & 16 \\
\hline 880 & 16 \\
\hline 870 & 15 \\
\hline 860 & 15 \\
\hline 850 & 15 \\
\hline 840 & 15 \\
\hline 830 & 15 \\
\hline 820 & 14 \\
\hline 810 & 14 \\
\hline 800 & 14 \\
\hline 790 & 14 \\
\hline 780 & 14 \\
\hline 770 & 13 \\
\hline 760 & 13 \\
\hline 750 & 13 \\
\hline 740 & 13 \\
\hline 730 & 13 \\
\hline 720 & 12 \\
\hline 710 & 12 \\
\hline 700 & 12 \\
\hline 690 & 12 \\
\hline 680 & 11 \\
\hline 670 & 11 \\
\hline 660 & 11 \\
\hline 650 & 11 \\
\hline 640 & 10 \\
\hline 630 & 10 \\
\hline 620 & 10 \\
\hline 610 & 9 \\
\hline 600 & 9 \\
\hline 590 & 9 \\
\hline
\end{tabular}


APPENDIX C

Data Request 


\section{Mountaineer Success Academy Data Request Report}

December 21, 2019

Criteria/Population Selection: Please include: First-time, Full-time Freshmen entering WVU in Fall 2012, 2013, 2014 and 2015

Data Items Needed on Report:

1. Ethnicity

2. Gender

3. High School GPA

4. Residency

5. ACT

6. SAT

7. Graduation Date

8. Final College GPA

9. First-generation students 
VITA

Ashley D. Watts

Education: $\quad$ May 2004

Associate of Arts with a major in General Studies, Potomac State College, Keyser, West Virginia

May 2006

Bachelor of Science in Agriculture with a major in Animal and Veterinary Science, West Virginia University, Morgantown, West Virginia

December 2006 Bachelor of Science in Agriculture with a major in Agricultural and Environmental Education, West Virginia University, Morgantown, West Virginia

December 2006 Associate of Arts with a major in Animal Science, Potomac State College, Keyser, West Virginia

May 2008

Master of Science in Agricultural and Extension Education, West Virginia University, Morgantown, West Virginia

May 2020

Doctor of Philosophy in Human and Community Development, West Virginia University, Morgantown, West Virginia 


\title{
IMPACT OF THE WEST VIRGINIA UNIVERSITY MOUNTAINEER
}

SUCCESS ACADEMY PROGRAM FROM 2012-2015

\author{
Ashley Dawn Watts \\ Dissertation submitted to the College of Agriculture, Natural Resources and \\ Design at West Virginia University in partial fulfillment of the requirements for the \\ degree of \\ Doctor of Philosophy \\ In
}

Human and Community Development

Department of Human and Community Development

APPROVAL OF THE EXAMINING COMMITTEE

Harry N. Boone, Jr., Ph.D., Chair

Deborah A. Boone. Ph. D.

Jason B. McKibben, Ph.D.

Ann M. Richards, Ph.D.

Date

Nathan M. Sorber, Ph.D. 